OPEN ACCESS

Edited by:

Venkata Subba Rao Atluri

Florida International University, USA

Reviewed by:

Santhi Gorantla,

University of Nebraska Medical

Center, USA

Slava Rom,

Temple University School of Medicine,

USA

*Correspondence:

Anuja Ghorpade

anuja.ghorpade@unthsc.edu

Specialty section This article was submitted to

Virology,

a section of the journa

Frontiers in Microbiology

Received: 14 August 2015 Accepted: 05 October 2015

Published: 27 October 2015

Citation:

Borgmann K and Ghorpade A (2015)

HIV-1, methamphetamine and

astrocytes at neuroinflammatory

Crossroads. Front. Microbiol. 6:1143

doi: 10.3389/fmicb.2015.01143

\section{HIV-1, methamphetamine and astrocytes at neuroinflammatory Crossroads}

\author{
Kathleen Borgmann and Anuja Ghorpade * \\ Department of Cell Biology and Immunology, University of North Texas Health Science Center, Fort Worth, TX, USA
}

As a popular psychostimulant, methamphetamine (METH) use leads to long-lasting, strong euphoric effects. While METH abuse is common in the general population, between 10 and 15\% of human immunodeficiency virus-1 (HIV-1) patients report having abused METH. METH exacerbates the severity and onset of HIV-1-associated neurocognitive disorders (HAND) through direct and indirect mechanisms. Repetitive METH use impedes adherence to antiretroviral drug regimens, increasing the likelihood of HIV-1 disease progression toward AIDS. METH exposure also directly affects both innate and adaptive immunity, altering lymphocyte numbers and activity, cytokine signaling, phagocytic function and infiltration through the blood brain barrier. Further, METH triggers the dopamine reward pathway and leads to impaired neuronal activity and direct toxicity. Concurrently, METH and HIV-1 alter the neuroimmune balance and induce neuroinflammation, which modulates a wide range of brain functions including neuronal signaling and activity, glial activation, viral infection, oxidative stress, and excitotoxicity. Pathologically, reactive gliosis is a hallmark of both HIV-1- and METH-associated neuroinflammation. Significant commonality exists in the neurotoxic mechanisms for both METH and HAND; however, the pathways dysregulated in astroglia during METH exposure are less clear. Thus, this review highlights alterations in astrocyte intracellular signaling pathways, gene expression and function during METH and HIV-1 comorbidity, with special emphasis on HAND-associated neuroinflammation. Importantly, this review carefully evaluates interventions targeting astrocytes in HAND and METH as potential novel therapeutic approaches. This comprehensive overview indicates, without a doubt, that during HIV-1 infection and METH abuse, a complex dialog between all neural cells is orchestrated through astrocyte regulated neuroinflammation.

Keywords: neuroinflammation, astroglia, HIV, methamphetamine, neurocognitive impairment

\section{INTRODUCTION}

\section{Burden of HIV-1 and HAND}

Worldwide an estimated 33 million people are infected with human immunodeficiency virus (HIV) and without effective treatment, HIV results in a progressive failure of the immune system. Approximately 1.1 million Americans are currently living with HIV or acquired immune deficiency syndrome (AIDS), with an estimated 50,000 new infections occurring in the U.S each year ${ }^{1}$. While the age at which neurocognitive issues develop is

\footnotetext{
${ }^{1}$ http://www.unaids.org/en/resources/campaigns/2014/2014gapreport/factsheet;

http://www.cdc.gov/hiv/library/reports/surveillance/
} 
increasing with antiretroviral therapy (ART), 69\% of HIV+ patients continue to develop HIV-1-associated neurocognitive disorders (HAND; Matinella et al., 2015). Although the prevalence of HIV-1-associated dementia (HAD) has decreased from $\sim 20 \%$ to less than $5 \%$ with wide-spread use of ART, other neuropsychiatric complications of HIV, including delirium, neurobehavioral impairments (depression), asymptomatic neurocognitive impairment (ANI) and minor neurocognitive disorder (MND) remain prevalent (McArthur et al., 2005; Robertson et al., 2007; Matinella et al., 2015). Significant glial activation can be found in brain tissues even in the absence of HIV encephalitis (HIVE) or even active viral replication, implicating inflammation as a causative mechanism of HAND (Tavazzi et al., 2014).

\section{Burden of METH Abuse}

Abuse of the potent psychomotor stimulant methamphetamine $(\mathrm{METH})$ remains a significant public health concern as it results in neurotoxic outcomes including deficits in memory, executive function, anxiety, depression, psychosis and other neurologic manifestations (Cadet and Krasnova, 2009; Nagai and Yamada, 2010; Rusyniak, 2013). Despite declining use since 1999, 1.2 million people reported METH use in 2012, 133,000 of which were new users aged 12 and older ${ }^{2}$. An urban men's health study of over 2000 men who have sex with men (MSM) indicates that use of METH and other stimulants by MSM is 10 times greater than the general population and METH abusers are $20 \%$ more likely to contract sexually transmitted diseases, including HIV-1 (Stall et al., 2001; Rosenthal, 2006) ${ }^{3}$. METH administration occurs by various routes including oral, snorting, smoking and intravenous injection. The associated euphoria due to neurotransmitter release disappears before drug concentrations in the blood fall significantly, leading to "binging and crash" patterns of abuse, tolerance and increased METH intake ${ }^{2}$. Chronic METH exposure leads to a variety of adverse physiological consequences including skin lesions, tooth decay, weight loss, altered immunity, and cognitive impairment. It has been estimated that $40 \%$ of METH users exhibit global neuropsychological impairment (Rippeth et al., 2004).

\section{METH and HIV-1 Comorbidity}

Eight percent of newly diagnosed HIV-1 infections are attributed to intravenous drug use and the National Institute on Drug Abuse reports that $25 \%$ of diagnosed HIV-1-infected individuals report treatment for the use of drugs and alcohol ${ }^{4}$. While accurate statistics documenting METH abuse in HIV-1infected individuals are not available, studies show that METH use exacerbates HIV-1 infection, accelerating the severity and onset of HAND, along with immune dysfunction and resistance to ART therapy (reviewed in Passaro et al.,

${ }^{2}$ http://www.drugabuse.gov/publications/research-reports/methamphetamine/ what-scope-methamphetamine-abuse-in-united-states

${ }^{3}$ http://stacks.cdc.gov/view/cdc/11778/

${ }^{4} \mathrm{http}: / /$ www.drugabuse.gov/related-topics/trends-statistics/infographics/drugalcohol-use-significant-risk-factor-hiv; http://www.drugabuse.gov/publications/ drugfacts/hivaids-drug-abuse-intertwined-epidemics
2015) Studies report that 53-58\% of HIV + METH users exhibit neurocognitive impairment compared to $40 \%$ in either HIV+ or METH+ alone; however, their interaction is poorly understood (Rippeth et al., 2004; Gupta et al., 2011). In part, the neurological complications in both METH abuse and HAND are associated with increased permeability of the blood brain barrier (BBB) and neuroinflammation. These are mediated through cellular and molecular mechanisms such as gliosis, viral replication, oxidative stress and excitotoxicity (Rippeth et al., 2004; Ramirez et al., 2009; Potula et al., 2010; Sharma et al., 2011; Cisneros and Ghorpade, 2012).

The study of inflammation generally focuses on the contributions of professional immune cells. However, the unique nature of the brain as an immune privileged site implicates neural cells in the regulation of immune responses. Glia, specifically astroglia and microglia, account for $50-80 \%$ of the cells in the brain, outnumbering neurons in certain regions by as much as 10:1 (Dobbing and Sands, 1973; Kandel et al., 2000; Azevedo et al., 2009). As the resident immune cells of the brain, microglia are accountable for brain surveillance and immunity, while astrocytes have a significant repertoire of immune functions that complement their "neural" functions. Astrocytes, through regulation of neuroinflammation, are implicated in neurodegenerative diseases such as Alzheimer's disease (AD; Roth et al., 2005; Weinstein et al., 2013), hepatic encephalopathy (Coltart et al., 2013), multiple sclerosis (MS; Brosnan and Raine, 2013; Kostic et al., 2013), epilepsy (Devinsky et al., 2013), amyotrophic lateral sclerosis (Evans et al., 2013), Parkinson's disease (PD; Tufekci et al., 2012), aging and depression (Paradise et al., 2012) and HAND (Borjabad et al., 2010; Cisneros and Ghorpade, 2012). Reactive glia participate in neuroinflammation by synthesizing and releasing various powerful pro-inflammatory and neuroactive substances, like cytokines, chemokines, nitric oxide (NO), glutamate, reactive oxygen species (ROS), neurotrophins and transforming growth factors (TGF; da Cunha and Vitkovic, 1992; Chiueh and Rauhala, 1999; Wang et al., 2004; Hult et al., 2008; Fitting et al., 2012; Ramesh et al., 2013; Salamanca et al., 2014). Although astroglia play a central role in HIV1-associated neuropathogenesis, serving as reservoirs for latent HIV infection, chronic inflammation and as sources of neurotoxicity during HAND. There is a paucity of information regarding the mechanisms at play during HIV-1 and METH comorbidity. Due to the addictive nature of METH abuse, METH interactions with neurons leading to dopamine release and subsequent toxicity have been a focus of much investigation. However, despite apparent glial activation, the mechanisms through which METH interacts with glia to alter astrocyte and microglial function are much less apparent (Chiu and Schenk, 2012; Cisneros and Ghorpade, 2012; Friend and Keefe, 2013). A better understanding of astrocyte regulation of HIV-1 and METH-mediated neurodegeneration would help identify mechanistic targets coordinating glial activation. By therapeutically reducing acute and chronic inflammation, neurological impairments such as HAND could be ameliorated or even prevented. 


\section{ASTROCYTES IN HAND}

As a predominant cell in the brain, astrocytes regulate the central nervous system (CNS) physiological environment at both the $\mathrm{BBB}$ and in the parenchyma. As integral members of the BBB, astroglia respond to immunomodulatory signals including, but not limited to, cytokines and prostaglandins. During HIV-1 CNS infection, the $\mathrm{BBB}$ integrity is compromised thus permitting the peripheral immune system to trigger neuroinflammation and oxidative stress. Astrocytes secrete a variety of neuroactive molecules in response to HIV-1- and METH-associated stimuli. In this manner, astrocytes regulate the physiological functions of neural cells in their immediate vicinity and cells within the reach of their many foot processes. As neuroinflammation persists, the ability of astrocytes to regulate BBB integrity, and neurotransmission in tripartite synapses is impaired. Under chronic disease, astrocyte expression of critical transporters and enzymes that clear neurotransmitters, neutralize ROS and balance ECM remodeling dwindles to levels where homeostasis is no longer sustainable. Eventually, neuronal function and survival are impaired due to insufficient support and direct toxicity. Taken together, astrocyte dysfunction during METH abuse, in the setting of HIV-1 infection, contributes both to chronic BBB damage and propagation of a CNS environment dominated by inflammation, oxidative stress, and excitotoxic insults, that culminate in neurodegeneration.

\section{Blood Brain Barrier}

In the absence of trauma, infection or disease, and despite fenestration of the $\mathrm{BBB}$ in specific areas, the majority of the brain is sealed to peripheral immune surveillance Astrocyte foot processes cover tight junctions between brain microvascular endothelial cells (BMVECs). Astrocyte foot processes also traverse the basal lamina to physically interact with BMVEC, assist with BMVEC differentiation and provide biochemical support (Hamm et al., 2004; Ivey et al., 2009). In fact, in a coculture study, simply removing astrocytes was sufficient to cause tight junction opening and increased BBB permeability (Hamm et al., 2004). Multiple membrane proteins seal tight junctions, including claudin, occluding, and junctional adhesion molecules, while accessory proteins such as zonula occludens (ZO)-1/2 link these tight junction proteins to the BMVEC actin cytoskeleton. The expression and function of several key tight junction proteins are altered during HIV-1 infection and METH exposure leading to increased BBB permeability and viral neuroinvasion (Atluri et al., 2015; Northrop and Yamamoto, 2015).

The Trojan horse model of HIV-1 infection postulates, that early during infection circulating monocytes cross the BBB and carry virus into the CNS. Recent longitudinal studies indicate that the BBB then reseals or compartmentalizes the CNS HIV-1 infection. In ART naïve subjects HIV-1 replication and evolution proceeded independent from the periphery during the first 2 years of infection (Sturdevant et al., 2015). Further, cerebrospinal fluid (CSF) samples showed that compartmentalized HIV-1 replication correlated with a marked inflammatory response in the CSF indicative of ongoing or recurrent neuroinflammation
(Sturdevant et al., 2015). In both the periphery and the CNS, HIV-1-infected cells express viral proteins, including glycoprotein (gp)120, transactivator of transcription (Tat) and negative regulator factor (Nef), along with elevated levels of a host of inflammatory mediators such as cytokines and chemokines. These act alone, or in concert, to damage the integrity of the BBB. METH exposure has been shown to increase BBB permeability to small molecules by regulating both tight junction protein expression and intracellular vesicular transport (Dietrich, 2009; Salamanca et al., 2014). METH is capable of traversing the $\mathrm{BBB}$ without assistance and thus can act upon the BBB in the periphery and CNS concurrently. METH activates lymphocytes and promotes transendothelial migration (Martins et al., 2013). METH also increases HIV-1 replication in lymphocytes and increases HIV-1 receptor expression on dendritic cells (Liang et al., 2008; Nair et al., 2009; Cen et al., 2013; Atluri et al., 2015). Further, METH exposure suppresses antiHIV-1 activity in macrophages (MP) by downregulating toll-like receptor-9 expression. Decreased interferon (IFN)- $\alpha$ expression by METH-exposed MP impairs innate host immunity against HIV-1 (Cen et al., 2013). Together, METH and HIV increase $\mathrm{BBB}$ compromise and immune cell infiltration to increase neuroinflammation.

Since interactions between circulating immune cells and BMVECs are mediated through cytokines, chemokines and adhesion molecules; alterations in viral proteins and chemokines play an important role in regulating leukocyte extravasation through the BBB during HIV-1 CNS infection. Cells on either side of the $\mathrm{BBB}$ participate in the dialog, including circulating leukocytes, BMVEC, perivascular MP, microglia and astrocytes (Langford and Masliah, 2001; Strazza et al., 2011; Louboutin and Strayer, 2012; Woollard et al., 2014). BMVEC expression of cell adhesion molecules is increased by leukocyte binding or by cytokines, such as interleukin (IL)-17, tumor necrosis factor (TNF)- $\alpha$, IFN- $\gamma$, IL-22, and IL-1 $\beta$, from activated leukocytes, microglia and astrocytes. Activated leukocytes penetrate the BBB by interacting with cell adhesion molecules on BMVEC (Cayrol et al., 2008; Alvarez et al., 2011; Elahy et al., 2015). HIV-1 proteins Tat and gp120 are directly toxic to BMVECs, affecting expression of tight junction proteins, ZO-1, claudin-5 and occludin, and matrix metalloproteinases (MMP; Langford and Masliah, 2001; Strazza et al., 2011; Louboutin and Strayer, 2012; Woollard et al., 2014). Similarly, METH enhances BBB permeability by modulating tight junction protein expression in BMVECs. METH exposure alone significantly decreases the percentage of BMVEC expressing ZO-1, while increasing the percent expressing JAM-2. Combined treatment with gp120 decreased expression of tight junction proteins compared to control (Mahajan et al., 2008). In an in vitro BBB model, METH exposure significantly increased transmigration of peripheral blood mononuclear cells (PBMCs) in response to a CCL5 chemotactic gradient compared to unexposed controls. The transmigration of HIV-1-infected PBMCs increased significantly compared to control PBMCs and doubled upon METH exposure, as compared to HIV-1 alone (Mahajan et al., 2008).

The entry of HIV-1-infected cells into the brain is the foundation of HIV-1-associated neurodegeneration; however, the 
outcome of HIV-1 CNS infection varies dramatically between individuals. Even before ART, disease progression to AIDS with and without neurocognitive impairment could take years. However, METH abuse exacerbates HIV-1-associated disease pathology, inducing changes that may last for decades even after METH is no longer abused (Cadet and Krasnova, 2007; Iudicello et al., 2014; Northrop and Yamamoto, 2015). HIVE, the most severe form of HAND, is pathologically characterized by inflammatory changes and accumulation of perivascular MP, formation of microglial nodules and multinucleated giant cells, astrogliosis, neuronal atrophy and death (Gendelman, 2005). With the effective use of ART helping to suppress disease progression, clinicians and researchers alike postulate that ANI and MND are stages of a similar disease process (Strazza et al., 2011). However, since HAND is often a comorbidity rather than the cause of death, HIV-1-associated neuropathology is often "non-specific," leading many to search for other more subtle mechanisms of neurodegeneration (Gelman, 2015). Neuroinflammation remains a focus of intense study as inhibiting viral replication alone has slowed, but not halted, HAND progression.

\section{Neuroinflammation}

The pro-inflammatory cascade leading to the disruption of the $\mathrm{BBB}$ and entry of HIV-1-infected leukocytes into CNS continues in the brain microenvironment. Resident microglia and perivascular MP perpetuate neuroinflammation, activating and or transmitting the infection to non-infected cells, including astroglia. As the resident immune cells, microglia are the primary HIV-infected cells in the brain mediating neuroinflammatory responses, by increasing cytokines, MMPs and cytotoxic factors (Ramesh et al., 2013). However, microglial activation and infection inevitably also lead to astrocyte activation and infection of a very small percentage of astrocytes with HIV. HIV infection in astrocytes is restricted to the extent that are capable of expressing viral proteins, including gp120, Tat and Nef, but not infectious virions (Messam and Major, 2000; Eugenin et al., 2011; Fitting et al., 2012; Li et al., 2015; Luo and He, 2015). Coculture experiments mimicking the interconnections between BMVEC and astroglia demonstrate that a small percentage (4.7\%) of HIV-1-infected astrocytes can lead to endothelial apoptosis, dysregulation of lipoxygenase/cyclooxygenase (COX), calcium $\left(\mathrm{Ca}^{2+}\right)$ channels and ATP receptor activation within astrocytes, significantly contributing to BBB disruption (Eugenin et al., 2011). Further, astrocytes exposed to HIV-1 proteins, along with those expressing them, have been shown to modulate to neuroinflammation through multiple regulatory pathways, summarized in Tables 1, 2.

Pro-inflammatory molecules also propagate inflammation by the spread of reactive gliosis and affect neuronal function and survival by direct and indirect mechanisms. In the healthy nervous system, cytokines and chemokines are neuromodulators, regulating neurodevelopment, neuroinflammation, and synaptic transmission. They are fundamental to the brain's proper immune function, serving to maintain immune surveillance, facilitate leukocyte traffic, and recruit other inflammatory factors (Chui and Dorovini-Zis, 2010). However, during neuroinflammation associated with both HIV-1 infection and METH exposure, activated glia mediate neuronal injury and death through neurotoxic signaling, generation of ROS, altered cellular metabolism, neurotransmission and cerebral blood flow, among others (Lau et al., 2000; Abdul Muneer et al., 2011; Hoefer et al., 2015). In such, reactive glia, infected or not, participate in the disruption of the BBB leading to infiltration of HIV-1-infected cells into the CNS and continuation of neuroinflammation in the brain. The specific contributions and regulation of these cytokines, chemokines and bioactive molecules in reactive astrocytes and other cells during HIV-1 and METH comorbidity are summarized in Tables 1, 2 and will be discussed in more detail below.

\section{Oxidative Stress}

ROS participate in signaling and metabolic pathways during physiological conditions (Ray et al., 2012). During homeostasis, anti-oxidant enzymes, including super oxide dismutase (SOD), glutathione peroxidase (GP), glutathione (GSH) and catalase (CAT), tightly regulate and neutralize reactive molecules such as superoxide, hydrogen peroxide and hydrogen radicals. Excessive ROS induced by a variety of mechanisms, including inflammatory cytokines, mitochondrial respiration, ischemia and infection, are implicated in aging, cardiovascular disease, diabetes, stroke and neurodegeneration (Cobb and Cole, 2015; Raz et al., 2015; Salisbury and Bronas, 2015). Reactive nitrogen species (RNS) also contribute the oxidative environment (Torre et al., 2002). Inducible NO synthase (iNOS) generates NO, which can interact with ROS to form peroxynitrite, a highly RNS (Pacher et al., 2007). Low levels of oxidative stress activate antioxidant machinery, initiate anti-microbial responses in immune cells and activate endothelial cells (Ma et al., 2014; Molteni et al., 2014; Salisbury and Bronas, 2015). Unchecked oxidative and nitrosative modifications to cellular components, such as the mitochondria, often augment oxidative stress and induce apoptosis (Cossarizza et al., 2002; Jou, 2008; Indo et al., 2015). Oxidative stress in the HIV-infected brain, through both the early effects of viral proteins and the later effects on mitochondrial integrity, are well established (Valcour and Shiramizu, 2004; Ozdener, 2005; Banerjee et al., 2010; Uzasci et al., 2013). Low ROS levels can promote viral replication and can be induced by viral virulence factors (Molteni et al., 2014). HIV-1 gp120, Tat and viral protein $\mathrm{R}$ (Vpr) induce ROS in neural cells, including astrocytes (Ferrucci et al., 2013; Shah et al., 2013). In addition to the direct generation of oxidative stress by HIV-1, antiretroviral therapies, particularly dideoxynucleotide reverse transcriptase inhibitors (NTRI), alter mitochondrial function and exacerbate oxidative damage in peripheral and central nervous systems (Lewis, 2003; Akay et al., 2014). During HIV disease progression, increased oxidative stress is accompanied by deficiencies in anti-oxidant enzymes, such as GP, GSH and SOD (Gil et al., 2003; Sundaram et al., 2008; Pang et al., 2013; Gill et al., 2014; Samikkannu et al., 2014). Astrocytes treated with indinavir or nelfinavir export GSH into the culture supernatant, indicating brain GSH homeostasis may also be dysregulated by HIV-1 protease inhibitors in astrocytes (Brandmann et al., 2012). 
TABLE 1 | Astroglial factors influencing neuronal survival and function.

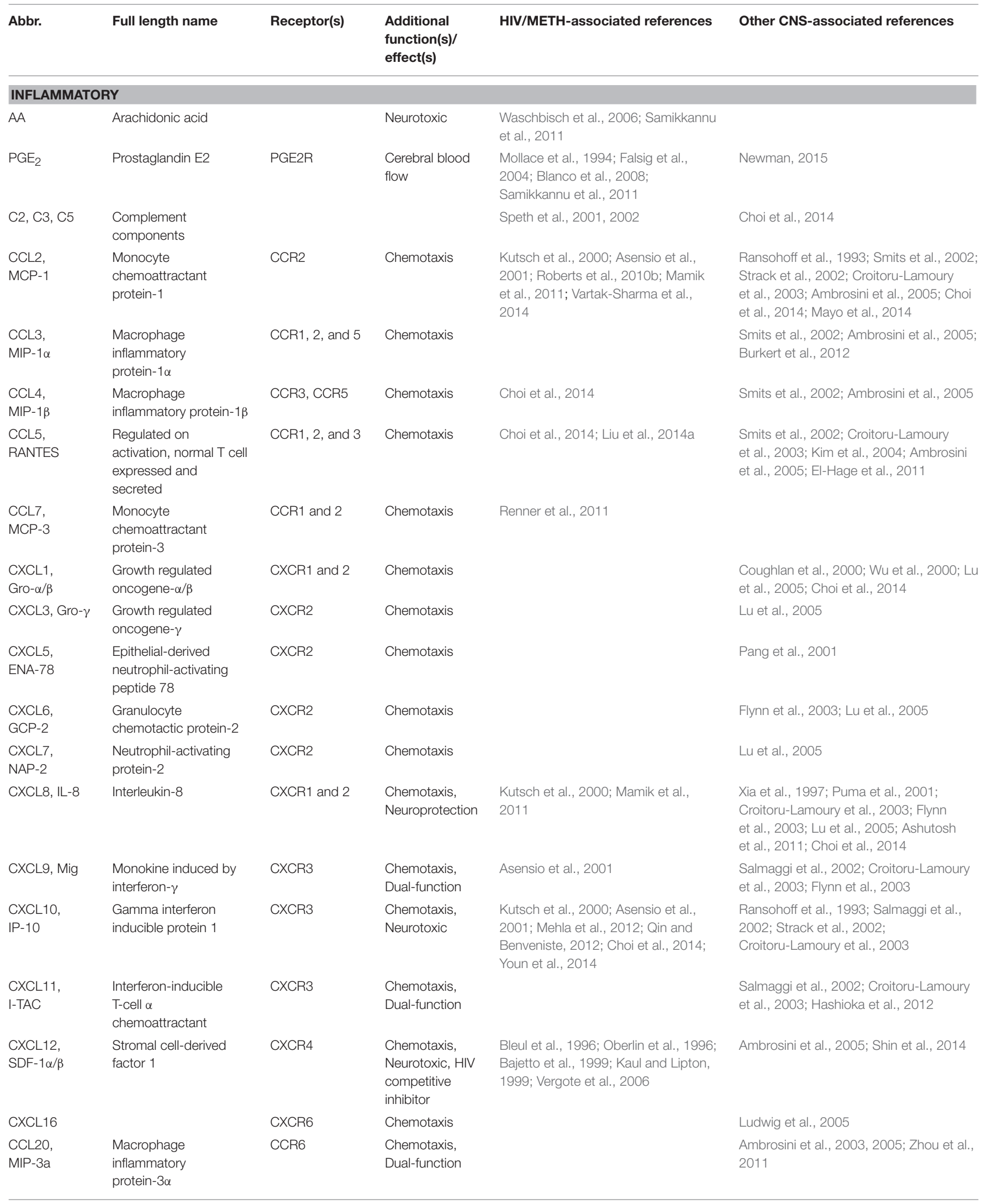


TABLE 1 | Continued

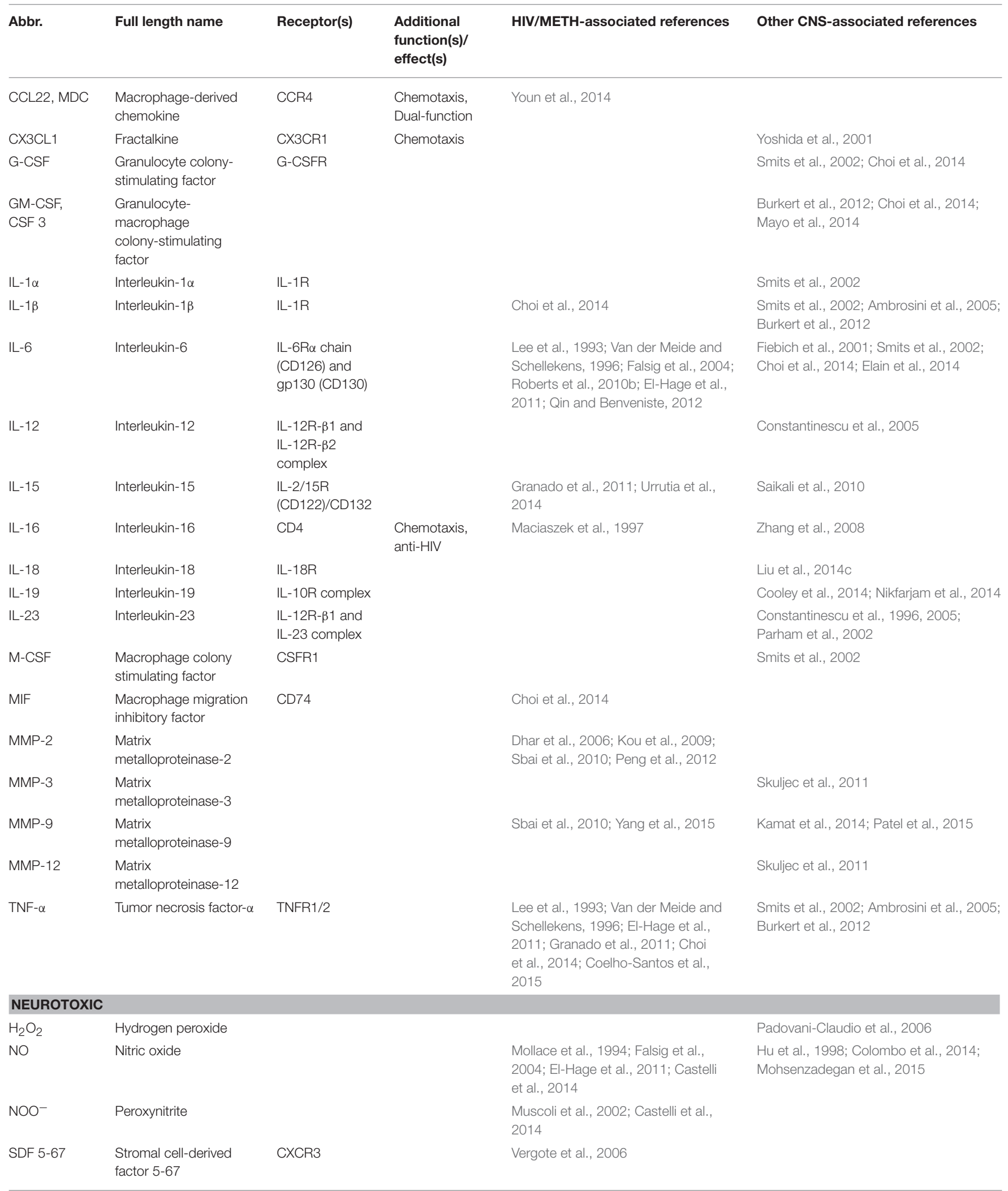


TABLE 1 | Continued

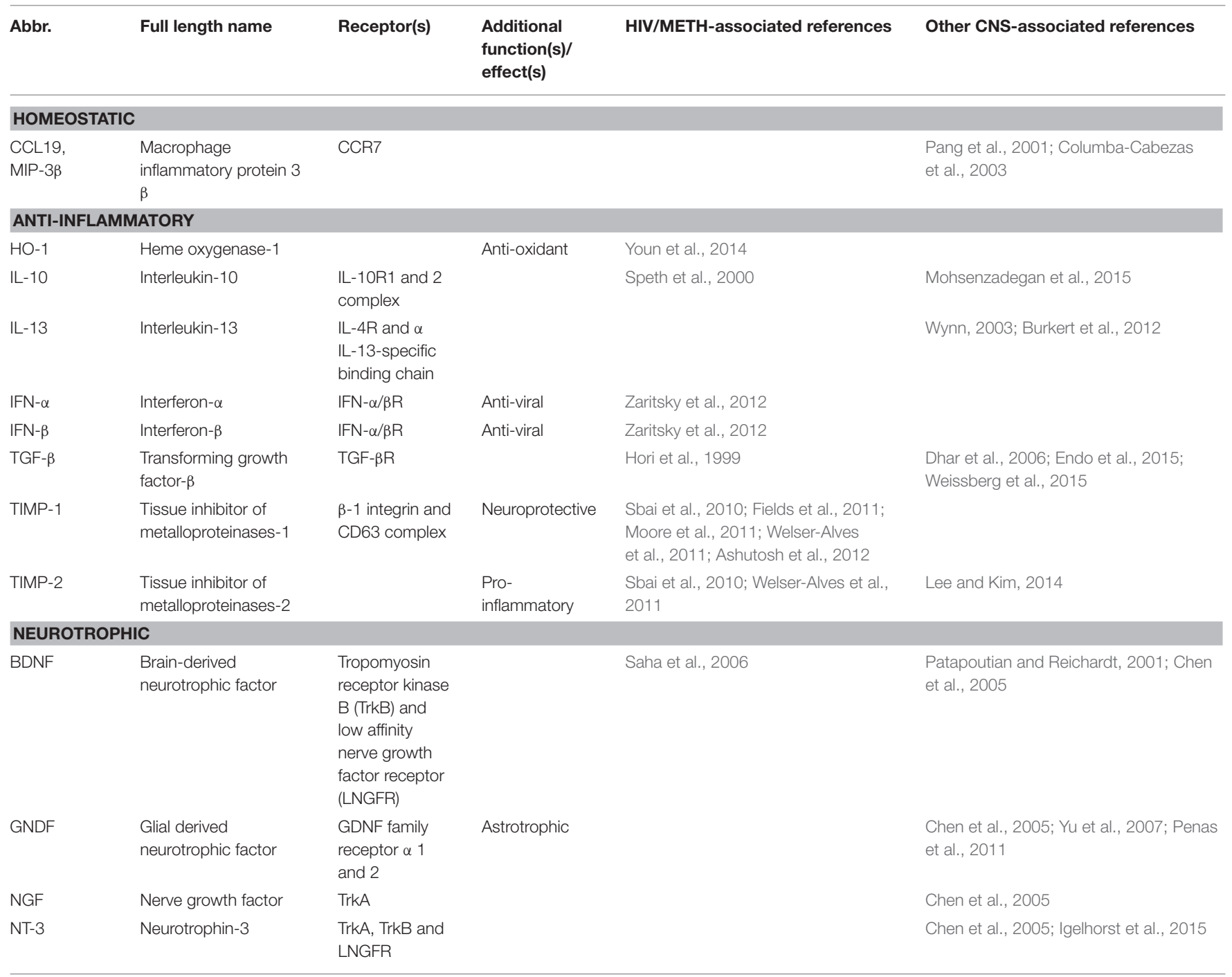

Relative oxidative stress also differs between HIV clades and may contribute to the neuropathogenesis of clade $\mathrm{B}$ as compared to clade C (Samikkannu et al., 2014). Clade B virus induced production of ROS, coupled with reduced expression of GSH synthase, GP, SOD and CAT, in monocyte derived dendritic cells and neuroblastoma cells compared to clade C virus (Samikkannu et al., 2014). The expression of detoxifying enzymes heme oxygenase (HO)-1 and $\mathrm{NAD}(\mathrm{P}) \mathrm{H}$ dehydrogenase increased in HIV-1 gp120-treated astrocytes (Reddy et al., 2012). However, HO-1 levels are decreased in the brain of HIV1 -infected individuals and correlate with increased cognitive dysfunction (Gill et al., 2014). An inability for astroglia and other neural cells to maintain anti-oxidant responses may implicate anti-oxidant exhaustion in the chronic neurodegenerative disease process.

Contributions of oxidative stress to METH-mediated neurotoxicity are also well accepted. Overexpression of various SODs or knockout (KO) of neuronal NOS, abrogate striatal depletion of dopamine and serotonin (Cadet et al., 1994; Hirata et al., 1995; Itzhak et al., 2000; Maragos et al., 2000). Regional differences in the anti-oxidant capacity of brain regions of HIV-1 transgenic rats exposed to METH show independent and combined effects on induction of oxidative stress (Pang et al., 2013). Coexposure to both HIV and METH increases oxidative stress and apoptosis in the brain, which is associated with neurological impairment (Banerjee et al., 2010; Ferrucci et al., 2013; Shah et al., 2013). Administration of N-acetylcysteine amide (NACA), a thiol anti-oxidant, protected the BBB from oxidative stress-mediated damage in HIV-1 gp120-, Tat- and METH-treated mice (Banerjee et al., 2010). Together these data support the importance of oxidative stress in HIV- and METH-mediated neurodegeneration.

\section{Excitotoxicity}

Excitotoxicity is a direct result of abnormal regulation of glutamate concentrations in the synapse. As a common neurotoxic mechanism, excitotoxicity is implicated in many neurodegenerative conditions including HAND and METH 
TABLE 2 | Astrocyte responses to HIV-1-relevant and METH stimuli.

\begin{tabular}{|c|c|c|c|}
\hline Outcomes & $\begin{array}{l}\text { HIV-1-relevant stimuli } \\
\text { and METH }\end{array}$ & Regulation or mechanism & References \\
\hline \multicolumn{4}{|l|}{ BBB PERMEABILITY } \\
\hline & Virus, IL-1 $1 \beta$, TNF- $\alpha$ & CXCR3/CXCR4, MAPK, PKC & Mehla et al., 2012 \\
\hline & Tat $_{1-72}$ treatment & p38 MAPK & Kutsch et al., 2000 \\
\hline $\begin{array}{l}\text { Increased ICAM-1 expression leading to } \\
\text { enhanced interactions with MP }\end{array}$ & gp120 treatment & PKC, TK, JAK2/STAT $1 \alpha$ & Shrikant et al., 1996 \\
\hline $\begin{array}{l}\text { Increased TNF- } \alpha \text { expression leading to } \\
\text { BBB impairment }\end{array}$ & METH & NF-кB pathway & Coelho-Santos et al., 2015 \\
\hline Dysregulation of TIMP-1: MMP Balance & Virus, IL-1 $\beta$ & $\begin{array}{l}\text { CAATT-enhancer binding protein (C/EBP)- } \beta \text {, ERK } \\
\text { 1/2, p38 MAPK }\end{array}$ & $\begin{array}{l}\text { Suryadevara et al., 2003; Fields et al., } \\
2011,2013\end{array}$ \\
\hline Increased pro-viral replication (FIV) & METH & Viral entry or integration & Gavrilin et al., 2002 \\
\hline Increased pro-viral replication (HIV) & $\mathrm{IFN}-\gamma$ & STAT3 and Dickkopf-related protein $1, \beta$-catenin & Li et al., 2011 \\
\hline \multicolumn{4}{|l|}{ Cytokines and chemokine expression } \\
\hline $\begin{array}{l}\text { Increased CCL2 production leading to } \\
\text { regulation of IFN- } \alpha / \beta \text { and TRAIL } \\
\text { expression in MP }\end{array}$ & Virus (SIV) & & Zaritsky et al., 2012 \\
\hline Increased C3 expression & $\begin{array}{l}\text { Virus, Nef, gp41 } \\
\text { treatment }\end{array}$ & $\begin{array}{l}\text { Activation of adenylate cyclase, increased cAMP, } \\
\text { IL-6/L- } 1 \beta \text { responsive promoter elements and } \\
\text { C/EBP- } \delta\end{array}$ & Speth et al., 2002; Bruder et al., 2004 \\
\hline $\begin{array}{l}\text { Increased C5, IL-1 } \beta \text {, IL-1ra, TNF- } \alpha \text {, } \\
\text { CXCL10, CCL3, CCL5 }\end{array}$ & $\mathrm{IL}-1 \beta, \mathrm{TNF}-\alpha$ & $\mathrm{NF}-\mathrm{kB}$ & Choi et al., 2014 \\
\hline $\begin{array}{l}\text { Increased CCL2, CXCL8 and CD38 } \\
\text { expression }\end{array}$ & HIV-1YY-2 expression & MAPK, ERK 1/2, NF-кB & Kou et al., 2009; Mamik et al., 2011 \\
\hline $\begin{array}{l}\text { Increased CCL2, CXCL8 and CXCL10 } \\
\text { expression }\end{array}$ & Tat treatment & MAPK, JNK, AP-1, NF-kB & Youn et al., 2014 \\
\hline Increased CCL2 and CXCL8 expression & Tat $_{1-72}$ treatment & Mitogen-activated protein kinase kinase (MEK) 1/2 & Kutsch et al., 2000 \\
\hline $\begin{array}{l}\text { Increased CCL2, CXCL8 and IL-6 } \\
\text { expression }\end{array}$ & VPR treatment & & Ferrucci et al., 2013 \\
\hline Increased CXCL8 and CXCL10 expression & Virus, VPR treatment & & Vivithanaporn et al., 2010 \\
\hline \multirow[t]{2}{*}{ Increased CXCL8 and IL-6 expression } & Tat expression & PI3K/Akt, p38 MAPK and NF-кB, p388, AP-1 & Nookala and Kumar, 2014 \\
\hline & METH & mGluR5, Akt/PI3K, NF-кB & Shah et al., 2012b \\
\hline Increased IL-6 and TNF- $\alpha$ expression & gp120 treatment & & Van der Meide and Schellekens, 1996 \\
\hline Increased IL-6 expression & gp120 treatment & IкB kinase $(\mid \mathrm{KK}) \beta$ and NF- $\mathrm{kB}$ & Shah et al., 2011 \\
\hline \multicolumn{4}{|l|}{ Eicosanoid expression and regulation } \\
\hline $\begin{array}{l}\text { Increased TNF- } \alpha \text {, IL-1 } \beta \text {, leukotriene B4, } \\
\text { leukotriene D4, lipoxin A4 and } \\
\text { platelet-activating factor (PAF) expression }\end{array}$ & $\begin{array}{l}\text { Virus (HIV-infected MP) } \\
\text { coculture }\end{array}$ & Astrocyte cellular contact, AA-dependent & Genis et al., 1992 \\
\hline Increased prostaglandin EP3R expression & $\mathrm{IL}-1 \beta$ & $\mathrm{PKC}, \mathrm{NF}-\mathrm{kB}$ & Waschbisch et al., 2006 \\
\hline Increased COX-2 expression & $\| \mathrm{L}-1 \beta$ & C/EBP- $\beta$ & Fields and Ghorpade, 2012 \\
\hline Increased PGE2 expression & gp120 treatment & NO & Mollace et al., 1994 \\
\hline
\end{tabular}


TABLE 2 | Continued



abuse (Erdmann et al., 2006; Jaiswal et al., 2009; VázquezSantiago et al., 2014). During physiologic glutamatergic signaling, glutamate interacts with its receptors, N-methyl-D-aspartate receptor (NMDA) and $\alpha$-amino-3-hydroxy-5-methyl-4isoxazolepropionic acid receptor (AMPA), to induce a $\mathrm{Ca}^{2+}$ influx and potentiation of the excitatory signal. Excitatory amino acid transporters (EAAT)-2 on adjacent astrocyte processes quickly clear glutamate from the synapse to end post-synaptic neuron excitation (Camacho and Massieu, 2006). Pathologically elevated levels of glutamate trigger high levels of intracellular $\mathrm{Ca}^{2+}\left(\left[\mathrm{Ca}^{2+}\right]_{\mathrm{i}}\right)$ and activate a variety of enzymes, including phospholipases, endonucleases and proteases. Opening of mitochondrial permeability transition pores, upon uptake of excessive $\mathrm{Ca}^{2+}$, releases ROS and pro-apoptotic compounds 
(Manev et al., 1989; Ankarcrona et al., 1995; Stavrovskaya and Kristal, 2005).

Plasma and CSF glutamate levels are elevated in HAD patients (Ferrarese et al., 2001; Espey et al., 2002). HIV1 infected macrophages and microglia convert glutamine to glutamate through the release of glutaminase from compromised mitochondria (Erdmann et al., 2009). In such MP and microglia increase extracellular glutamate levels by secreting both glutamate and glutaminase (Huang et al., 2011). HIV1 Tat also prolongs glutamate triggered $\mathrm{Ca}^{2+}$ influx by inducing the phosphorylation of NMDA receptors, leading to enhanced cell death (Haughey et al., 2001). In human brain tissues, EAAT-2 expression was decreased in HIV+ individuals, with and without HIVE. EAAT-2 expression correlated with areas of diffuse microglial reactivity, indicating that microglial activation contributes to astrocyte dysfunction (Xing et al., 2009). Astrocytes are responsible for clearing $\sim 90 \%$ of extracellular glutamate from the synapse. HIV-1 decreases EAAT-2 expression in cultured human astrocytes (Wang et al., 2003) and glutamate clearance is impaired by inflammation (Cisneros and Ghorpade, 2012, 2014).

METH alters the expression, composition and function of NMDA and AMPA receptors in the brain. Receptor levels increased with both acute and chronic models of METH administration and isoforms of $\mathrm{Ca}^{2+}$-impermeable receptors increased, suggesting a mechanism to counteract METH-induced excitotoxicity (Simões et al., 2008). The frequency of spontaneous and miniature excitatory postsynaptic currents increases at low METH doses and begin decreasing at higher doses (Zhang et al., 2014). Extracellular glutamate concentrations remain elevated, even after dopamine levels return to physiological levels (Mark et al., 2007). METH downregulates astrocyte EAAT-2 expression through trace amine associated receptor (TAAR)1, which is also associated with regulation of dopamine transporters in neurons (Cisneros and Ghorpade, 2014). EAAT-2 dysregulation in reactive astrocytes likely contributes to HIV- and METHmediated excitotoxicity.

\section{GLIOSIS}

Although infiltration of peripheral immune cells often leads to significant neural damage, leukocyte infiltration is not always associated with neurotoxicity (Boztug et al., 2002; Trifilo and Lane, 2003; Clark et al., 2011). In such, the resident glial cells, microglia and astroglia, are implicated as central players in the inflammatory responses associated with neurodegeneration. The term gliosis refers to a non-specific reactive change in glial cells in response to damage, disease or infection in the CNS. Reactive glia are often identified in brain tissue by morphological changes, including increased size, elongation of processes and increased reactivity with cellular markers. Morphological changes are indicative of altered glial function. The primary goal of gliosis is to restore brain homoeostasis by providing trophic support, tissue repair and containment of the affected region. As discussed above, reactive glia secrete many neuroactive substances capable of injuring neural cells, dependent upon the type, severity and duration of insult. Ultimately, the balance between the beneficial and detrimental effects of gliosis determines the outcome in the CNS.

\section{Microglia}

Microglia make up between 10 and $15 \%$ of neural glia and are accountable for the innate immune response in the brain (Lawson et al., 1992; Verkhratskiï and Butt, 2013; Elmore et al., 2014). The homeostatic functions of microglia tend to go unnoticed in the brain, even though they play an active role in embryonic brain development and clear neuronal or glial debris, while surveying their environment for threat and injury (Beyer et al., 2000; Casano and Peri, 2015). When injury or infection is detected, microglia undergo dramatic morphologic alterations, shifting from resting ramified cell into an activated amoeboid phenotype, and transforming into a more classically functioning immune cell (Burdo et al., 2013; Tavazzi et al., 2014). Activated microglia upregulate surface receptors, including major histocompatibility complex molecules, leading to secretion of factors that influence neuronal survival and a chronic neuroinflammatory state (Streit, 2000; Block and Hong, 2005). Reactive microgliosis is associated with the pathogenesis of many common types of neurodegeneration, including HAND (da Fonseca et al., 2014; Pasqualetti et al., 2015).

\section{Astroglia}

Despite the abundance of astrocytes in the brain, their proinflammatory functions have been less prominent than their microglial counterparts and continues to evolve (Ghorpade et al., 2003; Block and Hong, 2005; Ladeby et al., 2005; Ashutosh et al., 2011; Fields and Ghorpade, 2012; Van der Meide and Schellekens, 1996; Vartak-Sharma et al., 2014; Abudara et al., 2015). However, astrocytes play critical physiological roles in the brain, providing glia-neuron contact, ionic homeostasis, neurotransmitter buffering, secretion of neurotrophic factors and serve as integral members of the BBB (Van der Meide and Schellekens, 1996). Therefore, alterations in astroglial activities during reactive astrogliosis directly affect neuronal function and survival during CNS insult and infection (Abudara et al., 2015). Further, astrocyte dysfunction during neuroinflammation, injury and disease is amplified by the sheer number of cellular interactions in which each cell participates, stretching from BMVECs at the BBB to individual neurons and synapses (Giaume et al., 1997; Butt, 2011; Li et al., 2014; Muñoz et al., 2015). Astrocytes express glutamatergic, GABAergic, adrenergic, purinergic, serotonergic, muscarinic, and peptidergic receptors (reviewed in Porter and McCarthy, 1997). Thus, activated astrocytes respond to various neurotransmitters and release a variety of neuroactive molecules including glutamate, ATP, NO, and prostaglandins to influence neuronal function (Haydon, 2001; Table 1). Astrocytes are highly susceptible to cytokine and HIV-1 signaling as they express receptors (R) for both (IL1R, TNFR1/2 and CXCR4, among others; Table 2). Activated astrocytes secrete various cytokines and chemokines regulating leukocyte traffic into the brain (Peng et al., 2006; Ramesh et al., 2013; Nookala and Kumar, 2014). However, as most astrocyte responses are complex, astrocytes also mitigate inflammation with the secretion of anti-inflammatory and neurotrophic 
molecules (Table 1; Hauwel et al., 2005; Ashutosh et al., 2011, 2012; Cekanaviciute et al., 2014). In addition, astrocytes are the primary cells mediating glial scar formation during brain injury such as stroke and parasitic infections associated with AIDS (Kielian, 2004; Voskuhl et al., 2009). During glial scarring astrocytes migrate and replicate to encapsulate injury, which in turn impairs repair and neurite regrowth (Cregg et al., 2014; Hermann et al., 2014; Raposo and Schwartz, 2014).

As a pathological hallmark of HIVE, reactive astrogliosis is apparent in mouse and human HIV+ brain tissues. Astrogliosis is often visualized histologically by increased glial fibrillary acidic protein (GFAP) staining, near areas of active HIV-1 replication in multinucleated giant cells and microglial nodules (Reviewed in Sabri et al., 2003; Tavazzi et al., 2014). Astrocyte activation is also prevalent at perivascular locations, even in the absence of HIV+ perivascular MP, implicating astrocyte dysregulation of the $\mathrm{BBB}$ as a mechanism of neuroinflammation (Tavazzi et al., 2014). Several cytokines and other soluble MP activation factors implicated in HIVE pathogenesis, including TNF- $\alpha$, IL-1 $\beta$, NO and glutamate are reported to upregulate GFAP expression in astrocytes (Zhang et al., 2000; John et al., 2003; Brahmachari et al., 2006). HIV-1-Tat-induced increases in GFAP expression are regulated by the sequential activation of early growth response protein 1 (Egr-1) and p300 through a signal transducer and activator of transcription 3 (STAT3)-dependent mechanism (Zou et al., 2010; Fan et al., 2015). A similar mechanism is seen in METH-induced astrogliosis, which activates the Janus kinase 2 (JAK2)/signal transducer and STAT3 signaling cascade (Hebert and O'Callaghan, 2000; Robson et al., 2014). However, induction of astrogliosis in METH abuse studies is inconsistently increased across brain regions, METH dosing strategies and time points (Ernst et al., 2000; Kita et al., 2003, 2009; Moszczynska et al., 2004; Cadet and Krasnova, 2009; Krasnova and Cadet, 2009). In post-mortem brains of chronic METH abuse or overdose, the contribution of astrocytes to the neurodegenerative disease process is often reduced to alterations in GFAP expression or reactivity (Granado et al., 2011; Shah et al., 2013; Silva et al., 2014; Tong et al., 2014). While changes in GFAP expression are representative of astrocyte activation, they are not indicative measures of changes in the multitude of astrocyte functions capable of influencing neuron function and survival, which have primarily been investigated in vitro. Concurrently, some investigators examine astrocyte functions through behavioral testing and neuronal functional assays along side gene expression studies to evaluate changes in proteins implicated in astrocytemediated neurodegeneration (Roberts et al., 2010a; Liu et al., 2014b; Hoefer et al., 2015).

\section{METH ABUSE: IMPLICATIONS FOR ASTROCYTES AS VIRAL RESERVOIRS}

HIV-1 can invade the CNS early during infection, primarily infecting infiltrating monocytes and resident microglia, along with a small proportion of astroglia. HIV-1 then integrates with the host cell genome as a provirus, leading to both active and latent infection. During active HIV-1 infection in permissive cells, budding of infectious virions ensues. However, in nonpermissive cells such as astrocytes, active HIV-1 infection is restricted to expression of viral proteins, which are incapable of maturing into infectious particles (Messam and Major, 2000; Eugenin et al., 2011; Fitting et al., 2012; Li et al., 2015; Luo and He, 2015). Viral replication is limited in astrocytes at various steps of the virus life cycle including virus entry, reverse transcription, transport and translation of viral RNA, and maturation of progeny virions (reviewed in Messam and Major, 2000; Gorry et al., 2003). Other studies suggest that if restrictions on viral entry into astrocytes are bypassed, the intracellular environment may be conducive to productive viral infection (Canki et al., 2001; Chauhan, 2014).

Astrocytes lack the CD4 coreceptor that interacts with gp120 coat protein, restricting the proportion of astrocytes ultimately infected with HIV-1 (Harouse et al., 1989). In early studies, human embryonic astrocytes were found to express CCR5 and CXCR4 transcripts; however, neither R5 nor X4 tropic viruses could directly infect pure astrocyte cultures (Boutet et al., 2001). Recently, viral entry of fluorescently labeled viral RNA in HIV-1 NL4-3 virions was visualized in human astrocytes (Xu et al., 2015) and by mannose receptor-mediated endocytosis (Liu et al., 2004). In addition, astrocytes are susceptible to direct viral transfer of either $\mathrm{R} 5$ or $\mathrm{X} 4$ tropic viruses by cell-to-cell contact with infected T lymphocytes (Li et al., 2015; Luo and He, 2015). Viral transfer though the formation of virological synapses between astrocyte and lymphocyte filopodia can be blocked by CXCR4 antibodies and antagonists (Li et al., 2015). Further, astrocytes need not secrete mature virions to directly infect neighboring cells (Luo and He, 2015) and can "trans-infect" T lymphocytes by protecting exogenous HIV-1 particles in CD81-lined vesicles (Gray et al., 2014). Thus, if infected astrocytes are capable of directly propagating CNS HIV-1 infection, the elimination of latent astrocyte infection needs to be aggressively studied as HIV1 replication may be reactivated by inflammation and drug abuse (Gavrilin et al., 2002; Carroll-Anzinger et al., 2007; Li et al., 2011; Chauhan, 2015).

In the brains of HIV-1-infected individuals with METH dependence, epigenetic changes were associated with increased global DNA methylation as compared to the brains of HIV-1+ individuals without METH use. METH exposure led to differential methylation in genes connected to neurodegeneration, oxidative phosphorylation, dopamine metabolism and transport (Desplats et al., 2014). Differential regulation of gene expression in microglia and astrocytes during METH and HIV comorbidity may induce viral replication and expression of pro-inflammatory mediators to contribute to neurodegeneration. METH enhances viral replication in macrophages and may upregulate or downregulate infection in T cells (Liang et al., 2008; Wang et al., 2012; Mantri et al., 2014). METH activates transcription of proviral DNA in latently HIV-1-infected human microglial cells, leading to activation of the NF-кB signaling pathway (Wires et al., 2012). Feline immunodeficiency virus (FIV), a lentivirus related to HIV-1, leads to astrogliosis and microgliosis. METH has been shown to increase cell-associated FIV replication in feline astrocytes and cell lines (Phillips et al., 2000; Gavrilin et al., 2002). Reactivation 
of viral expression in latently infected astrocytes could contribute to either increased neuroinflammation and toxicity or the elimination of viral reservoirs by viral cytopathic effects and lysis by effector cells. During METH, adherence to ART is decreased and the immune system is depressed (Reback et al., 2003; In et al., 2005), tipping the balance toward increased HIV-1- and METH-associated neurodegeneration. A quick, wide-spread activation of latently infected cells, coupled with effective ART delivery to counter the spread of infection, may lead to the clearance of HIV-1-infected neural cells (Díaz et al., 2015). However, the implications of widespread elimination of infected astrocytes and other latently infected cells on neural function are unknown; the results of which may favor strategies for maintaining a latent CNS infection, rather than radical activation and elimination. (reviewed by Brew et al., 2013; Churchill and Nath, 2013).

\section{ASTROCYTE INTERACTIONS WITH HIV-1 VIRIONS, PROTEINS, AND METH}

In astrocytes, expression of and exposure to virus, HIV-1 proteins, such as gp120, Tat, Nef, or Vpr, and HIV-1relevant cytokines induce a host of factors that influence neuronal survival and function (Table 2). Both HIV-1 and METH alter astrocyte expression of inflammatory mediators, neurotransmitter receptors and transporters, which in turn alter the brain microenvironment, leading directly and indirectly to neuronal dysfunction or death. HIV-1-relevant cytokines also regulate astrocyte cytotoxicity, function and glia-neuron crosstalk during HIV-1 infection and METH abuse.

Astrocytes harboring HIV secrete various viral proteins, including gp120, Tat, Vpr and $\mathrm{p} 24$, the capsid protein. In some models of latent astrocyte infection, viral expression has been reactivated by pro-inflammatory cytokines such as TNF- $\alpha$ and IFN- $\gamma$ or PKC agonists (Carroll-Anzinger et al., 2007; Li et al., 2011; Chauhan, 2015). Expression of viral proteins activates both the infected cell and those in the vicinity by altering astrocyte physiological functions and secretion of factors that recruit immune cells and influence neuronal survival and function (Table 2). Direct interaction between astrocytes and HIV-infected MP reduces MP activation, but ultimately increases arachidonic acid (AA)-mediated eicosanoid, IL-1 $\beta$ and TNF- $\alpha$ levels (Genis et al., 1992; Nottet et al., 1995). SIV/HIV-treated and HIV-genome expressing astrocytes upregulate complement and chemokine expression, leading to increased PBMC infiltration (Speth et al., 2002; Bruder et al., 2004; Vivithanaporn et al., 2010; Zaritsky et al., 2012). HIV-1 also downregulates astrocyte EAAT-2 expression and function, contributing to excitotoxicity (Cisneros and Ghorpade, 2012, 2014).

\section{HIV-1 gp120}

As a viral coat protein, HIV-1 gp120 interacts with CCR5 and CXCR4 coreceptors on target cells leading to intracellular signaling and virion fusion with the cell. CXCR4 renders astrocytes susceptible to activation by HIV-1 via gp120-coated virus and secreted gp120. Astrocytes exposed to gp120 undergo apoptosis, while also inducing neuronal apoptosis. In astrocytes HIV-1 gp120 upregulates pro-inflammatory cytokines, adhesion proteins, and chemokines that mediate lymphocyte recruitment and extravasation (Table 2; Shrikant et al., 1996; Van der Meide and Schellekens, 1996; Kaul and Lipton, 1999).

Differences in astrocyte responses to clade B vs. clade C gp120 may contribute to increased neurodegeneration associated with clade B viruses. Clade B gp120 differentially increases COX-2-mediated AA responses in astrocytes, leading to downregulation of NMDA receptor expression and increasing PGE2 (Samikkannu et al., 2011). Bioactive molecules, such as METH, NO and PGE2, regulate the proinflammatory environment, cerebral blood flow and glucose uptake in the brain, contributing to HIV-and METH-associated neurodegeneration (Mollace et al., 1994; Falsig et al., 2004; Blanco et al., 2008; Abdul Muneer et al., 2011; Samikkannu et al., 2011). Further, during cotreatment with METH, clade B gp120 significantly decreased astrocyte expression of both dopamine receptor D2 and dopamine active transporter (DAT) as compared to METH alone or clade C gp120 (Samikkannu et al., 2015). Downregulation of dopamine receptors and transporters could impair astrocyte responses to increased synaptic dopamine levels, leading to reduced dopamine clearance and dopamine-mediated neurotoxicity through the generation of reactive dopamine quinones and oxygen/nitrogen species (Mollace et al., 1994; LaVoie and Hastings, 1999; Lau et al., 2000; Falsig et al., 2004; Guillot et al., 2008; Miyazaki et al., 2011; Castelli et al., 2014).

Behavioral testing in transgenic mice expressing HIV-1 gp120, under the control of the GFAP promoter, with and without METH administration, showed impaired learning and memory and increased disinhibition even after months of METH abstinence (Hoefer et al., 2015). Both METH and gp120 alone lead to loss of dendrites and presynaptic terminals, along with reduced long-term potentiation, which is associated with learning and memory. Further, post-tetanic potentiation, a measure of synaptic plasticity, was also decreased in METHtreated, gp120-transgenic mice (Hoefer et al., 2015).

\section{HIV-1 Tat}

As its name suggests, HIV-1 Tat activates transcription of HIV-1 genes during viral infection. However, Tat also regulates expression of cellular genes as a transcription factor and by altering signaling within the cell. Similar to gp120-treated astrocytes, Tat-exposed/expressing astrocytes have increased expression of various cytokines, chemokines, prostaglandins, adhesion protein expression, neurotransmitter receptors and transporters, and ROS (Table 2). HIV-1 Tatmediated neurotoxicity is exacerbated by METH cotreatment, leading to increased autophagy, mitochondrial damage and oxidative stress in neuronal cell lines and mouse astrocytes (Lau et al., 2000; Langford et al., 2004; Cai and Cadet, 2008; Qi et al., 2011). Further, rodents cotreated with HIV-1 Tat and METH showed increased astroglial activation and synergistic cytokine expression (including TNF- $\alpha$ and IL-1 $\beta$ ), oxidative stress, coupled with striatal neurotoxicity and degeneration of neuronal dopamine terminals (Flora et al., 2003; Theodore et al., 
2006b; Liu et al., 2014b). METH and Tat synergistically reduce dopamine levels and DAT expression, contributing to sustained behavioral impairment (Cass et al., 2003; Liu et al., 2014b). In double TNFR1/2 KO mice, dopamine levels were significantly higher than WT treated with Tat and METH, indicating the involvement of TNF- $\alpha$ and inflammation in neurodegenerative mechanisms (Theodore et al., 2006b).

\section{HIV-1 Nef}

As a virulence factor HIV-1 Nef is expressed early during the viral life cycle and ensures a persistent state of infection, while promoting T-cell activation. Whereas, HIV-1 gp120 and Tat exhibit direct astroglial and neuronal toxicity, HIV-1 Nef has been shown to induce indirect neurotoxicity through upregulation of astroglial CXCL10. Astrocytes expressing HIV$1_{\mathrm{YU}-2}$ Nef protein showed increased CXCL10 expression. CXCL10 mediated neurotoxicity through interaction with neuronal CXCR3 (van Marle et al., 2004). CXCL10 levels are also increased in HAD brains where it localizes primarily to astrocytes and is a prognostic marker for hepatitis $\mathrm{C}$ virus (HCV) and HIV/HCV coinfection (van Marle et al., 2004; Falconer et al., 2010; Vivithanaporn et al., 2010). CXCL10 is also known as IFN$\gamma$ induced protein (IP)-10. As a chemokine, CXCL10 recruits MP and T cells and promotes cell adhesion to BMVEC (Dufour et al., 2002). Astrocyte exposure to Tat also increases CXCL10 and expression of adhesion proteins such as ICAM-1 and VCAM-1, which together lead to increased trafficking of $\mathrm{T}$ cells into the brain (Kutsch et al., 2000; Dufour et al., 2002; Youn et al., 2014). Further, astrocyte CXCL10, from gp41-treated astrocytes, leads to increased CCR 5 expression by MP, increasing their susceptibility to HIV-1 infection (Speth et al., 2000).

Transgenic mice, expressing HIV-1 Nef in microglia and macrophages, showed increased CCL2 expression, decreased anti-viral IFN- $\alpha$ expression and disruption of striatal dopaminergic transmission. Monoamine oxidase activity and DAT expression in the striatum were significantly lower than non-transgenic mice. Astroglial activation was not evaluated. The Nef-expressing mice demonstrated hyperactive behaviors, which are observed in mania and other psychiatric comorbidities among HIV-infected individuals (Sherbourne et al., 2000; Acharjee et al., 2014). This suggests that HIV-1 Nef could also regulate the dopaminergic system during HIV CNS infection and METH abuse.

\section{HIV-1-relevant Cytokines}

In addition to direct astrocyte activation by binding of HIV-1 gp120 to CXCR4 or viral endocytosis (Liu et al., 2004; Fitting et al., 2012; Chauhan et al., 2014), astrocytes may also become indirectly stimulated by HIV-infected and activated microglia and MP (Tavazzi et al., 2014). Infiltrating monocytes and T helper cells secrete classical inflammatory cytokines into the brain microenvironment during HIV-1 CNS infection, leading to astrocyte activation and increased neuroinflammatory responses. With prolonged exposure to HIV-relevant neuroinflammation, astrocytic neuroprotective and homeostatic functions become exhausted, leading to insufficient support of neuronal function and survival (Gardner and Ghorpade, 2003; Suryadevara et al.,
2003; Cisneros and Ghorpade, 2012). Alternatively, chronic neurodegeneration can also prime astrocytes for exaggerated pro-inflammatory responses (Hennessy et al., 2015). Concurrent and long-term exposure of astrocytes to HIV, pro-inflammatory cytokines and METH can exacerbate astrocyte activation and exhaustion to accelerate the neurodegenerative process (Cisneros and Ghorpade, 2012, 2014; Shah et al., 2012a).

As prototypical mediators of neuroinflammation, IL-1 $\beta$ and TNF- $\alpha$ are primarily expressed in the CNS by activated and HIV-1-infected microglia and infiltrating MP (Mrak and Griffin, 1997; Witwer et al., 2009). Astrocytes are highly sensitive to IL-1 $\beta$-activation, as they possess an IL- $1 \beta$ autocrine loop, which perpetuates astrogliosis in a self-renewing manner during chronic neuroinflammation, neurodegeneration and HAND (Mrak and Griffin, 1997; Moynagh, 2005). TNF- $\alpha$, in conjunction with HIV, is a key regulator of astroglia-microglia crosstalk during neurodegeneration and can directly target neurons through TNFR $1 / 2$ and increased oxidative stress leading to apoptosis (Shi et al., 1998; Viviani et al., 1998; Ryan et al., 2004; Batlle et al., 2015). TNF- $\alpha$ regulates astrogliosis and impairs astrocyte function during HIV-1 and METH exposure (Nomura et al., 2006; Gonçalves et al., 2008; Vartak-Sharma et al., 2014; Coelho-Santos et al., 2015). Upon activation, astrocytes convert from flat, polygonal cells to small, contracted, highly branched cells, with intense GFAP and vimentin reactivity (Liu et al., 1994). IL-6, CCL2 and CXCL8 are upregulated in astroglia in response to HIV-relevant stimuli, including IL- $1 \beta$ activation and expression of viral proteins, and are increased in the plasma and brain during HIV-1 infection (Linder and Gagel, 1968; Cota et al., 2000; Witwer et al., 2009; Jing et al., 2010; Mamik et al., 2011; Shah et al., 2011; Mamik and Ghorpade, 2012; Zaritsky et al., 2012; Nookala and Kumar, 2014; French et al., 2015). These, and other cytokines, signal to peripheral and tissue immune cells, recruiting them to the site of neuroinflammation, inducing maturation and activating their effector functions.

Cytokines and chemokines can have alternate, indirect functions on non-immune cells in the brain, leading to both neuroprotective and neurotoxic outcomes. For example, CXCL8 has neuroinflammatory and neuroprotective effects in the CNS, as CXCL8 enhances viral replication in monocytes and microglia, while protecting neurons from apoptosis (Ashutosh et al., 2011; Mamik and Ghorpade, 2014). Further, METH exposure induces CXCL8 expression in SVG astrocytes. Regulation of CXCL8 expression through metabotropic glutamate receptor 5 (mGlutR5) implicates glutamate dysregulation in METHinduced neuroinflammation (Shah et al., 2012a,b). A more complex example involves the upregulation of CXCL12, MMP2 and stromal cell derived factor (SDF) 5-67 during HIV-1 CNS infection (Vergote et al., 2006). Infected or gp120-treated MP regulate astrogliosis by secreting CXCL12 and IL-1 $1 \beta$. In response, activated astrocytes secrete both CXCL12 and MMP-2 (Bajetto et al., 2001; Rostasy et al., 2003; Okamoto et al., 2005; Peng et al., 2006). These factors share a unique interaction where in MMP-2, an enzyme normally involved in the degradation of the extracellular matrix, cleaves CXCL12 to generate SDF 5-67. As a cytotoxic fragment SDF 5-67 induces neurotoxicity and upregulates IL- $1 \beta$, TNF- $\alpha$, indoleamine $2^{\prime}, 3^{\prime}$ dioxygenase 
(IDO) and IL-10 in activated astrocytes (Vergote et al., 2006). Alternately, CXCL12 impairs HIV-1 infection by CXCR4 tropic virus by competitively binding CXCR4 and blocking interactions with gp120 (Bleul et al., 1996; Oberlin et al., 1996; Amara et al., 1997; Kaul and Lipton, 1999).

Downregulation of astrocyte EAAT-2 expression and function by pro-inflammatory cytokines contributes to HIV-1and METH-associated excitotoxicity. During chronic HIV-1 infection, $\mathrm{MP} /$ microglia glutamate secretion increases and HIV1 Tat sensitizes neurons to glutamate-mediated excitotoxicity (Haughey et al., 2001; Erdmann et al., 2009; Huang et al., 2011). EAAT-2 is the primary transporter for glutamate uptake in astrocytes. Astrocyte activation by IL- $1 \beta$ or TNF- $\alpha$ decreases both the expression and function of EAAT-2; effects that are exacerbated by HIV-1 or METH cotreatment (Fine et al., 1996; Cisneros and Ghorpade, 2012). Gene expression, posttranslational modifications and protein targeting or trafficking regulate EAAT-2 activity (reviewed in Takahashi et al., 2015). The EAAT-2 promoter contains multiple NF- $\mathrm{KB}$ elements and a CREB binding element (Su et al., 2003; Allritz et al., 2010). Both signaling cascades are activated in astrocytes during HIV-1, METH and neuroinflammation (Mamik et al., 2011; Samikkannu et al., 2015). Astrocyte elevated gene-1, first identified as an HIV- 1 and TNF- $\alpha$-inducible gene, contributes to IL-1 $\beta /$ TNF$\alpha /$ HIV-1-mediated downregulation of EAAT-2 through direct interactions with NF- $\mathrm{KB}$ (Kang et al., 2005; Vartak-Sharma et al., 2014). The multifaceted mechanisms regulating EAAT-2 expression and function remain to be elucidated. A better understanding of astrocyte EAAT-2 regulation could lead to novel therapeutic options targeting astroglial dysfunction during neuroinflammatory diseases including HAND and METH abuse.

Another consequence of astrocyte exhaustion during chronic neuroinflammation is dysregulation of the tissue inhibitor of metalloproteinase (TIMP):MMP balance. Four TIMPs regulate MMP, enzymes that affect $\mathrm{BBB}$ integrity by altering the extracellular matrix. TIMP-1 is the only inducible member of the TIMP family of four inhibitors (Brew et al., 2000). Interestingly, CSF and brain tissue samples from HAD patients showed reduced TIMP-1 and increased MMP-2 levels compared to seronegative controls (Suryadevara et al., 2003). However, astrocytes upregulate TIMP-1 expression during acute IL- $1 \beta$ activation, HIV-1 gene expression or exposure (Suryadevara et al., 2003; Dhar et al., 2006; Fields et al., 2011). It is only during chronic activation that the astrocyte TIMP-1 expression falls, while expression of some MMPs is sustained, or augmented by infiltrating PBMC (Suryadevara et al., 2003; Chao and Ghorpade, 2009). TGF- $\beta 1 / 2$, an anti-inflammatory cytokine, decreases acute TIMP-1 expression in IL-1 $\beta$-activated astrocytes. In contrast to TIMP-1, TGF- $\beta$ 1/2 levels are increased in HAD brains compared to controls, thus TGF- $\beta$ may contribute to TIMP-1 depletion during chronic neuroinflammation (Dhar et al., 2006). Since TIMP-1 also protects human neurons from HIV-1-induced apoptosis, decreased TIMP-1 expression also contributes to increased neurotoxicity due to diminished neurotrophic support (Ashutosh et al., 2012). TIMP-1 and other pro-inflammatory cytokine levels remained significantly elevated in rat striatum $24 \mathrm{~h}$ after HIV-1 Tat and METH injections, compared to either alone or vehicle (Theodore et al., 2006a). Repeated METH exposure increases MMP-2 and MMP-1 expression, which in turn enhances dopamine release and reward. The METH-mediated alterations in dopamine signaling and receptor expression were significantly attenuated in MMP-2 and MMP-9 KO mice, indicating that the MMP/TIMP system also regulates METH-induced behavioral sensitization (Mizoguchi et al., 2007a,b, 2008).

\section{Common Signaling Pathways}

A large majority of bioactive molecules discussed above facilitate communication among various CNS cells.

Signals received by target receptors regulate astrocyte function during HIV-1 and METH-associated neuroinflammation through a variety of cross-linking pathways. As IL-1 $\beta$ is a prototypical cytokine for astrocyte activation, the NF- $\mathrm{KB}$ pathway contributes to the regulation of many astrocyte genes and is involved in cellular responses to stimuli such as stress, cytokines, free radicals, glutamate or viral antigens (reviewed in Mémet, 2006). Downstream of the IL-1 receptor (IL-1R), the I $\kappa \mathrm{B}$ kinase complex phosphorylates and degrades the NF- $\kappa \mathrm{B}$ sequestering protein, I $\kappa \mathrm{B} \alpha$, leading to NF- $\kappa \mathrm{B}$ release. Persistent NF- $\kappa B$ activation is implicated in the prolonged induction of selective pro-inflammatory genes in human glial cells (Griffin and Moynagh, 2006). The mitogen activated protein family of kinases (MAPK), including extracellular signal-regulated kinases (ERK), c-Jun $\mathrm{N}$-terminal kinases (JNK) and p38, also regulate many HIV-1- and METH-induced astrocyte responses, which often culminate in NF-kB-mediated gene transcription (Table 2). IL-1 $\beta$ signaling can also be negatively regulated by expression of inhibitory type IL-1R, IL-1R antagonist, soluble and decoy receptors. Dysregulation of the IL- $1 \beta$ system in the brain has been implicated in AD, MS and epilepsy (Garlind et al., 1999; Ravizza et al., 2006; Dujmovic et al., 2009) Cytokine receptors for IFNs and a few ILs are coupled to the JAK/STAT pathway. Here, JAK phosphorylation of various tyrosine kinases facilitates STAT dimerization and gene transcription. METHand Tat-induced astrogliosis and GFAP expression are also regulated through STAT3 (Robson et al., 2014; Fan et al., 2015) Ligation of G-coupled receptors such as CXCR4 can differentially initiate downstream elements including cAMP and $\left[\mathrm{Ca}^{2+}\right]_{\mathrm{i}}$ to mediate function. CXCL12 and gp120 induce ERK 1/2 activation in human neurons, while only CXCL12 did so in astrocytes (Griffin and Moynagh, 2006). Induction of differential signaling pathways also influences HIV-1 gene transcription in astrocytes, where TGF- $\beta$-linked transcription factors, Smad3 and 4 , interact with C/EBP- $\beta$ to offset Tat-mediated LTR activity (Coyle-Rink et al., 2002).

A consequence of extended activation of neuroinflammatory signaling cascades is $\mathrm{Ca}^{2+}$ dysregulation in both glia and neurons. Intracellular $\mathrm{Ca}^{2+}$, when released from the ER, acts as a secondary messenger and regulates the activity of many enzymes, ion channels and cytoskeletal components. In astrocytes, $\left[\mathrm{Ca}^{2+}\right]_{\mathrm{i}}$ signaling is induced by activity in adjacent neurons, glutamate, ATP, METH and HIV (Banerjee et al., 2008; Reddy et al., 2012). Dysregulation of $\left[\mathrm{Ca}^{2+}\right]_{i}$ is implicated in astrocyte $A \beta$ associated neurotoxicity and ischemia, through $\mathrm{Ca}^{2+}$-mediated 
TABLE 3 | Therapies targeting astroglial activation and function.

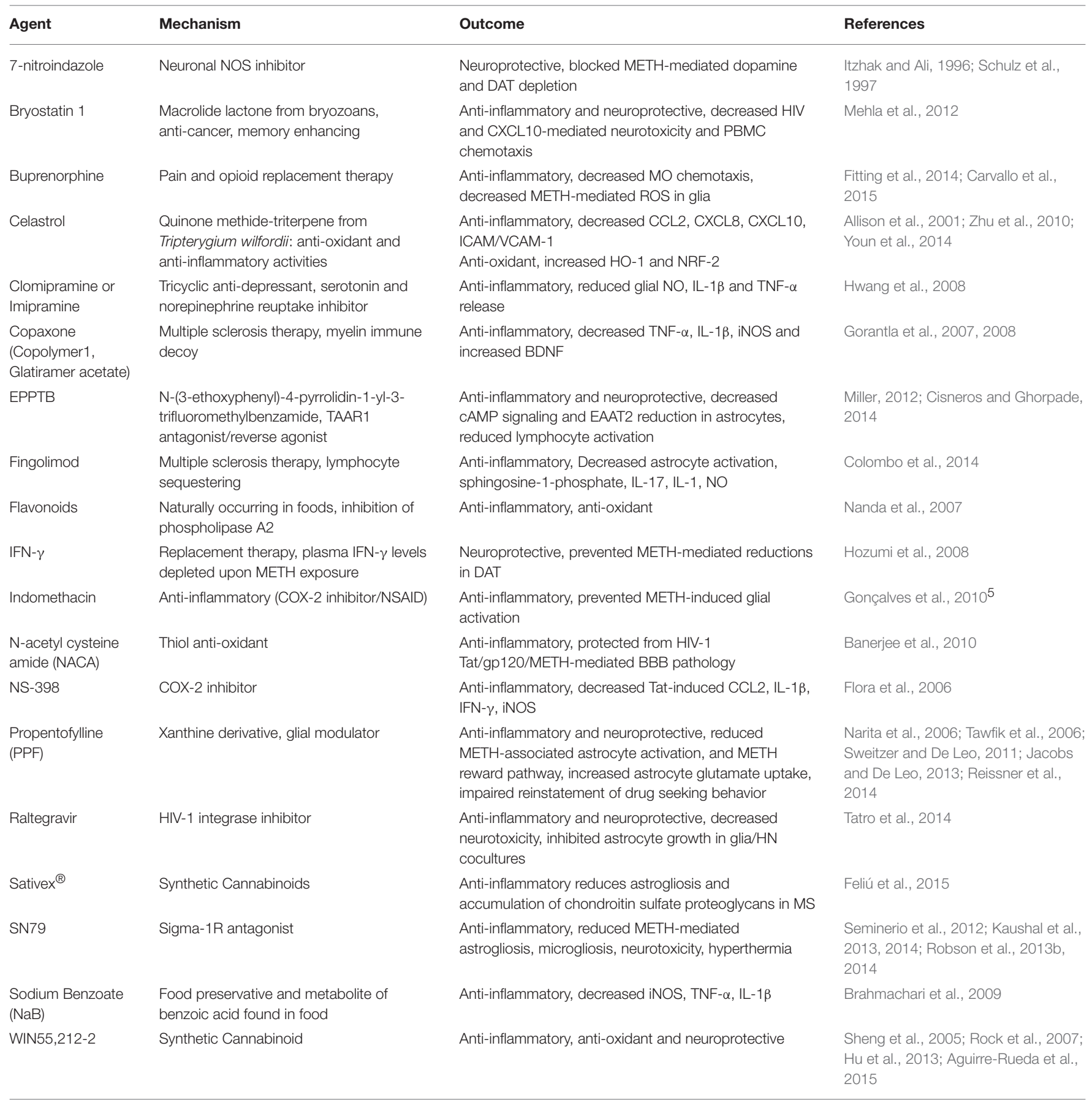

glutathione depletions and voltage-gated $\mathrm{Ca}^{2+}$ influx (Duffy and MacVicar, 1996; Abramov et al., 2003). These various routes of $\mathrm{Ca}^{2+}$ signaling converge on a common pathway involving $\mathrm{Ca}^{2+}$ overload-induced mitochondrial dysfunction, including oxidative stress, cytochrome $\mathrm{c}$ release and injury or apoptosis in neurons and astrocytes alike (Stanika et al., 2009; Eugenin and Berman, 2013).

\footnotetext{
$\overline{{ }^{5} \mathrm{https} / / \text { clinicaltrials.gov/ct2/show/NCT00172627 }}$
}

\section{THERAPEUTICS TO TARGET ASTROGLIA}

The various roles of astroglia in CNS pathology are only beginning to be defined and reactive gliosis is now well recognized as a ubiquitous feature of CNS pathologies. Astrogliosis is not a simple on or off switch, but rather a finely tuned continuum of molecular, cellular and functional alterations. These changes in gene expression and function can exert both beneficial and detrimental effects in the 
brain milieu, dependent upon the duration and context of the specific molecular signaling cascades. Glial activation and dysfunction are emerging as important targets during neuroinflammation (Jha and Suk, 2014). Astroglia actively participate in neurodegeneration through the loss of normal functions and gain of abnormal activities. The ever-expanding understanding of the mechanisms regulating these changes has the potential to identify many molecules that may serve as therapeutic targets for neuroinflammatory disorders including METH abuse and HAND (Table 3).

\section{US Food and Drug Administration (FDA) Approved Medications}

Medications already in use for non-HIV/METH/astrocyte related therapies have shown changes in HIV-1- or METH-associated neuroinflammation, glial activation and neurotoxicity. Tricyclic antidepressants, such as clomipramine, are cited in the 2015 WHO model list of essential medicines needed in a basic health system to treat anxiety and depressive disorders by inhibiting serotonin and norepinephrine reuptake ${ }^{6}$. However, in a recent study on microglia and astrocyte cultures both clomipramine and imipramine reduced NO, iNOS, IL- $1 \beta$ and TNF- $\alpha$ expression by inhibiting I $\kappa$ B degradation, NF- $\mathrm{B}$ p 65 translocation to the nucleus and phosphorylation of p38 MAPK (Hwang et al., 2008). When used in microglia-neuroblastoma cocultures, both antidepressants significantly reduced glia-mediated-cell death (Hwang et al., 2008).

Fingolimod, an immune modulating drug used to treat MS, decreases astroglial activation and NO production in response to sphingosine-1-phosphate (S1P), IL-1 $\beta$ and IL-17 (Colombo et al., 2014). Fingolimod modulates autoimmune lymphocyte release from the lymph node by agonizing the S1P receptor, and also prevents monocyte: endothelial interactions (Bolick et al., 2005; Baumruker et al., 2007). However, in astrocytes fingolimod also decreased IL-induced, NF-кBmediated signaling and reduced neurotoxicity following transfer of conditioned supernatants from activated astrocytes. Further, in an experimental autoimmune encephalomyelitis mouse model, fingolimod hampered astrocyte activation and NO production (Colombo et al., 2014). These results indicate that fingolimod can traverse the $\mathrm{BBB}$ and/or decrease monocyte infiltration into the CNS, supporting it as a candidate to decrease glial activation during HAND. However, these positive effects on glia would have to be balanced with impaired lymphocyte maturation in the lymph node. Copolymer-1, another MS drug that serves as a myelin decoy, showed anti-inflammatory benefits in an HIVE mouse model, with decreased pro-inflammatory cytokine and iNOS expression, coupled with increased BDNF levels. Both microgliosis and astrogliosis were reduced with treatment, which correlated with diminished neurodegeneration (Gorantla et al., 2007, 2008). These and other glial modulating, MS drugs may warrant future therapeutic consideration for HAND.

${ }^{6} \mathrm{http} / /$ www.who.int/selection_medicines/committees/expert/20/EML_2015_ FINAL_amended_JUN2015.pdf?ua=1
Over-the-counter COX-2 inhibitors and other non-steroidal anti-inflammatory drugs are widely used to treat pain and inflammation by blocking prostaglandin activation. Regulation of astrocyte gene expression during HIV-1- and METHassociated neuroinflammation involves common signaling intermediates including NF- $\mathrm{BB}$ and prostaglandins. In mouse studies indomethacin, a potent COX-2 inhibitor prescribed to treat inflammatory disorders such as rheumatoid arthritis, prevented or diminished METH-induced glial activation. GFAP and CD11b immunoreactivity and TNF- $\alpha /$ TNFR1 protein levels were reduced. Indomethacin inhibited METH-induced glial activation and hippocampal neuronal toxicity, preserving beta III tubulin, calbindin and tau expression (Gonçalves et al., 2010). NS-398, a COX-2 inhibitor in clinical trials for gastric cancer, decreased Tat-induced iNOS, CCL2, IL- $1 \beta$ and IFN- $\gamma$ expression in brain glia. NS-398 was more effective than pyrrolidine dithiocarbamate, a potent anti-oxidant and NF- $\kappa \mathrm{B}$ inhibitor (Huang, 2005; Flora et al., 2006). Current FDA-approved drugs capable of inhibiting these pathways in astroglia, may effectively reduce gain of function pro-inflammatory responses and reduce brain inflammation, if expeditiously approved for off-label uses to treat HIV-1 CNS infection and possibly METH abuse.

\section{Naturally Occurring Glia Modulators}

Food additives alter glial neuroinflammatory responses by regulating NF- $\kappa$ B activation. Sodium benzoate $(\mathrm{NaB})$, a food preservative and a metabolite of benzoic acid, occurs naturally in cinnamon, cranberries, prunes, plums and apples. $\mathrm{NaB}$ is designated as "generally recognized as safe" by the $\mathrm{FDA}^{7}$, and is used pharmaceutically to treat urea cycle disorders and schizophrenia (Häberle et al., 2012; Lane et al., 2013). In vitro, microglial pro-inflammatory responses to LPS, HIV1 Tat or $A \beta$, as measured by iNOS, TNF- $\alpha$, IL- $1 \beta$ and surface markers, were significantly reduced by $\mathrm{NaB}$ treatment. IL- $1 \beta$-activated mouse astroglia showed reduced GFAP and iNOS expression with $\mathrm{NaB}$ treatment (Brahmachari et al., 2009).

Celastrol is a triterpenoid quinone methide derived from perennial plants belonging to the Celastraceae family. Celastrol has exhibited anti-oxidant and anti-inflammatory effects in microglia and astrocytes (Jung et al., 2007; Nakamichi et al., 2010; Boridy et al., 2012; Youn et al., 2014). In astrocytes, celastrol inhibited HIV-1 Tat-induced expression of ICAM-1/VCAM-1 and pro-inflammatory chemokines CXCL8, CXCL10, and CCL2 in a JNK MAPK, AP-1, and NF- $\kappa$ B dependent manner. Further, celastrol downregulated these pro-inflammatory mediators by inducing $\mathrm{HO}-1$ expression and Nrf-2 activation, both antioxidant responsive genes (Youn et al., 2014). Celastrol stands out as a prime therapeutic candidate for targeting glial activation as it inhibits glial-mediated inflammation while upregulating anti-oxidant machinery (Nakamichi et al., 2010; Youn et al., 2014).

Another class of plant metabolites, known as flavonoids, are found in tea, red wine, dark chocolate, Ginkgo biloba and berries

${ }^{7}$ http://www.accessdata.fda.gov/scripts/cdrh/cfdocs/cfcfr/CFRSearch.cfm? CFRPart $=184$ 
(Haytowitz ${ }^{8}$ ). Research into their potential broad health benefits against oxidative stress, inflammation, cancer and cardiovascular disease is currently ongoing; yet, no health claims have been approved by the FDA or European Food Safety Authority for use as pharmaceutical drugs (Agostoni et al., 2010). However, flavonoids such as silibinin have been shown to possess antiHIV-1 and HCV effects in T-cells by blocking viral replication, cell activation and proliferation (McClure et al., 2012). Orally administered anti-oxidants, such as flavonoids, have the capacity to inhibit microglial migration, ROS and IL- $1 \beta$ production, AAand COX-2-mediated inflammation and toxicity (Nanda et al., 2007; Chuang et al., 2014; Singh and Pai, 2015). Assessment of ROS/RNS-mediated post-translational modifications of brain proteins in the CSF and brain tissues may reveal biomarkers associated with HIV-1-neurodegeneration (Uzasci et al., 2013). Biomolecules available in food by targeted dietary changes or supplementation that exert both generalized anti-oxidant and anti-inflammatory effects could penetrate the brain and reduce glial activation.

Therapeutic cannabis has been proposed in management of common comorbidities of HIV-1 infection (Woolridge et al., 2005; Whiting et al., 2015). Dronabinol (Marinol $\left.{ }^{\circledR}\right)$ is an FDA approved synthetic $\Delta$ 9-tetrahydrocannabinol (THC) that has been used to treat ART-associated nausea, appetite reductions and wasting syndrome (de Jong et al., 2005; Badowski and Pandit, 2014). Studies in Canada and England indicate that $27-38.5 \%$ of HIV-1-infected individuals used cannabis on a regular basis and self-reported benefits include relief of anxiety or depression, improved appetite, pleasure and pain relief (Woolridge et al., 2005; Harris et al., 2014). The physiological endocannabinoid (eCB) system consisting of cannabinoid receptors (CBR) and their endogenous ligands, eCB, are expressed by neurons, microglia and astrocytes (reviewed in Woolridge et al., 2005; Navarrete and Araque, 2008; Oliveira da Cruz et al., 2015). Hippocampal tripartite synapse signaling between astrocytes and neurons involves $\mathrm{CB} 1 \mathrm{R}$, a G-coupled protein receptor. CB1R stimulation by neuronal eCB leads to increased $\mathrm{Ca}^{2+}$ levels, glutamate release and activation of NMDA receptors of pyramidal neurons (Navarrete and Araque, 2008, 2010; RasooliNejad et al., 2014). Studies of memory impairments induced by exogenous $\mathrm{CB}$ exposure were unchanged in neuronal CB1R KO and abolished in astrocyte CB1R KO mice. Further, inhibition of NMDA receptors also blocked CB-induced memory impairment, implicating astrocyte glutamatergic signaling as a key player in memory and learning (Han et al., 2012). Activation of astrocyte connexin- 43 hemichannels by eCB releases ATP, which upregulates microglial pro-inflammatory responses during CNS injury (Vazquez et al., 2015).

In chronic neuroinflammatory disease models of HAND, AD, MS and stroke, eCB exert anti-inflammatory and neuroprotective effects in the CNS (Schiavon et al., 2014; Aguirre-Rueda et al., 2015; Feliú et al., 2015; Hind et al., 2015). A CBR

\footnotetext{
${ }^{8}$ Haytowitz, D.B., Bhagwat, S., Harnly, J., Holden, J.M., Gebhardt, S.E. Sources of Flavonoids in the U.S. Diet Using USDA's Updated Database on the Flavonoid Content of Selected Foods. [Online]. Available: http://www.ars. usda.gov/SP2UserFiles/Place/80400525/Articles/AICR06_flav.pdf [Accessed 7/15 2015].
}

synthetic agonist, WIN55,212-2 (WIN), protects neurons from gp120-mediated damage ( $\mathrm{Hu}$ et al., 2013). In IL-1 $\beta$-activated astrocytes, WIN decreases pro-inflammatory expression of TNF$\alpha$, CCL2, CCL5, and CXCL10 (Sheng et al., 2005). In microglia, WIN inhibits HIV-1 replication and decreases gp120-induced superoxide production (Rock et al., 2007; Hu et al., 2013). METH administration also increases $\mathrm{eCB}$ and $\mathrm{CBR}$ expression in the brain, suggesting that they may participate in METH-mediated neurotoxicity and behavioral changes. $\mathrm{CBR}$ antagonists reduce METH-seeking behavior following METH cessation and protect dopamine terminals from damage in mice (Anggadiredja et al., 2004; Loewinger et al., 2012). However, $\Delta 9$-THC administration with METH reinstatement reduced subsequent METH-seeking behaviors (Anggadiredja et al., 2004). Pretreatment with $\Delta 9$ THC blocks METH-induced neurotoxicity and astrogliosis by decreasing neuronal NOS and TNF- $\alpha$ levels, and by preserving tyrosine hydroxylase expression (Castelli et al., 2014; Nader et al., 2014). Together these studies suggest that synthetic cannabinoids may reduce glial activation during chronic HIV-1- and METHassociated neuroinflammation and protect neurons.

\section{Propentofylline}

Propentofylline (PPF), a phosphodiesterase and adenosine reuptake inhibitor has been studied as a therapeutic treatment for various dementias and glioblastoma (Frampton et al., 2003; Jacobs et al., 2012). Interestingly, PPF treatment blocks METH-induced astrocyte activation and attenuates the METH reward pathway in mice. Further, intracranial injection of METH-treated conditioned media from astrocytes, but not from microglia, enhanced METH rewarding effects; suggesting astrocyte-specific regulation of METH reward pathways (Narita et al., 2006). PPF has also been shown to impair reinstatement of cocaine seeking behavior, which was dependent upon GLT1/EAAT-2 expression and function (Reissner et al., 2014). PPF therapy increases EAAT-2 expression in astrocytes and dampens pro-inflammatory cytokine levels (Tawfik et al., 2006; Sweitzer and De Leo, 2011; Jacobs and De Leo, 2013). Since dysregulation of astrocyte EAAT-2 expression and function is implicated in both HAND and METH abuse, PPF could potentially target astrogliosis-mediated excitotoxicity and propagation of the neuroinflammatory environment by glia.

\section{Receptor Antagonists}

Astrocyte activation during METH abuse leads to persistent increase in GFAP immunoreactivity and reactive phenotypes even months after cessation of METH abuse. Therapeutic targeting of METH signaling receptors in astrocytes may reduce astroglial activation and impaired astrocyte function. In-depth studies on neuronal METH receptors have led to significant insight into the addictive and euphoric effects of METH abuse. In astrocytes; however, there is a paucity of these investigations with few recent reports that document METH receptors on astrocytes (Cisneros and Ghorpade, 2014; Robson et al., 2014; Zhang et al., 2015).

During METH exposure, trace amine associated receptor 1 (TAAR1) modulates dopamine levels in the synapse by regulating 
DAT activity in neurons. Activation of TAAR1 by METH stimulates protein kinase (PK)A and PKC to phosphorylate DAT. It has been proposed through studies in TAAR1 KO mice that phospho-DAT either acts in reverse, effluxing dopamine into the synapse, or is internalized, preventing dopamine reuptake from the synapse (Miller, 2011). TAAR1 is also expressed in primary human astrocytes, lymphocytes, B-cells and is upregulated during activation with METH and pro-inflammatory mediators (Panas et al., 2012; Babusyte et al., 2013; Cisneros and Ghorpade, 2014). In astrocytes, TAAR1 is upregulated during METH/HIV1 cotreatment. Further, astrocyte TAAR1 activation by METH increases cAMP levels and downregulates EAAT-2 expression and function, which may lead to excitotoxicity and neuronal dysfunction or death due to impaired glutamate clearance from the synapse by astrocytes (Cisneros and Ghorpade, 2014). METH-induced alterations in EAAT-2 expression and function were blocked by TAAR1 knockdown, implicating TAAR1 as a therapeutic target for astrocyte-mediated neurotoxicity during METH and HIV-1 neurodegeneration (Miller, 2012; Cisneros and Ghorpade, 2014). In lymphocytes, METH-induced phosphorylation of PKA and PKC could be significantly reduced by EPPTB, a selective TAAR1 antagonist/reverse antagonist (Miller, 2012; Panas et al., 2012). However, TAAR1 KO mice show increased sensitivity to METH as measured by striatal dopamine release and augmentation of METH-induced behaviors (Wolinsky et al., 2007; Lindemann et al., 2008; AchatMendes et al., 2012). TAAR1 overexpression in the neurons of transgenic mice decreased sensitivity to amphetamine, even with increased extracellular dopamine levels in the accumbens nucleus and serotonin in the medial prefrontal cortex (Revel et al., 2012). Interestingly, attenuation of TAAR1 activation with a selective partial antagonist, RO5073012, restored METHmediated changes in locomotor activity. Therefore, constitutive or tonic activation of TAAR1 by natural agonists may regulate physiological monoamine activity in neurons (Revel et al., 2012). TAAR1 agonists also suppress hyperactivity and improve cognition in glutamate receptor deficiency models (Revel et al., 2011, 2013) and TAAR1 modulates cortical glutamate NMDA receptor function in TAAR1 KO mice (Espinoza et al., 2015). Thus, a balance between agonism of neuronal TAAR1 and antagonism of astrocyte TAAR1 will need to be further investigated to balance the neuroprotective benefits of TAAR1 targeting drugs.

Sigma receptors have also garnered much attention in the neurodegenerative disease field as they have been implicated in pathology of neurodegenerative conditions including $\mathrm{AD}, \mathrm{PD}$, stroke and METH neurotoxicity (reviewed in Nguyen et al., 2014). Sigma receptor $1(\sigma-1 \mathrm{R})$ antagonists have been shown to attenuate METH-induced neurotoxicity, hyperthermia and behavior changes (Matsumoto et al., 2008; Kitanaka et al., 2009, 2012; Smith et al., 2010; Kaushal and Matsumoto, 2011; Kaushal et al., 2011; Robson et al., 2013a). Only recently have $\sigma$-R been studied in METH-mediated brain gliosis, where METH-induced GFAP expression was abrogated in $\sigma-1 \mathrm{R}$ KO mice compared to controls (Robson et al., 2014). Further, METH-exposure leads to a positive feedback regulation in astrocyte $\sigma-1 \mathrm{R}$ expression that could be inhibited with $\sigma-1 \mathrm{R}$ antagonist BD1047 (Zhang et al.,
2015). SN79, a $\sigma-1 \mathrm{R}$ antagonist, has also been shown to block microglial and astrocyte activation, reducing expression of proinflammatory cytokine expression following $\mathrm{METH}$ treatment (Robson et al., 2013b, 2014), further implicating glial $\sigma-1 \mathrm{R}$ as a therapeutic target for neurodegeneration. While $\sigma-1 \mathrm{R}$ do not have intrinsic signaling machinery, they appear to modulate the activity of $\mathrm{Ca}^{2+}$ channels and signaling molecules by translocation and protein-protein interactions to regulate diverse cellular functions, including intracellular $\mathrm{Ca}^{2+}$ signaling, oxidative stress response, mitochondrial function, transcriptional regulation and cell survival. In such, drugs targeting sigma receptors in neurons and glia have vast implications in neurodegenerative disease and drug abuse (reviewed in Nguyen et al., 2014).

\section{CONCLUDING REMARKS: HIV-1, METH, AND ASTROCYTES AT NEUROINFLAMMATORY CROSSROADS}

In this review, we have provided an in-depth summary of the existing literature about METH effects on astrocytes in the setting of HIV. This comprehensive overview indicates, without a doubt, that astrocyte regulation of neuroinflammation during HIV-1 infection and METH abuse involves a complex dialog between all neural cells. Figure 1 provides a graphic summary of ongoing events and a proposed temporal order for these activities. (1) As HIV-1 and METH gain access to the brain across the BBB, they interact with astrocytes and induce production of reactive oxygen and nitrogen species. (2.1) These along with cytokines and chemokines from either side of the $\mathrm{BBB}$, act to increase $\mathrm{BBB}$ permeability. Chemokine gradients recruit leukocytes, which bring $\mathrm{HIV}-1$ and inflammation as they extravagate into CNS. Brain microglia and perivascular macrophages, when activated and infected, secrete cytokines, virus, viral proteins and ROS, which in turn activate astrocytes to perpetuate (2.2) neuroinflammation and (2.3) oxidative stress. In response to activation, astrocyte EAAT-2 levels decrease and extra cellular glutamate levels rise. (2.4) Pathological glutamate levels overexcite neurons impairing function through excitotoxicity. (3) Concurrently, METH and neuroinflammation activate astrocytes and microglia in the vicinity, instigating reactive gliosis. (4) METH and other pro-inflammatory cytokines can activate proviral gene expression in astrocytes and microglia. (5) Infected glia secrete viral proteins and pro-inflammatory mediators, which alter astrocytes homeostatic functions and perpetuate neuroinflammation. Cytotoxic molecules, including cytokines, viral proteins and ROS, coupled with depletion of astrocytic neurotrophic support, induce neuronal dysfunction and death. (6) Intervening with therapeutics targeting astroglia may disrupt the neuroinflammatory dialogue and protect neurons during HAND and METH abuse.

Taken together, this comprehensive review further emphasizes that additional studies regarding glial-based mechanisms/interactions, implicated in the combined setting of METH and HIV, are timely and highly warranted. Moreover, this review presents a platform to persuade future investigators 


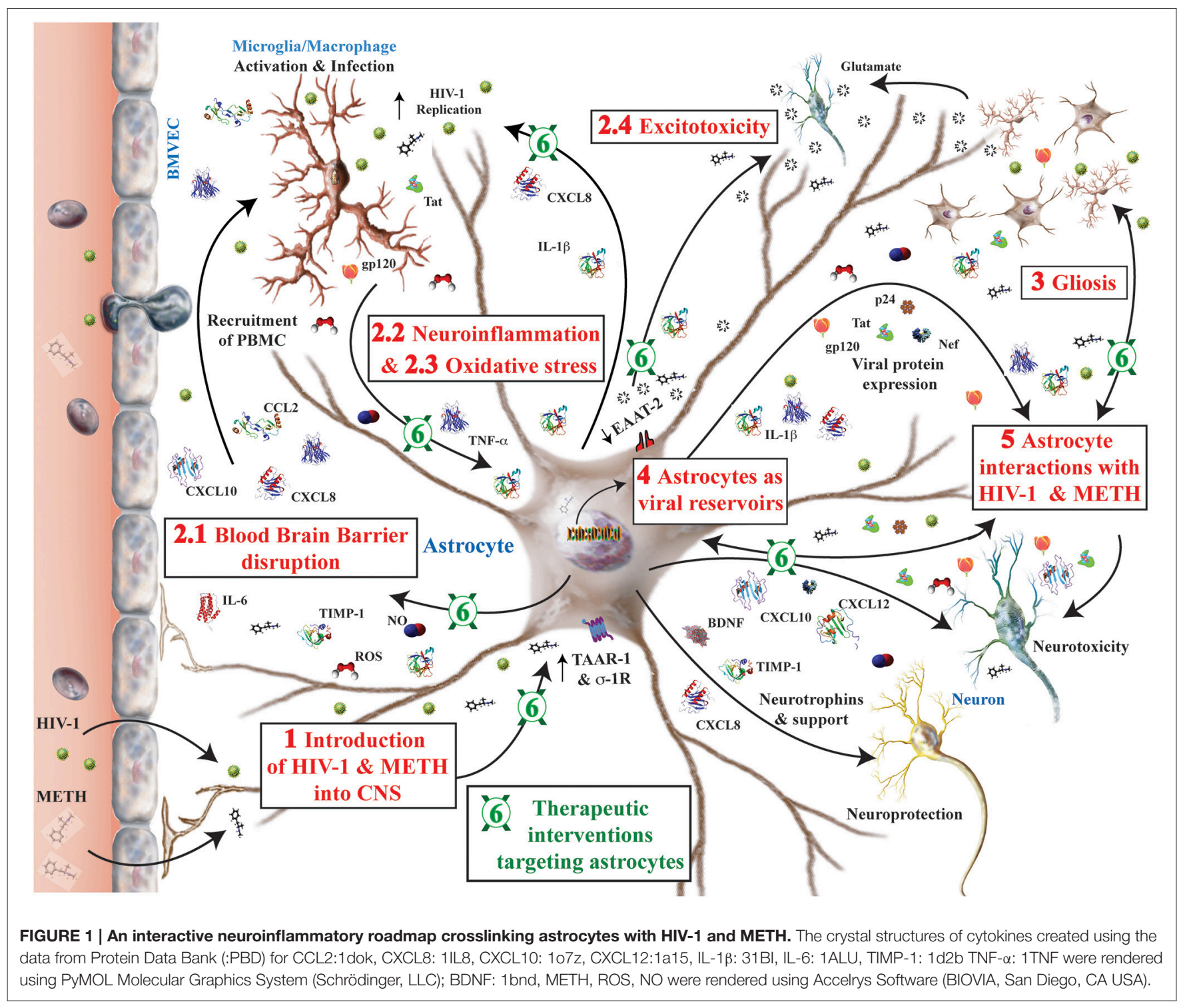

to examine several critical questions that remain unanswered and are likely to influence therapeutic outcomes. Perhaps, most importantly, it is yet unknown how these interactions differ in the setting of long-term ART. Are there any disparities related to the outcomes of the combined interplay outlined in Figure 1 in the setting of race and/or gender? Epigenetic factors may play a significant role in these phenomena and we have only begun to scratch the surface of the role of genetic background and/or predisposition. Over the next several years, HIV-associated comorbidities including neurological and metabolic complications and related astroglial contributions, will continue to hold high research priorities. While we have highlighted several salient features of astroglial contributions to neuroinflammation, the role of METH and other drugs of abuse in this setting will continue to unravel. Continued elucidation of the regulatory mechanisms governing astroglial responses to METH and HIV-1 will provide the foundation for the generation of novel therapeutic interventions for neuroinflammatory disorders by targeting a key player, astrocytes.

\section{FUNDING}

The studies were supported by grant R01DA039789 from NIDA to AG. 


\section{REFERENCES}

Abdul Muneer, P. M., Alikunju, S., Szlachetka, A. M., and Haorah, J. (2011). Methamphetamine inhibits the glucose uptake by human neurons and astrocytes: stabilization by acetyl-L-carnitine. PLOS ONE 6:e19258. doi: 10.1371/journal.pone.0019258

Abramov, A. Y., Canevari, L., and Duchen, M. R. (2003). Changes in intracellular calcium and glutathione in astrocytes as the primary mechanism of amyloid neurotoxicity. J. Neurosci. 23, 5088-5095.

Abudara, V., Roux, L., Dallérac, G., Matias, I., Dulong, J., Mothet, J. P., et al. (2015). Activated microglia impairs neuroglial interaction by opening Cx43 hemichannels in hippocampal astrocytes. Glia 63, 795-811. doi: 10.1002/glia.22785

Acharjee, S., Branton, W. G., Vivithanaporn, P., Maingat, F., Paul, A. M., Dickie, P., et al. (2014). HIV-1 Nef expression in microglia disrupts dopaminergic and immune functions with associated mania-like behaviors. Brain Behav. Immun. 40, 74-84. doi: 10.1016/j.bbi.2014.02.016

Achat-Mendes, C., Lynch, L. J., Sullivan, K. A., Vallender, E. J., and Miller, G. M. (2012). Augmentation of methamphetamine-induced behaviors in transgenic mice lacking the trace amine-associated receptor 1. Pharmacol. Biochem. Behav. 101, 201-207. doi: 10.1016/j.pbb.2011.10.025

Agostoni, C., Bresson, J.-L, Fairweather-Tait, S., Flynn, A., Golly, I., Korhonen, H., et al. (2010). Scientific Opinion on the substantiation of health claims related to various food(s)/food constituent(s) and protection of cells from premature aging, antioxidant activity, antioxidant content and antioxidant properties, and protection of DNA, proteins and lipids from oxidative damage pursuant to Article 13(1) of Regulation (EC) No 1924/2006. Eur. Food Saf. Authority J. 8, 63. doi: 10.2903/j.efsa.2010.1489

Aguirre-Rueda, D., Guerra-Ojeda, S., Aldasoro, M., Iradi, A., Obrador, E., Mauricio, M. D., et al. (2015). WIN 55,212-2, agonist of cannabinoid receptors, prevents amyloid beta1-42 effects on astrocytes in primary culture. PLoS ONE 10:e122843. doi: 10.1371/journal.pone.0122843

Akay, C., Cooper, M., Odeleye, A., Jensen, B. K., White, M. G., Vassoler, F., et al. (2014). Antiretroviral drugs induce oxidative stress and neuronal damage in the central nervous system. J. Neurovirol. 20, 39-53. doi: 10.1007/s13365-0130227-1

Allison, A. C., Cacabelos, R., Lombardi, V. R., Alvarez, X. A., and Vigo, C. (2001). Celastrol, a potent antioxidant and anti-inflammatory drug, as a possible treatment for Alzheimer's disease. Prog. Neuropsychopharmacol. Biol. Psychiatry 25, 1341-1357. doi: 10.1016/S0278-5846(01)00192-0

Allritz, C., Bette, S., Figiel, M., and Engele, J. (2010). Comparative structural and functional analysis of the GLT-1/EAAT-2 promoter from man and rat. J. Neurosci. Res. 88, 1234-1241. doi: 10.1002/jnr.22303

Alvarez, J. I., Dodelet-Devillers, A., Kebir, H., Ifergan, I., Fabre, P. J., Terouz, S., et al. (2011). The Hedgehog pathway promotes blood-brain barrier integrity and CNS immune quiescence. Science 334, 1727-1731. doi: $10.1126 /$ science. 1206936

Amara, A., Gall, S. L., Schwartz, O., Salamero, J., Montes, M., Loetscher, P., et al. (1997). HIV coreceptor downregulation as antiviral principle: SDF-1alphadependent internalization of the chemokine receptor CXCR4 contributes to inhibition of HIV replication. J. Exp. Med. 186, 139-146.

Ambrosini, E., Columba-Cabezas, S., Serafini, B., Muscella, A., and Aloisi, F. (2003). Astrocytes are the major intracerebral source of macrophage inflammatory protein-3alpha/CCL20 in relapsing experimental autoimmune encephalomyelitis and in vitro. Glia 41, 290-300. doi: 10.1002/glia. 10193

Ambrosini, E., Remoli, M. E., Giacomini, E., Rosicarelli, B., Serafini, B., Lande, R., et al. (2005). Astrocytes produce dendritic cell-attracting chemokines in vitro and in multiple sclerosis lesions. J. Neuropathol. Exp. Neurol. 64, 706-715. doi: 10.1097/01.jnen.0000173893.01929.fc

Anggadiredja, K., Nakamichi, M., Hiranita, T., Tanaka, H., Shoyama, Y., Watanabe, S., et al. (2004). Endocannabinoid system modulates relapse to methamphetamine seeking: possible mediation by the arachidonic acid cascade. Neuropsychopharmacology 29, 1470-1478. doi: 10.1038/sj.npp. 1300454

Ankarcrona, M., Dypbukt, J. M., Bonfoco, E., Zhivotovsky, B., Orrenius, S., Lipton, S. A., et al. (1995). Glutamate-induced neuronal death: a succession of necrosis or apoptosis depending on mitochondrial function. Neuron 15, 961-973.
Asensio, V. C., Maier, J., Milner, R., Boztug, K., Kincaid, C., Moulard, M., et al. (2001). Interferon-independent, human immunodeficiency virus type 1 gp120mediated induction of CXCL10/IP-10 gene expression by astrocytes in vivo and in vitro. J. Virol. 75, 7067-7077. doi: 10.1128/JVI.75.15.7067-7077.2001

Ashutosh, Chao, C., Borgmann, K., Brew, K., and Ghorpade, A. (2012). Tissue inhibitor of metalloproteinases-1 protects human neurons from staurosporine and HIV-1-induced apoptosis: mechanisms and relevance to HIV-1-associated dementia. Cell Death Dis. 3, e332. doi: 10.1038/cddis.2012.54

Ashutosh, Kou, W., Cotter, R., Borgmann, K., Wu, L., Persidsky, R., et al. (2011). CXCL8 protects human neurons from amyloid-beta-induced neurotoxicity: relevance to Alzheimer's disease. Biochem. Biophys. Res. Commun. 412, 565-571. doi: 10.1016/j.bbrc.2011.07.127

Atluri, V. S., Hidalgo, M., Samikkannu, T., Kurapati, K. R., Jayant, R. D., Sagar, V., et al. (2015). Effect of human immunodeficiency virus on blood-brain barrier integrity and function: an update. Front. Cell. Neurosci. 9:212. doi: $10.3389 /$ fncel.2015.00212

Azevedo, F. A., Carvalho, L. R., Grinberg, L. T., Farfel, J. M., Ferretti, R. E., Leite, R. E., et al. (2009). Equal numbers of neuronal and nonneuronal cells make the human brain an isometrically scaled-up primate brain. J. Comp. Neurol. 513, 532-541. doi: 10.1002/cne.21974

Babusyte, A., Kotthoff, M., Fiedler, J., and Krautwurst, D. (2013). Biogenic amines activate blood leukocytes via trace amine-associated receptors TAAR1 and TAAR2. J. Leukoc. Biol. 93, 387-394. doi: 10.1189/jlb.0912433

Badowski, M., and Pandit, N. S. (2014). Pharmacologic management of human immunodeficiency virus wasting syndrome. Pharmacotherapy $34,868-881$. doi: 10.1002/phar.1431

Bajetto, A., Barbero, S., Bonavia, R., Piccioli, P., Pirani, P., Florio, T., et al. (2001). Stromal cell-derived factor-1alpha induces astrocyte proliferation through the activation of extracellular signal-regulated kinases $1 / 2$ pathway. J. Neurochem. 77, 1226-1236.

Bajetto, A., Bonavia, R., Barbero, S., Piccioli, P., Costa, A., Florio, T., et al. (1999). Glial and neuronal cells express functional chemokine receptor CXCR4 and its natural ligand stromal cell-derived factor 1 . J. Neurochem. 73, 2348-2357. doi: 10.1046/j.1471-4159.2001.00350.x

Banerjee, A., Zhang, X., Manda, K. R., Banks, W. A., and Ercal, N. (2010). HIV proteins (gp120 and Tat) and methamphetamine in oxidative stressinduced damage in the brain: potential role of the thiol antioxidant $\mathrm{N}$-acetylcysteine amide. Free Radic. Biol. Med. 48, 1388-1398. doi: 10.1016/j.freeradbiomed.2010.02.023

Banerjee, S., Walseth, T. F., Borgmann, K., Wu, L., Bidasee, K. R., Kannan, M. S., et al. (2008). CD38/cyclic ADP-ribose regulates astrocyte calcium signaling: implications for neuroinflammation and HIV-1-associated dementia. J. Neuroimmune Pharmacol. 3, 154-164. doi: 10.1007/s11481-008-9105-7

Batlle, M., Ferri, L., Andrade, C., Ortega, F. J., Vidal-Taboada, J. M., Pugliese, M., et al. (2015). Astroglia-microglia cross talk during neurodegeneration in the rat hippocampus. Biomed Res. Int. 2015:102419. doi: 10.1155/2015/102419

Baumruker, T., Billich, A., and Brinkmann, V. (2007). FTY720, an immunomodulatory sphingolipid mimetic: translation of a novel mechanism into clinical benefit in multiple sclerosis. Expert Opin. Investig. Drugs 16, 283-289. doi: 10.1517/13543784.16.3.283

Benos, D. J., McPherson, S., Hahn, B. H., Chaikin, M. A., and Benveniste, E. N. (1994). Cytokines and HIV envelope glycoprotein gp120 stimulate $\mathrm{Na}+\mathrm{H}+$ exchange in astrocytes. J. Biol. Chem. 269, 13811-13816.

Beyer, M., Gimsa, U., Eyüpoglu, I. Y., Hailer, N. P., and Nitsch, R. (2000). Phagocytosis of neuronal or glial debris by microglial cells: upregulation of MHC class II expression and multinuclear giant cell formation in vitro. Glia 31, 262-266. doi: 10.1002/1098-1136(200009)31:3<262::AID-GLIA70>3.0.CO;22

Blanco, A., Alvarez, S., Fresno, M., and Muñoz-Fernández, M. A. (2008). Extracellular HIV-Tat induces cyclooxygenase- 2 in glial cells through activation of nuclear factor of activated T cells. J. Immunol. 180, 530-540. doi: 10.4049/jimmunol.180.1.530

Bleul, C. C., Farzan, M., Choe, H., Parolin, C., Clark-Lewis, I., Sodroski, J., et al. (1996). The lymphocyte chemoattractant SDF-1 is a ligand for LESTR/fusin and blocks HIV-1 entry. Nature 382, 829-833. doi: 10.1038/382829a0

Block, M. L., and Hong, J. S. (2005). Microglia and inflammation-mediated neurodegeneration: multiple triggers with a common mechanism. Prog. Neurobiol. 76, 77-98. doi: 10.1016/j.pneurobio.2005.06.004 
Bolick, D. T., Srinivasan, S., Kim, K. W., Hatley, M. E., Clemens, J. J., Whetzel, A., et al. (2005). Sphingosine-1-phosphate prevents tumor necrosis factor-\{alpha\}mediated monocyte adhesion to aortic endothelium in mice. Arterioscler. Thromb. Vasc. Biol. 25, 976-981. doi: 10.1161/01.ATV.0000162171.30089.f6

Boridy, S., Soliman, G. M., and Maysinger, D. (2012). Modulation of inflammatory signaling and cytokine release from microglia by celastrol incorporated into dendrimer nanocarriers. Nanomedicine (Lond.) 7, 1149-1165. doi: 10.2217/nnm.12.16

Borjabad, A., Brooks, A. I., and Volsky, D. J. (2010). Gene expression profiles of HIV-1-infected glia and brain: toward better understanding of the role of astrocytes in HIV-1-associated neurocognitive disorders. J. Neuroimmune Pharmacol. 5, 44-62. doi: 10.1007/s11481-009-9167-1

Boutet, A., Salim, H., Taoufik, Y., Lledo, P. M., Vincent, J. D., Delfraissy, J. F., et al. (2001). Isolated human astrocytes are not susceptible to infection by M- and Ttropic HIV-1 strains despite functional expression of the chemokine receptors CCR5 and CXCR4. Glia 34, 165-177. doi: 10.1002/glia.1051

Boztug, K., Carson, M. J., Pham-Mitchell, N., Asensio, V. C., Demartino, J., and Campbell, I. L. (2002). Leukocyte infiltration, but not neurodegeneration, in the CNS of transgenic mice with astrocyte production of the CXC chemokine ligand 10. J. Immunol. 169, 1505-1515. doi: 10.4049/jimmunol.169.3.1505

Brahmachari, S., Fung, Y. K., and Pahan, K. (2006). Induction of glial fibrillary acidic protein expression in astrocytes by nitric oxide. J. Neurosci. 26, 4930-4939. doi: 10.1523/JNEUROSCI.5480-05.2006

Brahmachari, S., Jana, A., and Pahan, K. (2009). Sodium benzoate, a metabolite of cinnamon and a food additive, reduces microglial and astroglial inflammatory responses. J. Immunol. 183, 5917-5927. doi: 10.4049/jimmunol.0803336

Brandmann, M., Tulpule, K., Schmidt, M. M., and Dringen, R. (2012). The antiretroviral protease inhibitors indinavir and nelfinavir stimulate Mrp1mediated GSH export from cultured brain astrocytes. J. Neurochem. 120, 78-92. doi: 10.1111/j.1471-4159.2011.07544.x

Brew, B. J., Gray, L., Lewin, S., and Churchill, M. (2013). Is specific HIV eradication from the brain possible or needed? Expert Opin. Biol. Ther. 13, 403-409. doi: $10.1517 / 14712598.2013 .748029$

Brew, K., Dinakarpandian, D., and Nagase, H. (2000). Tissue inhibitors of metalloproteinases: evolution, structure and function. Biochim. Biophys. Acta 1477, 267-283. doi: 10.1016/S0167-4838(99)00279-4

Brosnan, C. F., and Raine, C. S. (2013). The astrocyte in multiple sclerosis revisited. Glia 61, 453-465. doi: 10.1002/glia.22443

Bruder, C., Hagleitner, M., Darlington, G., Mohsenipour, I., Würzner, R., Höllmüller, I., et al. (2004). HIV-1 induces complement factor C3 synthesis in astrocytes and neurons by modulation of promoter activity. Mol. Immunol. 40, 949-961.

Burdo, T. H., Lackner, A., and Williams, K. C. (2013). Monocyte/macrophages and their role in HIV neuropathogenesis. Immunol. Rev. 254, 102-113. doi: 10.1111/imr.12068

Burkert, K., Moodley, K., Angel, C. E., Brooks, A., and Graham, E. S. (2012). Detailed analysis of inflammatory and neuromodulatory cytokine secretion from human NT2 astrocytes using multiplex bead array. Neurochem. Int. 60, 573-580. doi: 10.1016/j.neuint.2011.09.002

Butt, A. M. (2011). ATP: a ubiquitous gliotransmitter integrating neuron-glial networks. Semin. Cell Dev. Biol. 22, 205-213. doi: 10.1016/j.semcdb.2011.02.023

Cadet, J. L., and Krasnova, I. N. (2007). Interactions of HIV and methamphetamine: cellular and molecular mechanisms of toxicity potentiation. Neurotox. Res. 12, 181-204. doi: 10.1007/BF03033915

Cadet, J. L., and Krasnova, I. N. (2009). Molecular bases of methamphetamineinduced neurodegeneration. Int. Rev. Neurobiol. 88, 101-119. doi: 10.1016/S0074-7742(09)88005-7

Cadet, J. L., Sheng, P., Ali, S., Rothman, R., Carlson, E., and Epstein, C. (1994). Attenuation of methamphetamine-induced neurotoxicity in copper/zinc superoxide dismutase transgenic mice. J. Neurochem. 62, 380-383.

Cai, N. S., and Cadet, J. L. (2008). The combination of methamphetamine and of the HIV protein, Tat, induces death of the human neuroblastoma cell line, SH-SY5Y. Synapse 62, 551-552. doi: 10.1002/syn.20512

Camacho, A., and Massieu, L. (2006). Role of glutamate transporters in the clearance and release of glutamate during ischemia and its relation to neuronal death. Arch. Med. Res. 37, 11-18. doi: 10.1016/j.arcmed.2005.05.014

Canki, M., Thai, J. N., Chao, W., Ghorpade, A., Potash, M. J., and Volsky, D. J. (2001). Highly productive infection with pseudotyped human immunodeficiency virus type 1 (hiv-1) indicates no intracellular restrictions to hiv-1 replication in primary human astrocytes. J. Virol. 75, 7925-7933. doi: 10.1128/JVI.75.17.7925-7933.2001

Carroll-Anzinger, D., Kumar, A., Adarichev, V., Kashanchi, F., and Al-Harthi, L. (2007). Human immunodeficiency virus-restricted replication in astrocytes and the ability of gamma interferon to modulate this restriction are regulated by a downstream effector of the Wnt signaling pathway. J. Virol. 81, 5864-5871. doi: 10.1128/JVI.02234-06

Carvallo, L., Lopez, L., Che, F. Y., Lim, J., Eugenin, E. A., Williams, D. W., et al. (2015). Buprenorphine decreases the CCL2-mediated chemotactic response of monocytes. J. Immunol. 194, 3246-3258. doi: 10.4049/jimmunol.13 02647

Casano, A. M., and Peri, F. (2015). Microglia: multitasking specialists of the brain Dev. Cell 32, 469-477. doi: 10.1016/j.devcel.2015.01.018

Cass, W. A., Harned, M. E., Peters, L. E., Nath, A., and Maragos, W. F. (2003). HIV1 protein Tat potentiation of methamphetamine-induced decreases in evoked overflow of dopamine in the striatum of the rat. Brain Res. 984, 133-142. doi: 10.1016/S0006-8993(03)03122-6

Castelli, M. P., Madeddu, C., Casti, A., Casu, A., Casti, P., Scherma, M., et al. (2014). Delta9-tetrahydrocannabinol prevents methamphetamine-induced neurotoxicity. PLoS ONE 9:e98079. doi: 10.1371/journal.pone.0098079

Cayrol, R., Wosik, K., Berard, J. L., Dodelet-Devillers, A., Ifergan, I., Kebir, H., et al. (2008). Activated leukocyte cell adhesion molecule promotes leukocyte trafficking into the central nervous system. Nat. Immunol. 9, 137-145. doi: $10.1038 /$ ni1551

Cekanaviciute, E., Dietrich, H. K., Axtell, R. C., Williams, A. M., Egusquiza, R., Wai, K. M., et al. (2014). Astrocytic TGF-beta signaling limits inflammation and reduces neuronal damage during central nervous system Toxoplasma infection. J. Immunol. 193, 139-149. doi: 10.4049/jimmunol.1303284

Cen, P., Ye, L., Su, Q. J., Wang, X., Li, J. L., Lin, X. Q., et al. (2013). Methamphetamine inhibits Toll-like receptor 9-mediated anti-HIV activity in macrophages. AIDS Res. Hum. Retroviruses 29, 1129-1137. doi: 10.1089/AID.2012.0264

Chao, C., and Ghorpade, A. (2009). Production and roles of glial tissue inhibitor of metalloproteinases-1 in human immunodeficiency virus-1associated dementia neuroinflammation: a Review. Am. J. Infect. Dis. 5, 314-320. doi: 10.3844/ajidsp.2009.307.313

Chauhan, A. (2014). Unperturbed posttranscriptional regulatory Rev protein function and HIV-1 replication in astrocytes. PLOS ONE 9:e106910. doi: 10.1371/journal.pone.0106910

Chauhan, A. (2015). Enigma of HIV-1 latent infection in astrocytes: an in-vitro study using protein kinase $\mathrm{C}$ agonist as a latency reversing agent. Microbes Infect. 17, 651-659. doi: 10.1016/j.micinf.2015.05.006

Chauhan, A., Tikoo, A., Patel, J., and Abdullah, A. M. (2014). HIV-1 endocytosis in astrocytes: a kiss of death or survival of the fittest? Neurosci. Res. 88, 16-22. doi: 10.1016/j.neures.2014.08.013

Chen, L. W., Yung, K. L., and Chan, Y. S. (2005). Reactive astrocytes as potential manipulation targets in novel cell replacement therapy of Parkinson's disease. Curr. Drug Targets 6, 821-833. doi: 10.2174/138945005774574506

Chiu, V. M., and Schenk, J. O. (2012). Mechanism of action of methamphetamine within the catecholamine and serotonin areas of the central nervous system. Curr. Drug Abuse Rev. 5, 227-242. doi: 10.2174/1874473711205 030227

Chiueh, C. C., and Rauhala, P. (1999). The redox pathway of S-nitrosoglutathione, glutathione and nitric oxide in cell to neuron communications. Free Radic. Res. 31, 641-650.

Choi, S. S., Lee, H. J., Lim, I., Satoh, J., and Kim, S. U. (2014). Human astrocytes: secretome profiles of cytokines and chemokines. PLOS ONE 9:e92325. doi: 10.1371/journal.pone.0092325

Chuang, J. Y., Chang, P. C., Shen, Y. C., Lin, C., Tsai, C. F., Chen, J. H., et al. (2014). Regulatory effects of fisetin on microglial activation. Molecules 19, 8820-8839. doi: 10.3390/molecules19078820

Chui, R., and Dorovini-Zis, K. (2010). Regulation of CCL2 and CCL3 expression in human brain endothelial cells by cytokines and lipopolysaccharide. J. Neuroinflammation 7:1. doi: 10.1186/1742-2094-7-1

Churchill, M., and Nath, A. (2013). Where does HIV hide? A focus on the central nervous system. Curr. Opin. HIV AIDS 8, 165-169. doi: 10.1097/COH.0b013e32835fc601 
Cisneros, I. E., and Ghorpade, A. (2012). HIV-1, methamphetamine and astrocyte glutamate regulation: combined excitotoxic implications for neuro-AIDS. Curr. HIV Res. 10, 392-406. doi: 10.2174/157016212802138832

Cisneros, I. E., and Ghorpade, A. (2014). Methamphetamine and HIV1-induced neurotoxicity: role of trace amine associated receptor 1 cAMP signaling in astrocytes. Neuropharmacology 85, 499-507. doi: 10.1016/j.neuropharm.2014.06.011

Clark, R. T., Nance, J. P., Noor, S., and Wilson, E. H. (2011). T-cell production of matrix metalloproteinases and inhibition of parasite clearance by TIMP-1 during chronic Toxoplasma infection in the brain. ASN Neuro 3:e00049. doi: 10.1042/AN20100027

Cobb, C. A., and Cole, M. P. (2015). Oxidative and nitrative stress in neurodegeneration. Neurobiol. Dis. doi: 10.1016/j.nbd.2015.04.020. [Epub ahead of print].

Coelho-Santos, V., Leitão, R. A., Cardoso, F. L., Palmela, I., Rito, M., Barbosa, M., et al. (2015). The TNF-alpha/NF-kappaB signaling pathway has a key role in methamphetamine-induced blood-brain barrier dysfunction. J. Cereb. Blood Flow Metab. 35, 1260-1271. doi: 10.1038/jcbfm.2015.59

Colombo, E., Di Dario, M., Capitolo, E., Chaabane, L., Newcombe, J., Martino, G., et al. (2014). Fingolimod may support neuroprotection via blockade of astrocyte nitric oxide. Ann. Neurol. 76, 325-337. doi: 10.1002/ana. 24217

Coltart, I., Tranah, T. H., and Shawcross, D. L. (2013). Inflammation and hepatic encephalopathy. Arch. Biochem. Biophys. 536, 189-196. doi: 10.1016/j.abb.2013.03.016

Columba-Cabezas, S., Serafini, B., Ambrosini, E., and Aloisi, F. (2003). Lymphoid chemokines CCL19 and CCL21 are expressed in the central nervous system during experimental autoimmune encephalomyelitis: implications for the maintenance of chronic neuroinflammation. Brain Pathol. 13, 38-51. doi: 10.1111/j.1750-3639.2003.tb00005.x

Constantinescu, C. S., Frei, K., Wysocka, M., Trinchieri, G., Malipiero, U., Rostami, A., et al. (1996). Astrocytes and microglia produce interleukin-12 p40. Ann. N.Y. Acad. Sci. 795, 328-333.

Constantinescu, C. S., Tani, M., Ransohoff, R. M., Wysocka, M., Hilliard, B., Fujioka, T., et al. (2005). Astrocytes as antigen-presenting cells: expression of IL-12/IL-23. J. Neurochem. 95, 331-340. doi: 10.1111/j.1471-4159.2005.03368.x

Cooley, I. D., Chauhan, V. S., Donneyz, M. A., and Marriott, I. (2014). Astrocytes produce IL-19 in response to bacterial challenge and are sensitive to the immunosuppressive effects of this IL-10 family member. Glia $62,818-828$. doi: 10.1002/glia.22644

Cossarizza, A., Troiano, L., and Mussini, C. (2002). Mitochondria and HIV infection: the first decade. J. Biol. Regul. Homeost. Agents 16, 18-24.

Cota, M., Kleinschmidt, A., Ceccherini-Silberstein, F., Aloisi, F., Mengozzi, M., Mantovani, A., et al. (2000). Upregulated expression of interleukin-8, RANTES and chemokine receptors in human astrocytic cells infected with HIV-1. J. Neurovirol. 6, 75-83. doi: 10.3109/13550280009006384

Coughlan, C. M., McManus, C. M., Sharron, M., Gao, Z., Murphy, D., Jaffer, S., et al. (2000). Expression of multiple functional chemokine receptors and monocyte chemoattractant protein-1 in human neurons. Neuroscience 97, 591-600. doi: 10.1016/S0306-4522(00)00024-5

Coyle-Rink, J., Sweet, T., Abraham, S., Sawaya, B., Batuman, O., Khalili, K., et al. (2002). Interaction between TGFbeta signaling proteins and C/EBP controls basal and Tat-mediated transcription of HIV-1 LTR in astrocytes. Virology 299, 240-247. doi: 10.1006/viro.2002.1439

Cregg, J. M., DePaul, M. A., Filous, A. R., Lang, B. T., Tran, A., and Silver, J. (2014). Functional regeneration beyond the glial scar. Exp. Neurol. 253, 197-207. doi: 10.1016/j.expneurol.2013.12.024

Croitoru-Lamoury, J., Guillemin, G. J., Boussin, F. D., Mognetti, B., Gigout, L. I., Chéret, A., et al. (2003). Expression of chemokines and their receptors in human and simian astrocytes: evidence for a central role of TNF alpha and IFN gamma in CXCR4 and CCR5 modulation. Glia 41, 354-370. doi: 10.1002/glia.10181

Cupp, C., Taylor, J. P., Khalili, K., and Amini, S. (1993). Evidence for stimulation of the transforming growth factor beta 1 promoter by HIV-1 Tat in cells derived from CNS. Oncogene 8, 2231-2236.

da Cunha, A., Jackson, R. W., and Vitkovic, L. (1995). HIV-1 non-specifically stimulates production of transforming growth factor-beta 1 transfer in primary astrocytes. J. Neuroimmunol. 60, 125-133. da Cunha, A., and Vitkovic, L. (1992). Transforming growth factor-beta 1 (TGFbeta 1) expression and regulation in rat cortical astrocytes. J. Neuroimmunol. $36,157-169$.

da Fonseca, A. C., Matias, D., Garcia, C., Amaral, R., Geraldo, L. H., Freitas, C., et al. (2014). The impact of microglial activation on blood-brain barrier in brain diseases. Front. Cell. Neurosci. 8:362. doi: 10.3389/fncel.2014.00362

de Jong, B. C., Prentiss, D., McFarland, W., Machekano, R., and Israelski, D. M. (2005). Marijuana use and its association with adherence to antiretroviral therapy among HIV-infected persons with moderate to severe nausea. J. Acquir. Immune Defic. Syndr. 38, 43-46. doi: 10.1097/00126334-20050101000008

Desplats, P., Dumaop, W., Cronin, P., Gianella, S., Woods, S., Letendre, S., et al. (2014). Epigenetic alterations in the brain associated with HIV-1 infection and methamphetamine dependence. PLOS ONE 9:e102555. doi: 10.1371/journal.pone.0102555

Devinsky, O., Vezzani, A., Najjar, S., De Lanerolle, N. C., and Rogawski, M. A. (2013). Glia and epilepsy: excitability and inflammation. Trends Neurosci. 36, 174-184. doi: 10.1016/j.tins.2012.11.008

Dhar, A., Gardner, J., Borgmann, K., Wu, L., and Ghorpade, A. (2006). Novel role of TGF-beta in differential astrocyte-TIMP-1 regulation: implications for HIV-1-dementia and neuroinflammation. J. Neurosci. Res. 83, 1271-1280. doi: 10.1002/jnr.20787

Díaz, L., Martínez-Bonet, M., Sánchez, J., Fernández-Pineda, A., Jiménez, J. L., Muñoz, E., et al. (2015). Bryostatin activates HIV-1 latent expression in human astrocytes through a PKC and NF-kB-dependent mechanism. Sci. Rep. 5:12442. doi: $10.1038 /$ srep 12442

Dietrich, J. B. (2009). Alteration of blood-brain barrier function by methamphetamine and cocaine. Cell Tissue Res. 336, 385-392. doi: 10.1007/s00441-009-0777-y

Dobbing, J., and Sands, J. (1973). Quantitative growth and development of human brain. Arch. Dis. Child. 48, 757-767.

Duffy, S., and MacVicar, B. A. (1996). In vitro ischemia promotes calcium influx and intracellular calcium release in hippocampal astrocytes. J. Neurosci. 16, $71-81$.

Dufour, J. H., Dziejman, M., Liu, M. T., Leung, J. H., Lane, T. E., and Luster, A. D. (2002). IFN-gamma-inducible protein 10 (IP-10; CXCL10)-deficient mice reveal a role for IP-10 in effector T cell generation and trafficking. J. Immunol. 168, 3195-3204. doi: 10.4049/jimmunol.168.7.3195

Dujmovic, I., Mangano, K., Pekmezovic, T., Quattrocchi, C., Mesaros, S., Stojsavljevic, N., et al. (2009). The analysis of IL-1 beta and its naturally occurring inhibitors in multiple sclerosis: the elevation of IL-1 receptor antagonist and IL-1 receptor type II after steroid therapy. J. Neuroimmunol. 207, 101-106. doi: 10.1016/j.jneuroim.2008.11.004

Elahy, M., Jackaman, C., Mamo, J. C., Lam, V., Dhaliwal, S. S., Giles, C., et al. (2015). Blood-brain barrier dysfunction developed during normal aging is associated with inflammation and loss of tight junctions but not with leukocyte recruitment. Immun. Ageing 12, 2. doi: 10.1186/s12979-015-0029-9

Elain, G., Jeanneau, K., Rutkowska, A., Mir, A. K., and Dev, K. K. (2014). The selective anti-IL17A monoclonal antibody secukinumab (AIN457) attenuates IL17A-induced levels of IL6 in human astrocytes. Glia 62, 725-735. doi: 10.1002/glia.22637

El-Hage, N., Podhaizer, E. M., Sturgill, J., and Hauser, K. F. (2011). Tolllike receptor expression and activation in astroglia: differential regulation by HIV-1 Tat, gp120, and morphine. Immunol. Invest. 40, 498-522. doi: 10.3109/08820139.2011.561904

Elmore, M. R., Najafi, A. R., Koike, M. A., Dagher, N. N., Spangenberg, E. E., Rice, R. A., et al. (2014). Colony-stimulating factor 1 receptor signaling is necessary for microglia viability, unmasking a microglia progenitor cell in the adult brain. Neuron 82, 380-397. doi: 10.1016/j.neuron.2014.02.040

Endo, F., Komine, O., Fujimori-Tonou, N., Katsuno, M., Jin, S., Watanabe, S., et al. (2015). Astrocyte-derived TGF-betal accelerates disease progression in ALS mice by interfering with the neuroprotective functions of microglia and T cells. Cell Rep. 11, 592-604. doi: 10.1016/j.celrep.2015. 03.053

Erdmann, N., Tian, C., Huang, Y., Zhao, J., Herek, S., Curthoys, N., et al. (2009). In vitro glutaminase regulation and mechanisms of glutamate generation in HIV-1-infected macrophage. J. Neurochem. 109, 551-561. doi: 10.1111/j.14714159.2009.05989.x 
Erdmann, N. B., Whitney, N. P., and Zheng, J. (2006). Potentiation of excitotoxicity in HIV-1 associated dementia and the significance of glutaminase. Clin. Neurosci. Res. 6, 315-328. doi: 10.1016/j.cnr.2006.09.009

Ernst, T., Chang, L., Leonido-Yee, M., and Speck, O. (2000). Evidence for longterm neurotoxicity associated with methamphetamine abuse: a 1H MRS study. Neurology 54, 1344-1349. doi: 10.1212/WNL.54.6.1344

Espey, M. G., Basile, A. S., Heaton, R. K., and Ellis, R. J. (2002). Increased glutamate in CSF and plasma of patients with HIV dementia. Neurology 58, 1439. author reply 1439-1440. doi: 10.1212/wnl.58.9.1439

Espinoza, S., Lignani, G., Caffino, L., Maggi, S., Sukhanov, I., Leo, D., et al. (2015). TAAR1 modulates cortical glutamate NMDA receptor function. Neuropsychopharmacology 40, 2217-2227. doi: 10.1038/npp.2015.65

Eugenin, E. A., and Berman, J. W. (2013). Cytochrome C dysregulation induced by HIV infection of astrocytes results in bystander apoptosis of uninfected astrocytes by an IP3 and calcium-dependent mechanism. J. Neurochem. 127, 644-651. doi: 10.1111/jnc.12443

Eugenin, E. A., Clements, J. E., Zink, M. C., and Berman, J. W. (2011). Human immunodeficiency virus infection of human astrocytes disrupts blood-brain barrier integrity by a gap junction-dependent mechanism. J. Neurosci. 31, 9456-9465. doi: 10.1523/JNEUROSCI.1460-11.2011

Evans, M. C., Couch, Y., Sibson, N., and Turner, M. R. (2013). Inflammation and neurovascular changes in amyotrophic lateral sclerosis. Mol. Cell. Neurosci. 53, 34-41. doi: 10.1016/j.mcn.2012.10.008

Falconer, K., Askarieh, G., Weis, N., Hellstrand, K., Alaeus, A., and Lagging, M. (2010). IP-10 predicts the first phase decline of HCV RNA and overall viral response to therapy in patients co-infected with chronic hepatitis C virus infection and HIV. Scand. J. Infect. Dis. 42, 896-901. doi: 10.3109/00365548.2010.498019

Falsig, J., Latta, M., and Leist, M. (2004). Defined inflammatory states in astrocyte cultures: correlation with susceptibility towards CD95-driven apoptosis. J. Neurochem. 88, 181-193. doi: 10.1111/j.1471-4159.2004.02144.x

Fan, Y., Timani, K. A., and He, J. J. (2015). STAT3 and its phosphorylation are involved in HIV-1 Tat-induced transactivation of glial fibrillary acidic protein. Curr. HIV Res. 13, 55-63. doi: 10.2174/1570162x13666150121115804

Feliú, A., Moreno-Martet, M., Mecha, M., Carrillo-Salinas, F. J., De Lago, E., Fernàndez-Ruiz, J., et al. (2015). A Sativex((R)) -like combination of phytocannabinoids as a disease-modifying therapy in a viral model of multiple sclerosis. Br. J. Pharmacol. 172, 3579-3595. doi: 10.1111/bph.13159

Ferrarese, C., Aliprandi, A., Tremolizzo, L., Stanzani, L., De Micheli, A., Dolara, A., et al. (2001). Increased glutamate in CSF and plasma of patients with HIV dementia. Neurology 57, 671-675. doi: 10.1212/WNL.57.4.671

Ferrucci, A., Nonnemacher, M. R., and Wigdahl, B. (2013). Extracellular HIV-1 viral protein $\mathrm{R}$ affects astrocytic glyceraldehyde 3-phosphate dehydrogenase activity and neuronal survival. J. Neurovirol. 19, 239-253. doi: 10.1007/s13365013-0170-1

Fiebich, B. L., Schleicher, S., Spleiss, O., Czygan, M., and Hüll, M. (2001). Mechanisms of prostaglandin E2-induced interleukin-6 release in astrocytes: possible involvement of EP4-like receptors, p38 mitogen-activated protein kinase and protein kinase C. J. Neurochem. 79, 950-958. doi: 10.1046/j.14714159.2001.00652.x

Fields, J., Cisneros, I. E., Borgmann, K., and Ghorpade, A. (2013). Extracellular regulated kinase $1 / 2$ signaling is a critical regulator of interleukin-1betamediated astrocyte tissue inhibitor of metalloproteinase-1 expression. PLoS ONE 8:e56891. doi: 10.1371/journal.pone.0056891

Fields, J., Gardner-Mercer, J., Borgmann, K., Clark, I., and Ghorpade, A. (2011). CCAAT/enhancer binding protein beta expression is increased in the brain during HIV-1-infection and contributes to regulation of astrocyte tissue inhibitor of metalloproteinase-1. J. Neurochem. 118, 93-104. doi: 10.1111/j.1471-4159.2011.07203.x

Fields, J., and Ghorpade, A. (2012). C/EBPbeta regulates multiple IL-1betainduced human astrocyte inflammatory genes. J. Neuroinflammation 9:177. doi: 10.1186/1742-2094-9-177

Fine, S. M., Angel, R. A., Perry, S. W., Epstein, L. G., Rothstein, J. D., Dewhurst, S., et al. (1996). Tumor necrosis factor alpha inhibits glutamate uptake by primary human astrocytes. Implications for pathogenesis of HIV-1 dementia. J. Biol. Chem. 271, 15303-15306.

Fitting, S., Scoggins, K. L., Xu, R., Dever, S. M., Knapp, P. E., Dewey, W. L., et al. (2012). Morphine efficacy is altered in conditional HIV-1 Tat transgenic mice. Eur. J. Pharmacol. 689, 96-103. doi: 10.1016/j.ejphar.2012. 05.029

Fitting, S., Zou, S., El-Hage, N., Suzuki, M., Paris, J. J., Schier, C. J., et al. (2014). Opiate addiction therapies and HIV-1 Tat: interactive effects on glial $[\mathrm{Ca}(2)(+)] \mathrm{i}$, oxyradical and neuroinflammatory chemokine production and correlative neurotoxicity. Curr. HIV Res. 12, 424-434. doi: 10.2174/1570162X1206150311161147

Flora, G., Lee, Y. W., Nath, A., Hennig, B., Maragos, W., and Toborek, M. (2003). Methamphetamine potentiates HIV-1 Tat protein-mediated activation of redox-sensitive pathways in discrete regions of the brain. Exp. Neurol. 179, 60-70. doi: 10.1006/exnr.2002.8048

Flora, G., Pu, H., Hennig, B., and Toborek, M. (2006). Cyclooxygenase-2 is involved in HIV-1 Tat-induced inflammatory responses in the brain. Neuromolecular Med. 8, 337-352. doi: 10.1385/NMM:8:3:337

Flynn, G., Maru, S., Loughlin, J., Romero, I. A., and Male, D. (2003). Regulation of chemokine receptor expression in human microglia and astrocytes. J. Neuroimmunol. 136, 84-93. doi: 10.1016/S0165-5728(03)00009-2

Frampton, M., Harvey, R. J., and Kirchner, V. (2003). Propentofylline for dementia. Cochrane Database Syst. Rev. CD002853. doi: 10.1002/14651858.CD002853

French, M. A., Cozzi-Lepri, A., Arduino, R. C., Johnson, M., Achhra, A. C., Landay, A., et al. (2015). Plasma levels of cytokines and chemokines and the risk of mortality in HIV-infected individuals: a case-control analysis nested in a large clinical trial. AIDS 29, 847-851. doi: 10.1097/QAD.0000000000000618

Friend, D. M., and Keefe, K. A. (2013). Glial reactivity in resistance to methamphetamine-induced neurotoxicity. J. Neurochem. 125, 566-574. doi: 10.1111/jnc. 12201

Gardner, J., Borgmann, K., Deshpande, M. S., Dhar, A., Wu, L., Persidsky, R., et al. (2006). Potential mechanisms for astrocyte-TIMP-1 downregulation in chronic inflammatory diseases. J. Neurosci. Res. 83, 1281-1292. doi: 10.1002/jnr. 20823

Gardner, J., and Ghorpade, A. (2003). Tissue inhibitor of metalloproteinase (TIMP)-1: the TIMPed balance of matrix metalloproteinases in the central nervous system. J. Neurosci. Res. 74, 801-806. doi: 10.1002/jnr.10835

Garlind, A., Brauner, A., Höjeberg, B., Basun, H., and Schultzberg, M. (1999). Soluble interleukin-1 receptor type II levels are elevated in cerebrospinal fluid in Alzheimer's disease patients. Brain Res. 826, 112-116.

Gavrilin, M. A., Mathes, L. E., and Podell, M. (2002). Methamphetamine enhances cell-associated feline immunodeficiency virus replication in astrocytes. J. Neurovirol. 8, 240-249. doi: 10.1080/13550280290049660

Gelman, B. B. (2015). Neuropathology of HAND with suppressive antiretroviral therapy: encephalitis and neurodegeneration reconsidered. Curr. HIV/AIDS Rep. 12, 272-279. doi: 10.1007/s11904-015-0266-8

Gendelman, H. E. (2005). The Neurology of AIDS. Oxford; New York, NY: Oxford University Press.

Genis, P., Jett, M., Bernton, E. W., Boyle, T., Gelbard, H. A., Dzenko, K., et al. (1992). Cytokines and arachidonic metabolites produced during human immunodeficiency virus (HIV)-infected macrophage-astroglia interactions: implications for the neuropathogenesis of HIV disease. J. Exp. Med. 176, 1703-1718.

Ghorpade, A., Holter, S., Borgmann, K., Persidsky, R., and Wu, L. (2003). HIV1 and IL-1beta regulate Fas ligand expression in human astrocytes through the NF-kappaB pathway. J. Neuroimmunol. 141, 141-149. doi: 10.1016/S01655728(03)00222-4

Giaume, C., Tabernero, A., and Medina, J. M. (1997). Metabolic trafficking through astrocytic gap junctions. Glia 21, 114-123.

Gil, L., Martínez, G., González, I., Tarinas, A., Alvarez, A., Giuliani, A., et al. (2003). Contribution to characterization of oxidative stress in HIV/AIDS patients. Pharmacol. Res. 47, 217-224. doi: 10.1016/S1043-6618(02)00320-1

Gill, A. J., Kovacsics, C. E., Cross, S. A., Vance, P. J., Kolson, L. L., Jordan-Sciutto, K. L., et al. (2014). Heme oxygenase-1 deficiency accompanies neuropathogenesis of HIV-associated neurocognitive disorders. J. Clin. Invest. 124, 4459-4472. doi: 10.1172/JCI72279

Gonçalves, J., Baptista, S., Martins, T., Milhazes, N., Borges, F., Ribeiro, C. F. et al. (2010). Methamphetamine-induced neuroinflammation and neuronal dysfunction in the mice hippocampus: preventive effect of indomethacin. Eur. J. Neurosci. 31, 315-326. doi: 10.1111/j.1460-9568.2009.07059.x

Gonçalves, J., Martins, T., Ferreira, R., Milhazes, N., Borges, F., Ribeiro, C. F. et al. (2008). Methamphetamine-induced early increase of IL- 6 and TNF-alpha 
mRNA expression in the mouse brain. Ann. N.Y. Acad. Sci. 1139, 103-111. doi: 10.1196/annals.1432.043

Gorantla, S., Liu, J., Sneller, H., Dou, H., Holguin, A., Smith, L., et al. (2007). Copolymer-1 induces adaptive immune anti-inflammatory glial and neuroprotective responses in a murine model of HIV-1 encephalitis. J. Immunol. 179, 4345-4356. doi: 10.4049/jimmunol.179.7.4345

Gorantla, S., Liu, J., Wang, T., Holguin, A., Sneller, H. M., Dou, H., et al. (2008). Modulation of innate immunity by copolymer-1 leads to neuroprotection in murine HIV-1 encephalitis. Glia 56, 223-232. doi: 10.1002/glia.20607

Gorry, P. R., Ong, C., Thorpe, J., Bannwarth, S., Thompson, K. A., Gatignol, A., et al. (2003). Astrocyte infection by HIV-1: mechanisms of restricted virus replication, and role in the pathogenesis of HIV-1-associated dementia. Curr. HIV Res. 1, 463-473. doi: 10.2174/1570162033485122

Granado, N., Lastres-Becker, I., Ares-Santos, S., Oliva, I., Martin, E., Cuadrado, A., et al. (2011). Nrf2 deficiency potentiates methamphetamine-induced dopaminergic axonal damage and gliosis in the striatum. Glia 59, 1850-1863. doi: 10.1002/glia.21229

Gray, L. R., Turville, S. G., Hitchen, T. L., Cheng, W. J., Ellett, A. M., Salimi, H., et al. (2014). HIV-1 entry and trans-infection of astrocytes involves CD81 vesicles. PLoS ONE 9:e90620. doi: 10.1371/journal.pone.0090620

Griffin, B. D., and Moynagh, P. N. (2006). Persistent interleukin-1beta signaling causes long term activation of NFkappaB in a promoter-specific manner in human glial cells. J. Biol. Chem. 281, 10316-10326. doi: 10.1074/jbc.M509973200

Guillot, T. S., Shepherd, K. R., Richardson, J. R., Wang, M. Z., Li, Y., Emson, P. C., et al. (2008). Reduced vesicular storage of dopamine exacerbates methamphetamine-induced neurodegeneration and astrogliosis. J. Neurochem. 106, 2205-2217. doi: 10.1111/j.1471-4159.2008.05568.x

Gupta, S., Bousman, C. A., Chana, G., Cherner, M., Heaton, R. K., Deutsch, R., et al. (2011). Dopamine receptor D3 genetic polymorphism (rs6280TC) is associated with rates of cognitive impairment in methamphetamine-dependent men with HIV: preliminary findings. J. Neurovirol. 17, 239-247. doi: 10.1007/s13365-0110028-3

Häberle, J., Boddaert, N., Burlina, A., Chakrapani, A., Dixon, M., Huemer, M., et al. (2012). Suggested guidelines for the diagnosis and management of urea cycle disorders. Orphanet J. Rare Dis. 7:32. doi: 10.1186/1750-1172-7-32

Hamm, S., Dehouck, B., Kraus, J., Wolburg-Buchholz, K., Wolburg, H., Risau, W., et al. (2004). Astrocyte mediated modulation of blood-brain barrier permeability does not correlate with a loss of tight junction proteins from the cellular contacts. Cell Tissue Res. 315, 157-166. doi: 10.1007/s00441-0030825-y

Han, J., Kesner, P., Metna-Laurent, M., Duan, T., Xu, L., Georges, F., et al. (2012). Acute cannabinoids impair working memory through astroglial CB1 receptor modulation of hippocampal LTD. Cell 148, 1039-1050. doi: 10.1016/j.cell.2012.01.037

Harouse, J. M., Kunsch, C., Hartle, H. T., Laughlin, M. A., Hoxie, J. A., Wigdahl, B., et al. (1989). CD4-independent infection of human neural cells by human immunodeficiency virus type 1. J. Virol. 63, 2527-2533.

Harris, G. E., Dupuis, L., Mugford, G. J., Johnston, L., Haase, D., Page, G., et al. (2014). Patterns and correlates of cannabis use among individuals with HIV/AIDS in Maritime Canada. Can. J. Infect. Dis. Med. Microbiol. 25, e1-e7.

Hashioka, S., Klegeris, A., and McGeer, P. L. (2012). Inhibition of human astrocyte and microglia neurotoxicity by calcium channel blockers. Neuropharmacology 63, 685-691. doi: 10.1016/j.neuropharm.2012.05.033

Haughey, N. J., Nath, A., Mattson, M. P., Slevin, J. T., and Geiger, J. D. (2001). HIV-1 Tat through phosphorylation of NMDA receptors potentiates glutamate excitotoxicity. J. Neurochem. 78, 457-467. doi: 10.1046/j.14714159.2001.00396.x

Hauwel, M., Furon, E., Canova, C., Griffiths, M., Neal, J., and Gasque, P. (2005). Innate (inherent) control of brain infection, brain inflammation and brain repair: the role of microglia, astrocytes, "protective" glial stem cells and stromal ependymal cells. Brain Res. Brain Res. Rev. 48, 220-233. doi: 10.1016/j.brainresrev.2004.12.012

Haydon, P. G. (2001). GLIA: listening and talking to the synapse. Nat. Rev. Neurosci. 2, 185-193. doi: 10.1038/35058528

Hebert, M. A., and O'Callaghan, J. P. (2000). Protein phosphorylation cascades associated with methamphetamine-induced glial activation. Ann. N.Y. Acad. Sci. 914, 238-262. doi: 10.1111/j.1749-6632.2000.tb05200.x
Hennessy, E., Griffin, É. W., and Cunningham, C. (2015). Astrocytes are primed by chronic neurodegeneration to produce exaggerated chemokine and cell infiltration responses to acute stimulation with the cytokines IL-1beta and TNF-alpha. J. Neurosci. 35, 8411-8422. doi: 10.1523/JNEUROSCI.274514.2015

Hermann, D. M., Peruzzotti-Jametti, L., Schlechter, J., Bernstock, J. D., Doeppner, T. R., and Pluchino, S. (2014). Neural precursor cells in the ischemic brain integration, cellular crosstalk, and consequences for stroke recovery. Front. Cell. Neurosci. 8:291. doi: 10.3389/fncel.2014.00291

Hind, W. H., Tufarelli, C., Neophytou, M., Anderson, S. I., England, T. J., and O'Sullivan, S. E. (2015). Endocannabinoids modulate human bloodbrain barrier permeability in vitro. Br. J. Pharmacol. 172, 3015-3027. doi: 10.1111/bph.13106

Hirata, H., Ladenheim, B., Rothman, R. B., Epstein, C., and Cadet, J. L. (1995). Methamphetamine-induced serotonin neurotoxicity is mediated by superoxide radicals. Brain Res. 677, 345-347.

Hoefer, M. M., Sanchez, A. B., Maung, R., de Rozieres, C. M., Catalan, I. C., Dowling, C. C., et al. (2015). Combination of methamphetamine and HIV1 gp120 causes distinct long-term alterations of behavior, gene expression, and injury in the central nervous system. Exp. Neurol. 263, 221-234. doi: 10.1016/j.expneurol.2014.09.010

Hori, K., Burd, P. R., Kutza, J., Weih, K. A., and Clouse, K. A. (1999). Human astrocytes inhibit HIV-1 expression in monocyte-derived macrophages by secreted factors. AIDS 13, 751-758.

Hozumi, H., Asanuma, M., Miyazaki, I., Fukuoka, S., Kikkawa, Y., Kimoto, N., et al. (2008). Protective effects of interferon-gamma against methamphetamine-induced neurotoxicity. Toxicol. Lett. 177, 123-129. doi: 10.1016/j.toxlet.2008.01.005

Hu, J., Akama, K. T., Krafft, G. A., Chromy, B. A., and Van Eldik, L. J. (1998). Amyloid-beta peptide activates cultured astrocytes: morphological alterations, cytokine induction and nitric oxide release. Brain Res. 785, 195-206.

Hu, S., Sheng, W. S., and Rock, R. B. (2013). CB2 receptor agonists protect human dopaminergic neurons against damage from HIV-1 gp120. PLoS ONE 8:e77577. doi: 10.1371/journal.pone.0077577

Huang, S.-P. (2005). Association and Mechanism Between Cyclooxygenase-2 and Interleukin-6 in Gastric Cancer. U.S. National Institutes of Health. Available online at: https://clinicaltrials.gov/ (September 12, 2005)

Huang, Y., Zhao, L., Jia, B., Wu, L., Li, Y., Curthoys, N., et al. (2011). Glutaminase dysregulation in HIV-1-infected human microglia mediates neurotoxicity: relevant to HIV-1-associated neurocognitive disorders. J. Neurosci. 31, 15195-15204. doi: 10.1523/JNEUROSCI.2051-11.2011

Hult, B., Chana, G., Masliah, E., and Everall, I. (2008). Neurobiology of HIV. Int. Rev. Psychiatry 20, 3-13. doi: 10.1080/09540260701862086

Hwang, J., Zheng, L. T., Ock, J., Lee, M. G., Kim, S. H., Lee, H. W., et al. (2008). Inhibition of glial inflammatory activation and neurotoxicity by tricyclic antidepressants. Neuropharmacology 55, 826-834. doi: 10.1016/j.neuropharm.2008.06.045

Igelhorst, B. A., Niederkinkhaus, V., Karus, C., Lange, M. D., and Dietzel, I. D. (2015). Regulation of neuronal excitability by release of proteins from glial cells. Philos. Trans. R. Soc. Lond. B Biol. Sci. 370:20140194. doi: 10.1098/rstb.2014.0194

In, S. W., Son, E. W., Rhee, D. K., and Pyo, S. (2005). Methamphetamine administration produces immunomodulation in mice. J. Toxicol. Environ. Health A 68, 2133-2145. doi: 10.1080/15287390500177156

Indo, H. P., Yen, H. C., Nakanishi, I., Matsumoto, K., Tamura, M., Nagano, Y., et al. (2015). A mitochondrial superoxide theory for oxidative stress diseases and aging. J. Clin. Biochem. Nutr. 56, 1-7. doi: 10.3164/jcbn.14-42

Itzhak, Y., and Ali, S. F. (1996). The neuronal nitric oxide synthase inhibitor, 7-nitroindazole, protects against methamphetamine-induced neurotoxicity in vivo. J. Neurochem. 67, 1770-1773.

Itzhak, Y., Martin, J. L., and Ail, S. F. (2000). nNOS inhibitors attenuate methamphetamine-induced dopaminergic neurotoxicity but not hyperthermia in mice. Neuroreport 11, 2943-2946. doi: 10.1097/00001756-200009110-00022

Iudicello, J. E., Morgan, E. E., Gongvatana, A., Letendre, S. L., Grant, I., Woods, S. P., et al. (2014). Detrimental impact of remote methamphetamine dependence on neurocognitive and everyday functioning in older but not younger HIV+ adults: evidence for a legacy effect? J. Neurovirol. 20, 85-98. doi: 10.1007/s13365-014-0233-y 
Ivey, N. S., MacLean, A. G., and Lackner, A. A. (2009). Acquired immunodeficiency syndrome and the blood-brain barrier. J. Neurovirol. 15, 111-122. doi: $10.1080 / 13550280902769764$

Jacobs, V. L., and De Leo, J. A. (2013). Increased glutamate uptake in astrocytes via propentofylline results in increased tumor cell apoptosis using the CNS-1 glioma model. J. Neurooncol. 114, 33-42. doi: 10.1007/s11060-013-1158-7

Jacobs, V. L., Landry, R. P., Liu, Y., Romero-Sandoval, E. A., and De Leo, J. A. (2012). Propentofylline decreases tumor growth in a rodent model of glioblastoma multiforme by a direct mechanism on microglia. Neuro Oncol. 14, 119-131. doi: 10.1093/neuonc/nor194

Jaiswal, M. K., Zech, W. D., Goos, M., Leutbecher, C., Ferri, A., Zippelius, A., et al. (2009). Impairment of mitochondrial calcium handling in a mtSOD1 cell culture model of motoneuron disease. BMC Neurosci. 10:64. doi: 10.1186/14712202-10-64

Jean, Y. Y., Lercher, L. D., and Dreyfus, C. F. (2008). Glutamate elicits release of BDNF from basal forebrain astrocytes in a process dependent on metabotropic receptors and the PLC pathway. Neuron Glia Biol. 4, 35-42. doi: 10.1017/S1740925X09000052

Jha, M. K., and Suk, K. (2014). Management of glia-mediated neuroinflammation and related patents. Recent Pat. Inflamm. Allergy Drug Discov. 8, 118-124.

Jing, T., Wu, L., Borgmann, K., Surendran, S., Ghorpade, A., Liu, J., et al. (2010). Soluble factors from IL-1beta-stimulated astrocytes activate NR1a/NR2B receptors: implications for HIV-1-induced neurodegeneration. Biochem. Biophys. Res. Commun. 402, 241-246. doi: 10.1016/j.bbrc.2010.10.006

John, G. R., Lee, S. C., and Brosnan, C. F. (2003). Cytokines: powerful regulators of glial cell activation. Neuroscientist 9, 10-22. doi: 10.1177/1073858402239587

Jou, M. J. (2008). Pathophysiological and pharmacological implications of mitochondria-targeted reactive oxygen species generation in astrocytes. Adv. Drug Deliv. Rev. 60, 1512-1526. doi: 10.1016/j.addr.2008.06.004

Jung, H. W., Chung, Y. S., Kim, Y. S., and Park, Y. K. (2007). Celastrol inhibits production of nitric oxide and proinflammatory cytokines through MAPK signal transduction and NF-kappaB in LPS-stimulated BV-2 microglial cells. Exp. Mol. Med. 39, 715-721. doi: 10.1038/emm.2007.78

Kamat, P. K., Swarnkar, S., Rai, S., Kumar, V., and Tyagi, N. (2014). Astrocyte mediated MMP-9 activation in the synapse dysfunction: an implication in Alzheimer disease. Ther. Targets Neurol. Dis. 1:e243. doi: 10.14800/ttnd.243

Kandel, E. R., Schwartz, J. H., and Jessell, T. M. (2000). Principles of Neural Science. New York, NY: McGraw-Hill, Health Professions Division.

Kang, D. C., Su, Z. Z., Sarkar, D., Emdad, L., Volsky, D. J., and Fisher, P. B. (2005). Cloning and characterization of HIV-1-inducible astrocyte elevated gene-1, AEG-1. Gene 353, 8-15. doi: 10.1016/j.gene.2005.04.006

Kaul, M., and Lipton, S. A. (1999). Chemokines and activated macrophages in HIV gp120-induced neuronal apoptosis. Proc. Natl. Acad. Sci. U.S.A. 96, 8212-8216.

Kaushal, N., and Matsumoto, R. R. (2011). Role of sigma receptors in methamphetamine-induced neurotoxicity. Curr. Neuropharmacol. 9, 54-57. doi: 10.2174/157015911795016930

Kaushal, N., Robson, M. J., Rosen, A., McCurdy, C. R., and Matsumoto, R. R. (2014). Neuroprotective targets through which 6-acetyl-3-(4-(4-(4fluorophenyl)piperazin-1-yl)butyl)benzo[d] oxazol-2(3H)-one (SN79), a sigma receptor ligand, mitigates the effects of methamphetamine in vitro. Eur. J. Pharmacol. 724, 193-203. doi: 10.1016/j.ejphar.2013.12.039

Kaushal, N., Seminerio, M. J., Robson, M. J., McCurdy, C. R., and Matsumoto, R. R. (2013). Pharmacological evaluation of SN79, a sigma (sigma) receptor ligand, against methamphetamine-induced neurotoxicity in vivo. Eur. Neuropsychopharmacol. 23, 960-971. doi: 10.1016/j.euroneuro.2012. 08.005

Kaushal, N., Seminerio, M. J., Shaikh, J., Medina, M. A., Mesangeau, C., Wilson, L. L., et al. (2011). CM156, a high affinity sigma ligand, attenuates the stimulant and neurotoxic effects of methamphetamine in mice. Neuropharmacology 61, 992-1000. doi: 10.1016/j.neuropharm.2011.06.028

Kielian, T. (2004). Immunopathogenesis of brain abscess. J. Neuroinflammation 1, 16. doi: 10.1186/1742-2094-1-16

Kim, M. O., Suh, H. S., Brosnan, C. F., and Lee, S. C. (2004). Regulation of RANTES/CCL5 expression in human astrocytes by interleukin-1 and interferon-beta. J. Neurochem. 90, 297-308. doi: 10.1111/j.1471-4159.2004.02487.x

Kita, T., Miyazaki, I., Asanuma, M., Takeshima, M., and Wagner, G. C. (2009). Dopamine-induced behavioral changes and oxidative stress in methamphetamine-induced neurotoxicity. Int. Rev. Neurobiol. 88, 43-64. doi: 10.1016/S0074-7742(09)88003-3

Kita, T., Wagner, G. C., and Nakashima, T. (2003). Current research on methamphetamine-induced neurotoxicity: animal models of monoamine disruption. J. Pharmacol. Sci. 92, 178-195. doi: 10.1254/jphs.92.178

Kitanaka, J., Kitanaka, N., Hall, F. S., Uhl, G. R., Tanaka, K., Nishiyama, N., et al. (2012). Straub tail reaction in mice treated with sigma(1) receptor antagonist in combination with methamphetamine. Brain Res. 1482, 40-46. doi: 10.1016/j.brainres.2012.09.001

Kitanaka, J., Kitanaka, N., Tatsuta, T., Hall, F. S., Uhl, G. R., Tanaka, K., et al. (2009). Sigmal receptor antagonists determine the behavioral pattern of the methamphetamine-induced stereotypy in mice. Psychopharmacology (Berl.) 203, 781-792. doi: 10.1007/s00213-008-1425-Z

Kostic, M., Zivkovic, N., and Stojanovic, I. (2013). Multiple sclerosis and glutamate excitotoxicity. Rev. Neurosci. 24, 71-88. doi: 10.1515/revneuro-2012-0062

Kou, W., Banerjee, S., Eudy, J., Smith, L. M., Persidsky, R., Borgmann, K., et al. (2009). CD38 regulation in activated astrocytes: implications for neuroinflammation and HIV-1 brain infection. J. Neurosci. Res. 87, 2326-2339. doi: 10.1002/jnr.22060

Krasnova, I. N., and Cadet, J. L. (2009). Methamphetamine toxicity and messengers of death. Brain Res. Rev. 60, 379-407. doi: 10.1016/j.brainresrev.2009.03.002

Kutsch, O., Oh, J., Nath, A., and Benveniste, E. N. (2000). Induction of the chemokines interleukin- 8 and IP-10 by human immunodeficiency virus type 1 tat in astrocytes. J. Virol. 74, 9214-9221. doi: 10.1128/JVI.74.19.9214-9221.2000

Ladeby, R., Wirenfeldt, M., Garcia-Ovejero, D., Fenger, C., Dissing-Olesen, L., Dalmau, I., et al. (2005). Microglial cell population dynamics in the injured adult central nervous system. Brain Res. Brain Res. Rev. 48, 196-206. doi: 10.1016/j.brainresrev.2004.12.009

Lane, H. Y., Lin, C. H., Green, M. F., Hellemann, G., Huang, C. C., Chen, P. W., et al. (2013). Add-on treatment of benzoate for schizophrenia: a randomized, double-blind, placebo-controlled trial of $\mathrm{D}$-amino acid oxidase inhibitor. JAMA Psychiatry 70, 1267-1275. doi: 10.1001/jamapsychiatry.2013.2159

Langford, D., Grigorian, A., Hurford, R., Adame, A., Crews, L., and Masliah, E. (2004). The role of mitochondrial alterations in the combined toxic effects of human immunodeficiency virus Tat protein and methamphetamine on calbindin positive-neurons. J. Neurovirol. 10, 327-337. doi: 10.1080/13550280490520961

Langford, D., and Masliah, E. (2001). Crosstalk between components of the blood brain barrier and cells of the CNS in microglial activation in AIDS. Brain Pathol. 11, 306-312. doi: 10.1111/j.1750-3639.2001.tb00401.x

Lau, J. W., Senok, S., and Stadlin, A. (2000). Methamphetamine-induced oxidative stress in cultured mouse astrocytes. Ann. N.Y. Acad. Sci. 914, 146-156. doi: 10.1111/j.1749-6632.2000.tb05192.x

LaVoie, M. J., and Hastings, T. G. (1999). Dopamine quinone formation and protein modification associated with the striatal neurotoxicity of methamphetamine: evidence against a role for extracellular dopamine. J. Neurosci. 19, 1484-1491.

Lawson, L. J., Perry, V. H., and Gordon, S. (1992). Turnover of resident microglia in the normal adult mouse brain. Neuroscience 48, 405-415.

Lee, E. J., and Kim, H. S. (2014). The anti-inflammatory role of tissue inhibitor of metalloproteinase-2 in lipopolysaccharide-stimulated microglia. J. Neuroinflammation 11:116. doi: 10.1186/1742-2094-11-116

Lee, S. C., Liu, W., Dickson, D. W., Brosnan, C. F., and Berman, J. W. (1993). Cytokine production by human fetal microglia and astrocytes. Differential induction by lipopolysaccharide and IL-1 beta. J. Immunol. 150, 2659-2667.

Lewis, W. (2003). Mitochondrial dysfunction and nucleoside reverse transcriptase inhibitor therapy: experimental clarifications and persistent clinical questions. Antiviral Res. 58, 189-197. doi: 10.1016/S0166-3542(03)00069-X

Li, G. H., Anderson, C., Jaeger, L., Do, T., Major, E. O., and Nath, A. (2015). Cellto-cell contact facilitates HIV transmission from lymphocytes to astrocytes via CXCR4. AIDS 29, 755-766. doi: 10.1097/QAD.0000000000000605

Li, T., Giaume, C., and Xiao, L. (2014). Connexins-mediated glia networking impacts myelination and remyelination in the central nervous system. Mol. Neurobiol. 49, 1460-1471. doi: 10.1007/s12035-013-8625-1

Li, W., Henderson, L. J., Major, E. O., and Al-Harthi, L. (2011). IFN-gamma mediates enhancement of HIV replication in astrocytes by inducing an antagonist of the beta-catenin pathway (DKK1) in a STAT 3-dependent manner. J. Immunol. 186, 6771-6778. doi: 10.4049/jimmunol.1100099 
Liang, H., Wang, X., Chen, H., Song, L., Ye, L., Wang, S. H., et al. (2008). Methamphetamine enhances HIV infection of macrophages. Am. J. Pathol. 172, 1617-1624. doi: 10.2353/ajpath.2008.070971

Lindemann, L., Meyer, C. A., Jeanneau, K., Bradaia, A., Ozmen, L., Bluethmann, H., et al. (2008). Trace amine-associated receptor 1 modulates dopaminergic activity. J. Pharmacol. Exp. Ther. 324, 948-956. doi: 10.1124/jpet.107.132647

Linder, M., and Gagel, C. (1968). [Virus infection and blood coagulation]. Thromb. Diath. Haemorrh. 20, 603-604.

Liu, W., Shafit-Zagardo, B., Aquino, D. A., Zhao, M. L., Dickson, D. W., Brosnan, C. F., et al. (1994). Cytoskeletal alterations in human fetal astrocytes induced by interleukin-1 beta. J. Neurochem. 63, 1625-1634.

Liu, X., Shah, A., Gangwani, M. R., Silverstein, P. S., Fu, M., and Kumar, A. (2014a). HIV-1 Nef induces CCL5 production in astrocytes through p38-MAPK and PI3K/Akt pathway and utilizes NF-kB, CEBP and AP-1 transcription factors. Sci. Rep. 4:4450. doi: 10.1038/srep04450

Liu, Y., Liu, H., Kim, B. O., Gattone, V. H., Li, J., Nath, A., et al. (2004). CD4independent infection of astrocytes by human immunodeficiency virus type 1: requirement for the human mannose receptor. J. Virol. 78, 4120-4133. doi: 10.1128/JVI.78.8.4120-4133.2004

Liu, Z., Shi, Z., Liu, J., and Wang, Y. (2014b). HIV transactivator of transcription enhances methamphetamine-induced Parkinson's-like behavior in the rats. Neuroreport. doi: 10.1097/WNR.0000000000000199. [Epub ahead of print].

Liu, Z., Zhao, F., and He, J. J. (2014c). Hepatitis C virus (HCV) interaction with astrocytes: nonproductive infection and induction of IL-18. J. Neurovirol. 20, 278-293. doi: 10.1007/s13365-014-0245-7

Loewinger, G. C., Beckert, M. V., Tejeda, H. A., and Cheer, J. F. (2012). Methamphetamine-induced dopamine terminal deficits in the nucleus accumbens are exacerbated by reward-associated cues and attenuated by CB1 receptor antagonism. Neuropharmacology 62, 2192-2201. doi: 10.1016/j.neuropharm.2012.01.013

Louboutin, J. P., and Strayer, D. S. (2012). Blood-brain barrier abnormalities caused by HIV-1 gp120: mechanistic and therapeutic implications. ScientificWorldJournal 2012:482575. doi: 10.1100/2012/482575

Lu, W., Maheshwari, A., Misiuta, I., Fox, S. E., Chen, N., Zigova, T., et al. (2005). Neutrophil-specific chemokines are produced by astrocytic cells but not by neuronal cells. Brain Res. Dev. Brain Res. 155, 127-134. doi: 10.1016/j.devbrainres.2005.01.004

Ludwig, A., Schulte, A., Schnack, C., Hundhausen, C., Reiss, K., Brodway, N., et al. (2005). Enhanced expression and shedding of the transmembrane chemokine CXCL16 by reactive astrocytes and glioma cells. J. Neurochem. 93, 1293-1303. doi: 10.1111/j.1471-4159.2005.03123.X

Luo, X., and He, J. J. (2015). Cell-cell contact viral transfer contributes to HIV infection and persistence in astrocytes. J. Neurovirol. 21, 66-80. doi: 10.1007/s13365-014-0304-0

Ma, R., Yang, L., Niu, F., and Buch, S. (2014). HIV Tat-mediated induction of human brain microvascular endothelial cell apoptosis involves endoplasmic reticulum stress and mitochondrial dysfunction. Mol. Neurobiol. doi: 10.1007/s12035-014-8991-3. [Epub ahead of print].

Maciaszek, J. W., Parada, N. A., Cruikshank, W. W., Center, D. M., Kornfeld, H., and Viglianti, G. A. (1997). IL-16 represses HIV-1 promoter activity. J. Immunol. 158, 5-8.

Mahajan, S. D., Aalinkeel, R., Sykes, D. E., Reynolds, J. L., Bindukumar, B., Adal, A., et al. (2008). Methamphetamine alters blood brain barrier permeability via the modulation of tight junction expression: implication for HIV-1 neuropathogenesis in the context of drug abuse. Brain Res. 1203, 133-148. doi: 10.1016/j.brainres.2008.01.093

Mamik, M. K., and Ghorpade, A. (2012). Src homology-2 domain-containing protein tyrosine phosphatase (SHP) 2 and p38 regulate the expression of chemokine CXCL8 in human astrocytes. PLoS ONE 7:e45596. doi: 10.1371/journal.pone.0045596

Mamik, M. K., and Ghorpade, A. (2014). Chemokine CXCL8 promotes HIV-1 replication in human monocyte-derived macrophages and primary microglia via nuclear factor-kappaB pathway. PLoS ONE 9:e92145. doi: 10.1371/journal.pone.0092145

Mamik, M. K., Banerjee, S., Walseth, T. F., Hirte, R., Tang, L., Borgmann, K., et al. (2011). HIV-1 and IL-1beta regulate astrocytic CD38 through mitogenactivated protein kinases and nuclear factor-kappaB signaling mechanisms. J. Neuroinflammation 8:145. doi: 10.1186/1742-2094-8-145
Manev, H., Favaron, M., Guidotti, A., and Costa, E. (1989). Delayed increase of Ca2+ influx elicited by glutamate: role in neuronal death. Mol. Pharmacol. 36, 106-112.

Mantri, C. K., Mantri, J. V., Pandhare, J., and Dash, C. (2014). Methamphetamine inhibits HIV-1 replication in CD4+ T cells by modulating anti-HIV-1 miRNA expression. Am. J. Pathol. 184, 92-100. doi: 10.1016/j.ajpath.2013.09.011

Maragos, W. F., Jakel, R., Chesnut, D., Pocernich, C. B., Butterfield, D. A., St Clair, D., et al. (2000). Methamphetamine toxicity is attenuated in mice that overexpress human manganese superoxide dismutase. Brain Res. 878, 218-222. doi: 10.1016/S0006-8993(00)02707-4

Mark, K. A., Quinton, M. S., Russek, S. J., and Yamamoto, B. K. (2007). Dynamic changes in vesicular glutamate transporter 1 function and expression related to methamphetamine-induced glutamate release. J. Neurosci. 27, 6823-6831. doi: 10.1523/JNEUROSCI.0013-07.2007

Martins, T., Burgoyne, T., Kenny, B. A., Hudson, N., Futter, C. E., Ambrósio, A. F., et al. (2013). Methamphetamine-induced nitric oxide promotes vesicular transport in blood-brain barrier endothelial cells. Neuropharmacology 65, 74-82. doi: 10.1016/j.neuropharm.2012.08.021

Matinella, A., Lanzafame, M., Bonometti, M. A., Gajofatto, A., Concia, E., Vento, S., et al. (2015). Neurological complications of HIV infection in preHAART and HAART era: a retrospective study. J. Neurol. 262, 1317-1327. doi: 10.1007/s00415-015-7713-8

Matsumoto, R. R., Shaikh, J., Wilson, L. L., Vedam, S., and Coop, A. (2008). Attenuation of methamphetamine-induced effects through the antagonism of sigma (sigma) receptors: evidence from in vivo and in vitro studies. Eur. Neuropsychopharmacol. 18, 871-881. doi: 10.1016/j.euroneuro.2008.07.006

Mayo, L., Trauger, S. A., Blain, M., Nadeau, M., Patel, B., Alvarez, J. I., et al. (2014). Regulation of astrocyte activation by glycolipids drives chronic CNS inflammation. Nat. Med. 20, 1147-1156. doi: 10.1038/nm.3681

McArthur, J. C., Brew, B. J., and Nath, A. (2005). Neurological complications of HIV infection. Lancet Neurol. 4, 543-555. doi: 10.1016/S1474-4422(05)70165-4

McClure, J., Lovelace, E. S., Elahi, S., Maurice, N. J., Wagoner, J., Dragavon, J., et al. (2012). Silibinin inhibits HIV-1 infection by reducing cellular activation and proliferation. PLoS ONE 7:e41832. doi: 10.1371/journal.pone.0041832

Mehla, R., Bivalkar-Mehla, S., Nagarkatti, M., and Chauhan, A. (2012). Programming of neurotoxic cofactor CXCL-10 in HIV-1-associated dementia: abrogation of CXCL-10-induced neuro-glial toxicity in vitro by $\mathrm{PKC}$ activator. J. Neuroinflammation 9:239. doi: 10.1186/1742-2094-9-239

Mémet, S. (2006). NF-kappaB functions in the nervous system: from development to disease. Biochem. Pharmacol. 72, 1180-1195. doi: 10.1016/j.bcp.2006.09.003

Messam, C. A., and Major, E. O. (2000). Stages of restricted HIV-1 infection in astrocyte cultures derived from human fetal brain tissue. J. Neurovirol. 6(Suppl. 1), S90-S94.

Miller, G. M. (2011). The emerging role of trace amine-associated receptor 1 in the functional regulation of monoamine transporters and dopaminergic activity. J. Neurochem. 116, 164-176. doi: 10.1111/j.1471-4159.2010.07109.x

Miller, G. M. (2012). Avenues for the development of therapeutics that target trace amine associated receptor 1 (TAAR1). J. Med. Chem. 55, 1809-1814. doi: $10.1021 /$ jm201437t

Miyazaki, I., Asanuma, M., Kikkawa, Y., Takeshima, M., Murakami, S., Miyoshi, K., et al. (2011). Astrocyte-derived metallothionein protects dopaminergic neurons from dopamine quinone toxicity. Glia 59, 435-451. doi: 10.1002/glia.21112

Mizoguchi, H., Yamada, K., Mouri, A., Niwa, M., Mizuno, T., Noda, Y., et al. (2007a). Role of matrix metalloproteinase and tissue inhibitor of MMP in methamphetamine-induced behavioral sensitization and reward: implications for dopamine receptor down-regulation and dopamine release. J. Neurochem. 102, 1548-1560. doi: 10.1111/j.1471-4159.2007.04623.x

Mizoguchi, H., Yamada, K., and Nabeshima, T. (2008). Neuropsychotoxicity of abused drugs: involvement of matrix metalloproteinase- 2 and -9 and tissue inhibitor of matrix metalloproteinase-2 in methamphetamine-induced behavioral sensitization and reward in rodents. J. Pharmacol. Sci. 106, 9-14. doi: 10.1254/jphs.FM0070139

Mizoguchi, H., Yamada, K., Niwa, M., Mouri, A., Mizuno, T., Noda, Y., et al. (2007b). Reduction of methamphetamine-induced sensitization and reward in matrix metalloproteinase-2 and -9-deficient mice. J. Neurochem. 100, 1579-1588. doi: 10.1111/j.1471-4159.2006.04288.x

Mohsenzadegan, M., Fayazi, M. R., Abdolmaleki, M., Bakhshayesh, M., Seif, F., and Mousavizadeh, K. (2015). Direct immunomodulatory influence of IFN-beta 
on human astrocytoma cells. Immunopharmacol. Immunotoxicol. 37, 214-219. doi: 10.3109/08923973.2015.1014559

Mollace, V., Colasanti, M., Rodino, P., Lauro, G. M., and Nistico, G. (1994). HIV coating gp 120 glycoprotein-dependent prostaglandin E2 release by human cultured astrocytoma cells is regulated by nitric oxide formation. Biochem. Biophys. Res. Commun. 203, 87-92. doi: 10.1006/bbrc.1994.2152

Molteni, C. G., Principi, N., and Esposito, S. (2014). Reactive oxygen and nitrogen species during viral infections. Free Radic. Res. 48, 1163-1169. doi: $10.3109 / 10715762.2014 .945443$

Moore, C. S., Milner, R., Nishiyama, A., Frausto, R. F., Serwanski, D. R., Pagarigan, R. R., et al. (2011). Astrocytic tissue inhibitor of metalloproteinase1 (TIMP-1) promotes oligodendrocyte differentiation and enhances CNS myelination. J. Neurosci. 31, 6247-6254. doi: 10.1523/JNEUROSCI.547410.2011

Moszczynska, A., Fitzmaurice, P., Ang, L., Kalasinsky, K. S., Schmunk, G. A., Peretti, F. J., et al. (2004). Why is parkinsonism not a feature of human methamphetamine users? Brain 127, 363-370. doi: 10.1093/brain/ awh046

Moynagh, P. N. (2005). The interleukin-1 signalling pathway in astrocytes: a key contributor to inflammation in the brain. J. Anat. 207, 265-269. doi: 10.1111/j.1469-7580.2005.00445.x

Mrak, R. E., and Griffin, W. S. (1997). The role of chronic self-propagating glial responses in neurodegeneration: implications for long-lived survivors of human immunodeficiency virus. J. Neurovirol. 3, 241-246.

Muñoz, M. F., Puebla, M., and Figueroa, X. F. (2015). Control of the neurovascular coupling by nitric oxide-dependent regulation of astrocytic $\mathrm{Ca}(2+)$ signaling. Front. Cell. Neurosci. 9:59. doi: 10.3389/fncel.2015.00059

Muscoli, C., Salvemini, D., Paolino, D., Iannone, M., Palma, E., Cufari, A., et al. (2002). Peroxynitrite decomposition catalyst prevents apoptotic cell death in a human astrocytoma cell line incubated with supernatants of HIV-infected macrophages. BMC Neurosci. 3:13. doi: 10.1186/1471-22 02-3-13

Nader, J., Rapino, C., Gennequin, B., Chavant, F., Francheteau, M., Makriyannis, A., et al. (2014). Prior stimulation of the endocannabinoid system prevents methamphetamine-induced dopaminergic neurotoxicity in the striatum through activation of CB2 receptors. Neuropharmacology 87, 214-221. doi: 10.1016/j.neuropharm.2014.03.014

Nagai, T., and Yamada, K. (2010). [Molecular mechanism for methamphetamineinduced memory impairment]. Nihon Arukoru Yakubutsu Igakkai Zasshi 45, 81-91.

Nair, M. P., Saiyed, Z. M., Nair, N., Gandhi, N. H., Rodriguez, J. W., Boukli, N., et al. (2009). Methamphetamine enhances HIV-1 infectivity in monocyte derived dendritic cells. J. Neuroimmune Pharmacol. 4, 129-139. doi: 10.1007/s11481008-9128-0

Nakamichi, K., Kitani, H., Takayama-Ito, M., Morimoto, K., Kurane, I., and Saijo, M. (2010). Celastrol suppresses morphological and transcriptional responses in microglial cells upon stimulation with double-stranded RNA. Int. J. Neurosci. 120, 252-257. doi: 10.3109/00207451003615763

Nanda, B. L., Nataraju, A., Rajesh, R., Rangappa, K. S., Shekar, M. A., and Vishwanath, B. S. (2007). PLA2 mediated arachidonate free radicals: PLA2 inhibition and neutralization of free radicals by anti-oxidants-a new role as anti-inflammatory molecule. Curr. Top. Med. Chem. 7, 765-777. doi: $10.2174 / 156802607780487623$

Narita, M., Miyatake, M., Narita, M., Shibasaki, M., Shindo, K., Nakamura, A., Kuzumaki, N., et al. (2006). Direct evidence of astrocytic modulation in the development of rewarding effects induced by drugs of abuse. Neuropsychopharmacology 31, 2476-2488. doi: 10.1038/sj.npp. 1301007

Navarrete, M., and Araque, A. (2008). Endocannabinoids mediate neuron-astrocyte communication. Neuron 57, 883-893. doi: 10.1016/j.neuron.2008.01.029

Navarrete, M., and Araque, A. (2010). Endocannabinoids potentiate synaptic transmission through stimulation of astrocytes. Neuron 68, 113-126. doi: 10.1016/j.neuron.2010.08.043

Newman, E. A. (2015). Glial cell regulation of neuronal activity and blood flow in the retina by release of gliotransmitters. Philos. Trans. R. Soc. Lond. B. Biol. Sci. 370:20140195. doi: 10.1098/rstb.2014.0195

Nguyen, L., Kaushal, N., Robson, M. J., and Matsumoto, R. R. (2014). Sigma receptors as potential therapeutic targets for neuroprotection. Eur. J. Pharmacol. 743, 42-47. doi: 10.1016/j.ejphar.2014.09.022
Nikfarjam, B. A., Ebtekar, M., Sabouni, F., Pourpak, Z., and Kheirandish, M. (2014). Detection of interleukin-19 mRNA in C57BL/6 mice astroglial cells and brain cortex. Basic Clin. Neurosci. 5, 88-95.

Nomura, A., Ujike, H., Tanaka, Y., Kishimoto, M., Otani, K., Morita, Y., et al. (2006). Association study of the tumor necrosis factor-alpha gene and its $1 \mathrm{~A}$ receptor gene with methamphetamine dependence. Ann. N.Y. Acad. Sci. 1074, 116-124. doi: 10.1196/annals.1369.011

Nookala, A. R., and Kumar, A. (2014). Molecular mechanisms involved in HIV-1 Tat-mediated induction of IL-6 and IL-8 in astrocytes. J. Neuroinflammation 11, 214. doi: 10.1186/s12974-014-0214-3

Northrop, N. A., and Yamamoto, B. K. (2015). Methamphetamine effects on blood-brain barrier structure and function. Front. Neurosci. 9:69. doi: $10.3389 /$ fnins.2015.00069

Nottet, H. S., Jett, M., Flanagan, C. R., Zhai, Q. H., Persidsky, Y., Rizzino, A., et al. (1995). A regulatory role for astrocytes in HIV-1 encephalitis. An overexpression of eicosanoids, platelet-activating factor, and tumor necrosis factor-alpha by activated HIV-1-infected monocytes is attenuated by primary human astrocytes. J. Immunol. 154, 3567-3581.

Oberlin, E., Amara, A., Bachelerie, F., Bessia, C., Virelizier, J. L., ArenzanaSeisdedos, F., et al. (1996). The CXC chemokine SDF-1 is the ligand for LESTR/fusin and prevents infection by T-cell-line-adapted HIV-1. Nature 382, 833-835. doi: 10.1038/382833a0

Okamoto, M., Wang, X., and Baba, M. (2005). HIV-1-infected macrophages induce astrogliosis by SDF-1alpha and matrix metalloproteinases. Biochem. Biophys. Res. Commun. 336, 1214-1220. doi: 10.1016/j.bbrc.2005.08.251

Oliveira da Cruz, J. F., Robin, L. M., Drago, F., Marsicano, G., and MetnaLaurent, M. (2015). Astroglial type-1 cannabinoid receptor (CB): a new player in the tripartite synapse. Neuroscience. doi: 10.1016/j.neuroscience.2015.05.002. [Epub ahead of print].

Ozdener, H. (2005). Molecular mechanisms of HIV-1 associated neurodegeneration. J. Biosci. 30, 391-405. doi: 10.1007/BF02703676

Pacher, P., Beckman, J. S., and Liaudet, L. (2007). Nitric oxide and peroxynitrite in health and disease. Physiol. Rev. 87, 315-424. doi: 10.1152/physrev.00029.2006

Padovani-Claudio, D. A., Liu, L., Ransohoff, R. M., and Miller, R. H. (2006). Alterations in the oligodendrocyte lineage, myelin, and white matter in adult mice lacking the chemokine receptor CXCR2. Glia 54, 471-483. doi: 10.1002/glia.20383

Panas, M. W., Xie, Z., Panas, H. N., Hoener, M. C., Vallender, E. J., and Miller, G. M. (2012). Trace amine associated receptor 1 signaling in activated lymphocytes. J. Neuroimmune Pharmacol. 7, 866-876. doi: 10.1007/s11481-011-9321-4

Pang, X., Panee, J., Liu, X., Berry, M. J., Chang, S. L., and Chang, L. (2013). Regional variations of antioxidant capacity and oxidative stress responses in HIV-1 transgenic rats with and without methamphetamine administration. J. Neuroimmune Pharmacol. 8, 691-704. doi: 10.1007/s11481-0139454-8

Pang, Y., Cai, Z., and Rhodes, P. G. (2001). Analysis of genes differentially expressed in astrocytes stimulated with lipopolysaccharide using cDNA arrays. Brain Res. 914, 15-22. doi: 10.1016/S0006-8993(01)02766-4

Paradise, M. B., Naismith, S. L., Norrie, L. M., Graeber, M. B., and Hickie, I. B. (2012). The role of glia in late-life depression. Int. Psychogeriatr. 24, 1878-1890. doi: $10.1017 / S 1041610212000828$

Parham, C., Chirica, M., Timans, J., Vaisberg, E., Travis, M., Cheung, J., et al. (2002). A receptor for the heterodimeric cytokine IL-23 is composed of IL12Rbeta1 and a novel cytokine receptor subunit, IL-23R. J. Immunol. 168, 5699-5708. doi: 10.4049/jimmunol.168.11.5699

Pasqualetti, G., Brooks, D. J., and Edison, P. (2015). The role of neuroinflammation in dementias. Curr. Neurol. Neurosci. Rep. 15:17. doi: 10.1007/s11910-0150531-7

Passaro, R. C., Pandhare, J., Qian, H. Z., and Dash, C. (2015). The Complex interaction between methamphetamine abuse and HIV-1 pathogenesis. J. Neuroimmune Pharmacol. 10, 477-486. doi: 10.1007/s11481-015-9604-2

Patapoutian, A., and Reichardt, L. F. (2001). Trk receptors: mediators of neurotrophin action. Curr. Opin. Neurobiol. 11, 272-280. doi: 10.1016/S09594388(00)00208-7

Patel, A., Vasanthan, V., Fu, W., Fahlman, R. P., MacTavish, D., and Jhamandas, J. H. (2015). Histamine induces the production of matrix metalloproteinase-9 in human astrocytic cultures via H1-receptor subtype. Brain Struct. Funct. doi: 10.1007/s00429-015-1007-x. [Epub ahead of print].

Penas, C., Pascual-Font, A., Mancuso, R., Forés, J., Casas, C., and Navarro, X. (2011). Sigma receptor agonist 2-(4-morpholinethyl)1 
phenylcyclohexanecarboxylate (Pre084) increases GDNF and BiP expression and promotes neuroprotection after root avulsion injury. J. Neurotrauma 28, 831-840. doi: 10.1089/neu.2010.1674

Peng, H., Erdmann, N., Whitney, N., Dou, H., Gorantla, S., Gendelman, H. E., et al. (2006). HIV-1-infected and/or immune activated macrophages regulate astrocyte SDF-1 production through IL-1beta. Glia 54, 619-629. doi: 10.1002/glia.20409

Peng, H., Wu, Y., Duan, Z., Ciborowski, P., and Zheng, J. C. (2012). Proteolytic processing of SDF-1alpha by matrix metalloproteinase-2 impairs CXCR4 signaling and reduces neural progenitor cell migration. Protein Cell 3, 875-882. doi: 10.1007/s13238-012-2092-8

Phillips, T. R., Billaud, J. N., and Henriksen, S. J. (2000). Methamphetamine and HIV-1: potential interactions and the use of the FIV/cat model. J. Psychopharmacol. 14, 244-250. doi: 10.1177/026988110001400309

Porter, J. T., and McCarthy, K. D. (1997). Astrocytic neurotransmitter receptors in situ and in vivo. Prog. Neurobiol. 51, 439-455.

Potula, R., Hawkins, B. J., Cenna, J. M., Fan, S., Dykstra, H., Ramirez, S. H., et al. (2010). Methamphetamine causes mitrochondrial oxidative damage in human T lymphocytes leading to functional impairment. J. Immunol. 185, 2867-2876. doi: 10.4049/jimmunol.0903691

Puma, C., Danik, M., Quirion, R., Ramon, F., and Williams, S. (2001). The chemokine interleukin- 8 acutely reduces $\mathrm{Ca}(2+)$ currents in identified cholinergic septal neurons expressing CXCR1 and CXCR2 receptor mRNAs. J. Neurochem. 78, 960-971. doi: 10.1046/j.1471-4159.2001.00469.x

Qi, L., Gang, L., Hang, K. W., Ling, C. H., Xiaofeng, Z., Zhen, L., et al. (2011). Programmed neuronal cell death induced by HIV-1 tat and methamphetamine. Microsc. Res. Tech. 74, 1139-1144. doi: 10.1002/jemt.21006

Qin, H., and Benveniste, E. N. (2012). ELISA methodology to quantify astrocyte production of cytokines/chemokines in vitro. Methods Mol. Biol. 814, 235-249. doi: 10.1007/978-1-61779-452-0_16

Ramesh, G., MacLean, A. G., and Philipp, M. T. (2013). Cytokines and chemokines at the crossroads of neuroinflammation, neurodegeneration, and neuropathic pain. Mediators Inflamm. 2013:480739. doi: 10.1155/2013/480739

Ramirez, S. H., Potula, R., Fan, S., Eidem, T., Papugani, A., Reichenbach, N., et al. (2009). Methamphetamine disrupts blood-brain barrier function by induction of oxidative stress in brain endothelial cells. J. Cereb. Blood Flow Metab. 29, 1933-1945. doi: $10.1038 / \mathrm{jcbfm} .2009 .112$

Ransohoff, R. M., Hamilton, T. A., Tani, M., Stoler, M. H., Shick, H. E., Major, J. A., et al. (1993). Astrocyte expression of mRNA encoding cytokines IP-10 and JE/MCP-1 in experimental autoimmune encephalomyelitis. FASEB J. 7, 592-600.

Raposo, C., and Schwartz, M. (2014). Glial scar and immune cell involvement in tissue remodeling and repair following acute CNS injuries. Glia 62, 1895-1904. doi: $10.1002 /$ glia. 22676

Rasooli-Nejad, S., Palygin, O., Lalo, U., and Pankratov, Y. (2014). Cannabinoid receptors contribute to astroglial $\mathrm{Ca}(2)(+)$-signalling and control of synaptic plasticity in the neocortex. Philos. Trans. R. Soc. Lond. B Biol. Sci. 369, 20140077. doi: 10.1098/rstb.2014.0077

Rasty, S., Thatikunta, P., Gordon, J., Khalili, K., Amini, S., and Glorioso, J. C. (1996). Human immunodeficiency virus tat gene transfer to the murine central nervous system using a replication-defective herpes simplex virus vector stimulates transforming growth factor beta 1 gene expression. Proc. Natl. Acad. Sci. U.S.A. 93, 6073-6078.

Ravizza, T., Boer, K., Redeker, S., Spliet, W. G., Van Rijen, P. C., Troost, D., et al. (2006). The IL-1beta system in epilepsy-associated malformations of cortical development. Neurobiol. Dis. 24, 128-143. doi: 10.1016/j.nbd.2006.06.003

Ray, P. D., Huang, B. W., and Tsuji, Y. (2012). Reactive oxygen species (ROS) homeostasis and redox regulation in cellular signaling. Cell. Signal. 24, 981-990. doi: 10.1016/j.cellsig.2012.01.008

Raz, L., Knoefel, J., and Bhaskar, K. (2015). The neuropathology and cerebrovascular mechanisms of dementia. J. Cereb. Blood Flow Metab. doi: 10.1038/jcbfm.2015.164. [Epub ahead of print].

Reback, C. J., Larkins, S., and Shoptaw, S. (2003). Methamphetamine abuse as a barrier to HIV medication adherence among gay and bisexual men. AIDS Care 15, 775-785. doi: 10.1080/09540120310001618621

Reddy, P. V., Gandhi, N., Samikkannu, T., Saiyed, Z., Agudelo, M., Yndart, A., et al. (2012). HIV-1 gp120 induces antioxidant response element-mediated expression in primary astrocytes: role in HIV associated neurocognitive disorder. Neurochem. Int. 61, 807-814. doi: 10.1016/j.neuint.2011.06.011

Reissner, K. J., Brown, R. M., Spencer, S., Tran, P. K., Thomas, C. A., and Kalivas, P. W. (2014). Chronic administration of the methylxanthine propentofylline impairs reinstatement to cocaine by a GLT-1-dependent mechanism. Neuropsychopharmacology 39, 499-506. doi: 10.1038/npp.2013.223

Renner, N. A., Ivey, N. S., Redmann, R. K., Lackner, A. A., and MacLean, A. G. (2011). MCP-3/CCL7 production by astrocytes: implications for SIV neuroinvasion and AIDS encephalitis. J. Neurovirol. 17, 146-152. doi: 10.1007/s13365-010-0017-y

Revel, F. G., Meyer, C. A., Bradaia, A., Jeanneau, K., Calcagno, E., André, C. B., et al. (2012). Brain-specific overexpression of trace amine-associated receptor 1 alters monoaminergic neurotransmission and decreases sensitivity to amphetamine. Neuropsychopharmacology 37, 2580-2592. doi: 10.1038/npp.2012.109

Revel, F. G., Moreau, J. L., Gainetdinov, R. R., Bradaia, A., Sotnikova, T. D., Mory, R., et al. (2011). TAAR1 activation modulates monoaminergic neurotransmission, preventing hyperdopaminergic and hypoglutamatergic activity. Proc. Natl. Acad. Sci. U.S.A. 108, 8485-8490. doi: 10.1073/pnas.1103029108

Revel, F. G., Moreau, J. L., Pouzet, B., Mory, R., Bradaia, A., Buchy, D., et al. (2013), A new perspective for schizophrenia: TAAR1 agonists reveal antipsychotic- and antidepressant-like activity, improve cognition and control body weight. Mol. Psychiatry 18, 543-556. doi: 10.1038/mp.2012.57

Rippeth, J. D., Heaton, R. K., Carey, C. L., Marcotte, T. D., Moore, D. J., Gonzalez, R., et al. (2004). Methamphetamine dependence increases risk of neuropsychological impairment in HIV infected persons. J. Int. Neuropsychol. Soc. 10, 1-14. doi: 10.1017/S1355617704101021

Roberts, A. J., Maung, R., Sejbuk, N. E., Ake, C., and Kaul, M. (2010a). Alteration of Methamphetamine-induced stereotypic behaviour in transgenic mice expressing HIV-1 envelope protein gp120. J. Neurosci. Methods 186, 222-225. doi: 10.1016/j.jneumeth.2009.11.007

Roberts, T. K., Eugenin, E. A., Morgello, S., Clements, J. E., Zink, M. C., and Berman, J. W. (2010b). PrPC, the cellular isoform of the human prion protein, is a novel biomarker of HIV-associated neurocognitive impairment and mediates neuroinflammation. Am. J. Pathol. 177, 1848-1860. doi: 10.2353/ajpath.2010.091006

Robertson, K. R., Smurzynski, M., Parsons, T. D., Wu, K., Bosch, R. J., Wu, J., et al. (2007). The prevalence and incidence of neurocognitive impairment in the HAART era. AIDS 21, 1915-1921. doi: 10.1097/QAD.0b013e3282 $8 \mathrm{e} 4 \mathrm{e} 27$

Robson, M. J., Seminerio, M. J., McCurdy, C. R., Coop, A., and Matsumoto, R. R. (2013a). sigma Receptor antagonist attenuation of methamphetamine-induced neurotoxicity is correlated to body temperature modulation. Pharmacol. Rep. 65, 343-349. doi: 10.1016/S1734-1140(13)71009-0

Robson, M. J., Turner, R. C., Naser, Z. J., McCurdy, C. R., Huber, J. D., and Matsumoto, R. R. (2013b). SN79, a sigma receptor ligand, blocks methamphetamine-induced microglial activation and cytokine upregulation. Exp. Neurol. 247, 134-142. doi: 10.1016/j.expneurol.2013.04.009

Robson, M. J., Turner, R. C., Naser, Z. J., McCurdy, C. R., O’Callaghan, J. P., Huber, J. D., et al. (2014). SN79, a sigma receptor antagonist, attenuates methamphetamine-induced astrogliosis through a blockade of OSMR/gp130 signaling and STAT3 phosphorylation. Exp. Neurol. 254, 180-189. doi: 10.1016/j.expneurol.2014.01.020

Rock, R. B., Gekker, G., Hu, S., Sheng, W. S., Cabral, G. A., Martin, B. R., et al. (2007). WIN55,212-2-mediated inhibition of HIV-1 expression in microglial cells: involvement of cannabinoid receptors. J. Neuroimmune Pharmacol. 2, 178-183. doi: 10.1007/s11481-006-9040-4

Rosenthal, M. (2006). Methamphetamine use Increases Risk of Acquiring HIV, STDs and MRSA [Online]. 2006 International Conference on Emerging Infectious Diseases: Healio. Available online at: http://www.healio.com/infectiousdisease/hiv-aids/news/print/infectious-disease-news/\%7B458a3b28-01a845ca-af13-dead2d781f8b\%7D/methamphetamine-use-increases-risk-ofacquiring-hiv-stds-and-mrsa (Accessed July 15, 2015).

Rostasy, K., Egles, C., Chauhan, A., Kneissl, M., Bahrani, P., Yiannoutsos, C., et al. (2003). SDF-1alpha is expressed in astrocytes and neurons in the AIDS dementia complex: an in vivo and in vitro study. J. Neuropathol. Exp. Neurol. $62,617-626$ 
Roth, A. D., Ramírez, G., Alarcón, R., and Von Bernhardi, R. (2005). Oligodendrocytes damage in Alzheimer's disease: beta amyloid toxicity and inflammation. Biol. Res. 38, 381-387. doi: 10.4067/S0716-97602005000400011

Rusyniak, D. E. (2013). Neurologic manifestations of chronic methamphetamine abuse. Psychiatr. Clin. North Am. 36, 261-275. doi: 10.1016/j.psc.2013.02.005

Ryan, L. A., Peng, H., Erichsen, D. A., Huang, Y., Persidsky, Y., Zhou, Y., et al. (2004). TNF-related apoptosis-inducing ligand mediates human neuronal apoptosis: links to HIV-1-associated dementia. J. Neuroimmunol. 148, 127-139. doi: 10.1016/j.jneuroim.2003.11.019

Sabri, F., Titanji, K., De Milito, A., and Chiodi, F. (2003). Astrocyte activation and apoptosis: their roles in the neuropathology of HIV infection. Brain Pathol. 13, 84-94. doi: 10.1111/j.1750-3639.2003.tb00009.x

Saha, R. N., Liu, X., and Pahan, K. (2006). Up-regulation of BDNF in astrocytes by TNF-alpha: a case for the neuroprotective role of cytokine. J. Neuroimmune Pharmacol. 1, 212-222. doi: 10.1007/s11481-006-9020-8

Saikali, P., Antel, J. P., Pittet, C. L., Newcombe, J., and Arbour, N. (2010). Contribution of astrocyte-derived IL-15 to CD8 T cell effector functions in multiple sclerosis. J. Immunol. 185, 5693-5703. doi: 10.4049/jimmunol.1002188

Salamanca, S. A., Sorrentino, E. E., Nosanchuk, J. D., and Martinez, L. R. (2014). Impact of methamphetamine on infection and immunity. Front. Neurosci. 8:445. doi: 10.3389/fnins.2014.00445

Salisbury, D., and Bronas, U. (2015). Reactive oxygen and nitrogen species: impact on endothelial dysfunction. Nurs. Res. 64, 53-66. doi: 10.1097/NNR.0000000000000068

Salmaggi, A., Gelati, M., Dufour, A., Corsini, E., Pagano, S., Baccalini, R., et al. (2002). Expression and modulation of IFN-gamma-inducible chemokines (IP10, Mig, and I-TAC) in human brain endothelium and astrocytes: possible relevance for the immune invasion of the central nervous system and the pathogenesis of multiple sclerosis. J. Interferon Cytokine Res. 22, 631-640. doi: 10.1089/10799900260100114

Samikkannu, T., Agudelo, M., Gandhi, N., Reddy, P. V., Saiyed, Z. M., Nwankwo, D., et al. (2011). Human immunodeficiency virus type 1 clade B and C gp120 differentially induce neurotoxin arachidonic acid in human astrocytes: implications for neuroAIDS. J. Neurovirol. 17, 230-238. doi: 10.1007/s13365011-0026-5

Samikkannu, T., Rao, K. V., Kanthikeel, S. P., Atluri, V. S., Agudelo, M., Roy, U., et al. (2014). Immunoneuropathogenesis of HIV-1 clades B and C: role of redox expression and thiol modification. Free Radic. Biol. Med. 69, 136-144. doi: 10.1016/j.freeradbiomed.2013.12.025

Samikkannu, T., Rao, K. V., Salam, A. A., Atluri, V. S., Kaftanovskaya, E. M., Agudelo, M., et al. (2015). HIV Subtypes B and C gp120 and methamphetamine interaction: dopaminergic system implicates differential neuronal toxicity. Sci. Rep. 5:11130. doi: 10.1038/srep11130

Sbai, O., Ould-Yahoui, A., Ferhat, L., Gueye, Y., Bernard, A., Charrat, E., et al. (2010). Differential vesicular distribution and trafficking of MMP-2, MMP-9, and their inhibitors in astrocytes. Glia 58, 344-366. doi: 10.1002/glia.20927

Schiavon, A. P., Soares, L. M., Bonato, J. M., Milani, H., Guimarães, F. S., and Weffort De Oliveira, R. M. (2014). Protective effects of cannabidiol against hippocampal cell death and cognitive impairment induced by bilateral common carotid artery occlusion in mice. Neurotox. Res. 26, 307-316. doi: 10.1007/s12640-014-9457-0

Schulz, J. B., Matthews, R. T., Klockgether, T., Dichgans, J., and Beal, M. F. (1997). The role of mitochondrial dysfunction and neuronal nitric oxide in animal models of neurodegenerative diseases. Mol. Cell. Biochem. 174, 193-197.

Seminerio, M. J., Robson, M. J., McCurdy, C. R., and Matsumoto, R. R. (2012). Sigma receptor antagonists attenuate acute methamphetamineinduced hyperthermia by a mechanism independent of IL-1beta mRNA expression in the hypothalamus. Eur. J. Pharmacol. 691, 103-109. doi: 10.1016/j.ejphar.2012.07.029

Shah, A., Kumar, S., Simon, S. D., Singh, D. P., and Kumar, A. (2013). HIV gp120and methamphetamine-mediated oxidative stress induces astrocyte apoptosis via cytochrome P450 2E1. Cell Death Dis. 4, e850. doi: 10.1038/cddis.2013.374

Shah, A., Silverstein, P. S., Kumar, S., Singh, D. P., and Kumar, A. (2012a). Synergistic cooperation between methamphetamine and HIV-1 gsp120 through the P13K/Akt pathway induces IL-6 but not IL-8 expression in astrocytes. PLoS ONE 7:e52060. doi: 10.1371/journal.pone.0052060

Shah, A., Silverstein, P. S., Singh, D. P., and Kumar, A. (2012b). Involvement of metabotropic glutamate receptor $5, \mathrm{AKT} / \mathrm{PI} 3 \mathrm{~K}$ signaling and NF-kappaB pathway in methamphetamine-mediated increase in IL-6 and IL-8 expression in astrocytes. J. Neuroinflammation 9:52. doi: 10.1186/1742-2094-9-52

Shah, A., Verma, A. S., Patel, K. H., Noel, R., Rivera-Amill, V., Silverstein, P. S., et al. (2011). HIV-1 gp120 induces expression of IL-6 through a nuclear factorkappa B-dependent mechanism: suppression by gp120 specific small interfering RNA. PLoS ONE 6:e21261. doi: 10.1371/journal.pone.0021261

Sharma, A., Hu, X. T., Napier, T. C., and Al-Harthi, L. (2011). Methamphetamine and HIV-1 Tat down regulate beta-catenin signaling: implications for methampetamine abuse and HIV-1 co-morbidity. J. NeuroImmune Pharmacol. 6, 597-607. doi: 10.1007/s11481-011-9295-2

Sheng, W. S., Hu, S., Min, X., Cabral, G. A., Lokensgard, J. R., and Peterson, P. K. (2005). Synthetic cannabinoid WIN55,212-2 inhibits generation of inflammatory mediators by IL-1beta-stimulated human astrocytes. Glia 49, 211-219. doi: 10.1002/glia.20108

Sherbourne, C. D., Hays, R. D., Fleishman, J. A., Vitiello, B., Magruder, K. M., Bing, E. G., et al. (2000). Impact of psychiatric conditions on health-related quality of life in persons with HIV infection. Am. J. Psychiatry 157, 248-254. doi: 10.1176/appi.ajp.157.2.248

Shi, B., Raina, J., Lorenzo, A., Busciglio, J., and Gabuzda, D. (1998). Neuronal apoptosis induced by HIV-1 Tat protein and TNF-alpha: potentiation of neurotoxicity mediated by oxidative stress and implications for HIV-1 dementia. J. Neurovirol. 4, 281-290.

Shin, J. H., Park, Y. M., Kim, D. H., Moon, G. J., Bang, O. Y., Ohn, T., et al. (2014). Ischemic brain extract increases SDF-1 expression in astrocytes through the CXCR2/miR-223/miR-27b pathway. Biochim. Biophys. Acta 1839, 826-836. doi: 10.1016/j.bbagrm.2014.06.019

Shrikant, P., Benos, D. J., Tang, L. P., and Benveniste, E. N. (1996). HIV glycoprotein 120 enhances intercellular adhesion molecule-1 gene expression in glial cells. involvement of janus kinase/signal transducer and activator of transcription and protein kinase C signaling pathways. J. Immunol. 156, 1307-1314.

Silva, C. D., Neves, A. F., Dias, A. I., Freitas, H. J., Mendes, S. M., Pita, I., et al. (2014). A single neurotoxic dose of methamphetamine induces a longlasting depressive-like behaviour in mice. Neurotox. Res. 25, 295-304. doi: 10.1007/s12640-013-9423-2

Simões, P. F., Silva, A. P., Pereira, F. C., Marques, E., Milhazes, N., Borges, F., et al. (2008). Methamphetamine changes NMDA and AMPA glutamate receptor subunit levels in the rat striatum and frontal cortex. Ann. N.Y. Acad. Sci. 1139, 232-241. doi: 10.1196/annals.1432.028

Singh, G., and Pai, R. S. (2015). Dawn of antioxidants and immune modulators to stop HIV-progression and boost the immune system in HIV/AIDS patients: An updated comprehensive and critical review. Pharmacol. Rep. 67, 600-605. doi: 10.1016/j.pharep.2014.12.007

Skuljec, J., Gudi, V., Ulrich, R., Frichert, K., Yildiz, O., Pul, R., et al. (2011). Matrix metalloproteinases and their tissue inhibitors in cuprizoneinduced demyelination and remyelination of brain white and gray matter. J. Neuropathol. Exp. Neurol. 70, 758-769. doi: 10.1097/NEN.0b013e3182 $294 \mathrm{fad}$

Smith, K. J., Butler, T. R., and Prendergast, M. A. (2010). Inhibition of sigma-1 receptor reduces $\mathrm{N}$-methyl-D-aspartate induced neuronal injury in methamphetamine-exposed and -naive hippocampi. Neurosci. Lett. 481, 144-148. doi: 10.1016/j.neulet.2010.06.069

Smits, H. A., Rijsmus, A., van Loon, J. H., Wat, J. W., Verhoef, J., Boven, L. A., et al. (2002). Amyloid-beta-induced chemokine production in primary human macrophages and astrocytes. J. Neuroimmunol. 127, 160-168. doi: 10.1016/S0165-5728(02)00112-1

Speth, C., Joebstl, B., Barcova, M., and Dierich, M. P. (2000). HIV-1 envelope protein gp41 modulates expression of interleukin-10 and chemokine receptors on monocytes, astrocytes and neurones. AIDS 14, 629-636. doi: 10.1097/00002030-200004140-00001

Speth, C., Schabetsberger, T., Mohsenipour, I., Stöckl, G., Würzner, R., Stoiber, H., et al. (2002). Mechanism of human immunodeficiency virus-induced complement expression in astrocytes and neurons. J. Virol. 76, 3179-3188. doi: 10.1128/JVI.76.7.3179-3188.2002

Speth, C., Stöckl, G., Mohsenipour, I., Würzner, R., Stoiber, H., Lass-Flörl, C., et al. (2001). Human immunodeficiency virus type 1 induces expression of complement factors in human astrocytes. J. Virol. 75, 2604-2615. doi: 10.1128/JVI.75.6.2604-2516.2001 
Stall, R., Paul, J. P., Greenwood, G., Pollack, L. M., Bein, E., Crosby, G. M., et al. (2001). Alcohol use, drug use and alcohol-related problems among men who have sex with men: the urban men's health study. Addiction 96, 1589-1601. doi: $10.1080 / 09652140120080723$

Stanika, R. I., Pivovarova, N. B., Brantner, C. A., Watts, C. A., Winters, C. A., and Andrews, S. B. (2009). Coupling diverse routes of calcium entry to mitochondrial dysfunction and glutamate excitotoxicity. Proc. Natl. Acad. Sci. U.S.A. 106, 9854-9859. doi: 10.1073/pnas.0903546106

Stavrovskaya, I. G., and Kristal, B. S. (2005). The powerhouse takes control of the cell: is the mitochondrial permeability transition a viable therapeutic target against neuronal dysfunction and death? Free Radic. Biol. Med. 38, 687-697. doi: 10.1016/j.freeradbiomed.2004.11.032

Strack, A., Asensio, V. C., Campbell, I. L., Schluter, D., and Deckert, M. (2002). Chemokines are differentially expressed by astrocytes, microglia and inflammatory leukocytes in toxoplasma encephalitis and critically regulated by interferon-gamma. Acta Neuropathol. 103, 458-468. doi: 10.1007/s00401-0010491-7

Strazza, M., Pirrone, V., Wigdahl, B., and Nonnemacher, M. R. (2011). Breaking down the barrier: the effects of HIV-1 on the blood-brain barrier. Brain Res. 1399, 96-115. doi: 10.1016/j.brainres.2011.05.015

Streit, W. J. (2000). Microglial response to brain injury: a brief synopsis. Toxicol. Pathol. 28, 28-30. doi: 10.1177/019262330002800104

Sturdevant, C. B., Joseph, S. B., Schnell, G., Price, R. W., Swanstrom, R., and Spudich, S. (2015). Compartmentalized replication of R5 T cell-tropic HIV1 in the central nervous system early in the course of infection. PLoS Pathog. 11:e1004720. doi: 10.1371/journal.ppat.1004720

Su, Z. Z., Leszczyniecka, M., Kang, D. C., Sarkar, D., Chao, W., Volsky, D. J., et al. (2003). Insights into glutamate transport regulation in human astrocytes: cloning of the promoter for excitatory amino acid transporter 2 (EAAT2). Proc. Natl. Acad. Sci. U.S.A. 100, 1955-1960. doi: 10.1073/pnas.01365 55100

Sundaram, M., Saghayam, S., Priya, B., Venkatesh, K. K., Balakrishnan, P., Shankar, E. M., et al. (2008). Changes in antioxidant profile among HIV-infected individuals on generic highly active antiretroviral therapy in southern India. Int. J. Infect. Dis. 12, e61-e66. doi: 10.1016/j.ijid.2008.04.004

Suryadevara, R., Holter, S., Borgmann, K., Persidsky, R., Labenz-Zink, C., Persidsky, Y., et al. (2003). Regulation of tissue inhibitor of metalloproteinase-1 by astrocytes: Links to HIV-1 dementia. Glia 44, 47-56. doi: 10.1002/glia.10266

Sweitzer, S., and De Leo, J. (2011). Propentofylline: glial modulation, neuroprotection, and alleviation of chronic pain. Handb. Exp. Pharmacol. 200, 235-250. doi: 10.1007/978-3-642-13443-2 8

Takahashi, K., Foster, J. B., and Lin, C. L. (2015). Glutamate transporter EAAT2: regulation, function, and potential as a therapeutic target for neurological and psychiatric disease. Cell. Mol. Life Sci. 72, 3489-3506. doi: 10.1007/s00018-0151937-8

Tatro, E. T., Soontornniyomkij, B., Letendre, S. L., and Achim, C. L. (2014). Cytokine secretion from brain macrophages infected with human immunodeficiency virus in vitro and treated with raltegravir. BMC Infect. Dis. 14:386. doi: 10.1186/1471-2334-14-386

Tavazzi, E., Morrison, D., Sullivan, P., Morgello, S., and Fischer, T. (2014). Brain inflammation is a common feature of HIV-infected patients without HIV encephalitis or productive brain infection. Curr. HIV Res. 12, 97-110. doi: $10.2174 / 1570162 X 12666140526114956$

Tawfik, V. L., Lacroix-Fralish, M. L., Bercury, K. K., Nutile-McMenemy, N., Harris, B. T., and Deleo, J. A. (2006). Induction of astrocyte differentiation by propentofylline increases glutamate transporter expression in vitro: heterogeneity of the quiescent phenotype. Glia 54, 193-203. doi: 10.1002/glia.20365

Thatikunta, P., Sawaya, B. E., Denisova, L., Cole, C., Yusibova, G., Johnson, E. M., et al. (1997). Identification of a cellular protein that binds to Tat-responsive element of TGF beta-1 promoter in glial cells. J. Cell. Biochem. 67, 466-477.

Theodore, S., Cass, W. A., and Maragos, W. F. (2006a). Involvement of cytokines in human immunodeficiency virus-1 protein Tat and methamphetamine interactions in the striatum. Exp. Neurol. 199, 490-498. doi: 10.1016/j.expneurol.2006.01.009

Theodore, S., Stolberg, S., Cass, W. A., and Maragos, W. F. (2006b). Human immunodeficiency virus-1 protein tat and methamphetamine interactions. Ann. N.Y. Acad. Sci. 1074, 178-190. doi: 10.1196/annals.1369.018
Tong, J., Fitzmaurice, P., Furukawa, Y., Schmunk, G. A., Wickham, D. J., Ang, L. C., et al. (2014). Is brain gliosis a characteristic of chronic methamphetamine use in the human? Neurobiol. Dis. 67, 107-118. doi: 10.1016/j.nbd.2014.03.015

Torre, D., Pugliese, A., and Speranza, F. (2002). Role of nitric oxide in HIV-1 infection: friend or foe? Lancet Infect. Dis. 2, 273-280. doi: 10.1016/S14733099(02)00262-1

Tousi, N. S., Buck, D. J., Curtis, J. T., and Davis, R. L. (2012). Alphasynuclein potentiates interleukin-1beta-induced CXCL10 expression in human A172 astrocytoma cells. Neurosci. Lett. 507, 133-136. doi: 10.1016/j.neulet.2011.12.001

Trifilo, M. J., and Lane, T. E. (2003). Adenovirus-mediated expression of CXCL10 in the central nervous system results in T-cell recruitment and limited neuropathology. J. Neurovirol. 9, 315-324. doi: 10.1080/13550280390201029

Tufekci, K. U., Meuwissen, R., Genc, S., and Genc, K. (2012). Inflammation in Parkinson's disease. Adv. Protein Chem. Struct. Biol. 88, 69-132. doi: 10.1016/B978-0-12-398314-5.00004-0

Urrutia, A., Granado, N., Gutierrez-Lopez, M. D., Moratalla, R., O’Shea, E., and Colado, M. I. (2014). The JNK inhibitor, SP600125, potentiates the glial response and cell death induced by methamphetamine in the mouse striatum. Int. J. Neuropsychopharmacol. 17, 235-246. doi: 10.1017/S1461145713000850

Uzasci, L., Nath, A., and Cotter, R. (2013). Oxidative stress and the HIVinfected brain proteome. J. Neuroimmune Pharmacol. 8, 1167-1180. doi: 10.1007/s11481-013-9444-x

Valcour, V., and Shiramizu, B. (2004). HIV-associated dementia, mitochondrial dysfunction, and oxidative stress. Mitochondrion 4, 119-129. doi: 10.1016/j.mito.2004.05.009

Van der Meide, P. H., and Schellekens, H. (1996). Cytokines and the immune response. Biotherapy 8, 243-249.

van Marle, G., Henry, S., Todoruk, T., Sullivan, A., Silva, C., Rourke, S. B. et al. (2004). Human immunodeficiency virus type 1 Nef protein mediates neural cell death: a neurotoxic role for IP-10. Virology 329, 302-318. doi: 10.1016/j.virol.2004.08.024

Vartak-Sharma, N., Gelman, B. B., Joshi, C., Borgamann, K., and Ghorpade, A. (2014). Astrocyte elevated gene-1 is a novel modulator of HIV1 -associated neuroinflammation via regulation of nuclear factor-kappaB signaling and excitatory amino acid transporter-2 repression. J. Biol. Chem. 289, 19599-19612. doi: 10.1074/jbc.M114.567644

Vazquez, C., Tolon, R. M., Pazos, M. R., Moreno, M., Koester, E. C., Cravatt, B. F., et al. (2015). Endocannabinoids regulate the activity of astrocytic hemichannels and the microglial response against an injury: in vivo studies. Neurobiol. Dis. 79, 41-50. doi: 10.1016/j.nbd.2015.04.005

Vázquez-Santiago, F. J., Noel, R. J. Jr., Porter, J. T., and Rivera-Amill, V. (2014). Glutamate metabolism and HIV-associated neurocognitive disorders. J. Neurovirol. 20, 315-331. doi: 10.1007/s13365-014-0258-2

Vergote, D., Butler, G. S., Ooms, M., Cox, J. H., Silva, C., Hollenberg, M. D., et al. (2006). Proteolytic processing of SDF-1alpha reveals a change in receptor specificity mediating HIV-associated neurodegeneration. Proc. Natl. Acad. Sci. U.S.A. 103, 19182-19187. doi: 10.1073/pnas.0604678103

Verkhratskii,, A. N., and Butt, A. (2013). Glial Physiology and Pathophysiology. Chichester; Hoboken, NJ: Wiley-Blackwell.

Viviani, B., Corsini, E., Galli, C. L., and Marinovich, M. (1998). Glia increase degeneration of hippocampal neurons through release of tumor necrosis factoralpha. Toxicol. Appl. Pharmacol. 150, 271-276.

Vivithanaporn, P., Maingat, F., Lin, L. T., Na, H., Richardson, C. D., Agrawal, B., et al. (2010). Hepatitis $C$ virus core protein induces neuroimmune activation and potentiates human immunodeficiency virus-1 neurotoxicity. PLoS ONE 5:e12856. doi: 10.1371/journal.pone.0012856

Voskuhl, R. R., Peterson, R. S., Song, B., Ao, Y., Morales, L. B., Tiwari-Woodruff, S., et al. (2009). Reactive astrocytes form scar-like perivascular barriers to leukocytes during adaptive immune inflammation of the CNS. J. Neurosci. 29, 11511-11522. doi: 10.1523/JNEUROSCI.1514-09.2009

Wahl, S. M., Allen, J. B., McCartney-Francis, N., Morganti-Kossmann, M. C., Kossmann, T., Ellingsworth, L., et al. (1991). Macrophage- and astrocytederived transforming growth factor beta as a mediator of central nervous system dysfunction in acquired immune deficiency syndrome. J. Exp. Med. 173, 981-991.

Wang, X., Wang, Y., Ye, L., Li, J., Zhou, Y., Sakarcan, S., et al. (2012). Modulation of intracellular restriction factors contributes to methamphetamine-mediated 
enhancement of acquired immune deficiency syndrome virus infection of macrophages. Curr. HIV Res. 10, 407-414. doi: 10.2174/157016212802138797

Wang, Z., Pekarskaya, O., Bencheikh, M., Chao, W., Gelbard, H. A., Ghorpade, A., et al. (2003). Reduced expression of glutamate transporter EAAT2 and impaired glutamate transport in human primary astrocytes exposed to HIV-1 or gp120. Virology 312, 60-73. doi: 10.1016/S0042-6822(03)00181-8

Wang, Z., Trillo-Pazos, G., Kim, S. Y., Canki, M., Morgello, S., Sharer, L. R., et al. (2004). Effects of human immunodeficiency virus type 1 on astrocyte gene expression and function: potential role in neuropathogenesis. J. Neurovirol. 10(Suppl. 1), 25-32. doi: 10.1080/753312749

Waschbisch, A., Fiebich, B. L., Akundi, R. S., Schmitz, M. L., Hoozemans, J. J., Candelario-Jalil, E., et al. (2006). Interleukin-1 beta-induced expression of the prostaglandin E-receptor subtype EP3 in U373 astrocytoma cells depends on protein kinase $C$ and nuclear factor-kappaB. J. Neurochem. 96, 680-693. doi: 10.1111/j.1471-4159.2005.03599.x

Weinstein, J. D., Gonzalez, E. R., Egleton, R. D., and Hunt, D. A. (2013). A paradigm shift for evaluating pharmacotherapy for Alzheimer's disease: the 10-patient screening protocol. Consult. pharm. 28, 443-454. doi: 10.4140/TCP.n.2013.443

Weissberg, I., Wood, L., Kamintsky, L., Vazquez, O., Milikovsky, D. Z., Alexander, A., et al. (2015). Albumin induces excitatory synaptogenesis through astrocytic TGF-beta/ALK5 signaling in a model of acquired epilepsy following blood-brain barrier dysfunction. Neurobiol. Dis. 78, 115-125. doi: 10.1016/j.nbd.2015.02.029

Welser-Alves, J. V., Crocker, S. J., and Milner, R. (2011). A dual role for microglia in promoting tissue inhibitor of metalloproteinase (TIMP) expression in glial cells in response to neuroinflammatory stimuli. J. Neuroinflammation 8:61. doi: 10.1186/1742-2094-8-61

Whiting, P. F., Wolff, R. F., Deshpande, S., Di Nisio, M., Duffy, S., Hernandez, A. V., et al. (2015). Cannabinoids for medical use: a systematic review and meta-analysis. JAMA 313, 2456-2473. doi: 10.1001/jama.2015.6358

Wires, E. S., Alvarez, D., Dobrowolski, C., Wang, Y., Morales, M., Karn, J., et al. (2012). Methamphetamine activates nuclear factor kappa-light-chain-enhancer of activated B cells (NF-kappaB) and induces human immunodeficiency virus (HIV) transcription in human microglial cells. J. Neurovirol. 18, 400-410. doi: 10.1007/s13365-012-0103-4

Witwer, K. W., Gama, L., Li, M., Bartizal, C. M., Queen, S. E., Varrone, J. J., et al. (2009). Coordinated regulation of SIV replication and immune responses in the CNS. PLoS ONE 4:e8129. doi: 10.1371/journal.pone.0008129

Wolinsky, T. D., Swanson, C. J., Smith, K. E., Zhong, H., Borowsky, B., Seeman, P., et al. (2007). The Trace Amine 1 receptor knockout mouse: an animal model with relevance to schizophrenia. Genes Brain Behav. 6, 628-639. doi: $10.1111 / j .1601-183 X .2006 .00292 . x$

Woollard, S. M., Bhargavan, B., Yu, F., and Kanmogne, G. D. (2014). Differential effects of Tat proteins derived from HIV-1 subtypes B and recombinant CRF02_AG on human brain microvascular endothelial cells: implications for blood-brain barrier dysfunction. J. Cereb. Blood Flow Metab. 34, 1047-1059. doi: $10.1038 /$ jcbfm.2014.54

Woolridge, E., Barton, S., Samuel, J., Osorio, J., Dougherty, A., and Holdcroft, A. (2005). Cannabis use in HIV for pain and other medical symptoms. J. Pain Symptom Manage 29, 358-367. doi: 10.1016/j.jpainsymman.2004.07.011

Wu, Q., Miller, R. H., Ransohoff, R. M., Robinson, S., Bu, J., and Nishiyama, A. (2000). Elevated levels of the chemokine GRO-1 correlate with elevated oligodendrocyte progenitor proliferation in the jimpy mutant. J. Neurosci. 20, 2609-2617.

Wynn, T. A. (2003). IL-13 effector functions. Annu. Rev. Immunol. 21, 425-456. doi: 10.1146/annurev.immunol.21.120601.141142

Wyss-Coray, T., Feng, L., Masliah, E., Ruppe, M. D., Lee, H. S., Toggas, S. M., et al. (1995). Increased central nervous system production of extracellular matrix components and development of hydrocephalus in transgenic mice overexpressing transforming growth factor-beta 1. Am. J. Pathol. 147, 53-67.

Xia, M., Qin, S., McNamara, M., Mackay, C., and Hyman, B. T. (1997). Interleukin8 receptor B immunoreactivity in brain and neuritic plaques of Alzheimer's disease. Am. J. Pathol. 150, 1267-1274.

Xing, H. Q., Hayakawa, H., Gelpi, E., Kubota, R., Budka, H., and Izumo, S. (2009). Reduced expression of excitatory amino acid transporter 2 and diffuse microglial activation in the cerebral cortex in AIDS cases with or without HIV encephalitis. J. Neuropathol. Exp. Neurol. 68, 199-209. doi: 10.1097/NEN.0b013e31819715df

Xu, R., El-Hage, N., and Dever, S. M. (2015). Fluorescently-labeled RNA packaging into HIV-1 particles: direct examination of infectivity across central nervous system cell types. J. Virol. Methods 224, 20-29. doi: 10.1016/j.jviromet.2015.07.023

Yang, C. M., Hsieh, H. L., Yu, P. H., Lin, C. C., and Liu, S. W. (2015). IL-1beta Induces MMP-9-dependent brain astrocytic migration via transactivation of PDGF receptor/NADPH oxidase 2-derived reactive oxygen species signals. Mol. Neurobiol. 52, 303-317. doi: 10.1007/s12035-014$8838-\mathrm{y}$

Yoshida, H., Imaizumi, T., Fujimoto, K., Matsuo, N., Kimura, K., Cui, X., et al. (2001). Synergistic stimulation, by tumor necrosis factor-alpha and interferongamma, of fractalkine expression in human astrocytes. Neurosci. Lett. 303, 132-136. doi: 10.1016/S0304-3940(01)01699-8

Youn, G. S., Kwon, D. J., Ju, S. M., Rhim, H., Bae, Y. S., Choi, S. Y., et al (2014). Celastrol ameliorates HIV-1 Tat-induced inflammatory responses via NF-kappaB and AP-1 inhibition and heme oxygenase-1 induction in astrocytes. Toxicol. Appl. Pharmacol. 280, 42-52. doi: 10.1016/j.taap.2014. 07.010

Yu, A. C., Liu, R. Y., Zhang, Y., Sun, H. R., Qin, L. Y., Lau, L. T., et al. (2007). Glial cell line-derived neurotrophic factor protects astrocytes from staurosporineand ischemia- induced apoptosis. J. Neurosci. Res. 85, 3457-3464. doi: $10.1002 /$ jnr. 21345

Zaritsky, L. A., Gama, L., and Clements, J. E. (2012). Canonical type I IFN signaling in simian immunodeficiency virus-infected macrophages is disrupted by astrocyte-secreted CCL2. J. Immunol. 188, 3876-3885. doi: 10.4049/jimmunol.1103024

Zhang, L., Zhao, W., Li, B., Alkon, D. L., Barker, J. L., Chang, Y. H., et al. (2000). TNF-alpha induced over-expression of GFAP is associated with MAPKs. Neuroreport 11, 409-412. doi: 10.1097/00001756-200002070-00037

Zhang, S., Jin, Y., Liu, X., Yang, L., Ge, Z. J., Wang, H., et al. (2014). Methamphetamine modulates glutamatergic synaptic transmission in rat primary cultured hippocampal neurons. Brain Res. 1582, 1-11. doi: 10.1016/j.brainres.2014.07.040

Zhang, Y., Lv, X., Bai, Y., Zhu, X., Wu, X., Chao, J., et al. (2015). Involvement of sigma-1 receptor in astrocyte activation induced by methamphetamine via up-regulation of its own expression. J. Neuroinflammation 12, 29. doi: 10.1186/s12974-015-0250-7

Zhang, Z., Fauser, U., and Schluesener, H. J. (2008). Early attenuation of lesional interleukin-16 up-regulation by dexamethasone and FTY720 in experimental traumatic brain injury. Neuropathol. Appl. Neurobiol. 34, 330-339. doi: 10.1111/j.1365-2990.2007.00893.x

Zhou, Y., Sonobe, Y., Akahori, T., Jin, S., Kawanokuchi, J., Noda, M., et al. (2011). IL-9 promotes Th17 cell migration into the central nervous system via CC chemokine ligand-20 produced by astrocytes. J. Immunol. 186, 4415-4421. doi: 10.4049/jimmunol.1003307

Zhu, H., Liu, X. W., Cai, T. Y., Cao, J., Tu, C. X., Lu, W., et al. (2010). Celastrol acts as a potent antimetastatic agent targeting betal integrin and inhibiting cell-extracellular matrix adhesion, in part via the p38 mitogenactivated protein kinase pathway. J. Pharmacol. Exp. Ther. 334, 489-499. doi: 10.1124/jpet.110.165654

Zou, W., Wang, Z., Liu, Y., Fan, Y., Zhou, B. Y., Yang, X. F., et al. (2010). Involvement of p300 in constitutive and HIV-1 Tat-activated expression of glial fibrillary acidic protein in astrocytes. Glia 58, 1640-1648. doi: 10.1002/glia.21038

Conflict of Interest Statement: The authors declare that the research was conducted in the absence of any commercial or financial relationships that could be construed as a potential conflict of interest.

Copyright (c) 2015 Borgmann and Ghorpade. This is an open-access article distributed under the terms of the Creative Commons Attribution License (CC BY). The use, distribution or reproduction in other forums is permitted, provided the original author(s) or licensor are credited and that the original publication in this journal is cited, in accordance with accepted academic practice. No use, distribution or reproduction is permitted which does not comply with these terms. 